\title{
MORAL FIBRE: INTEGRATING ETHICS AND SUSTAINABILITY INTO \\ FASHION CURRICULUM \\ MARK O'Connell
}




\section{Personal Statement}

Caroline and Connel, Marlowe and Rose, I'm doing this for you. So the world you inherit may be as vibrant and wonderful as your young spirits.

\section{DEDICATION}

This is dedicated to my parents: the late Professor Joseph T. O'Connell, and Professor Kathleen O'Connell. Your lifelong love of learning, and dedication to social justice has been inspirational.

\section{ACKNOWLEDGEMENTS}

Thank you to Dr. LuAnn Lafrenz of Ryerson University for guidance, mentorship and direction: Dr. Ben Barry for support: Alison Matthews David, Joseph Medaglia, Robert Ott, Elizabeth Semmelhack, Catherine Sutton, Kimberly Wahl, Tanya White, and all of the MA Fashion program faculty: and to Marysol Kim.

I would also like to thank Gitte Hansen, Chair of the School of Fashion at Seneca College for her unwavering support and encouragement.

Thank you to Dean Mary Davis, Barbara Campagna, Sass Brown, Grazyna Pilatowicz, Michael Renzulli, Pamela Ellsworth, and Shannon Leddy (FIT) as well as Timo Rissanen (Parsons): Tarah Burke (Seneca College) and Rachel MacHenry (OCADU); All graciously took time out of their packed schedules to meet with me and answer my queries at length and in depth.

\section{Table of Contents}

MORAL FIBRE: INTEGRATING ETHICS AND SUSTAINABILITY INTO

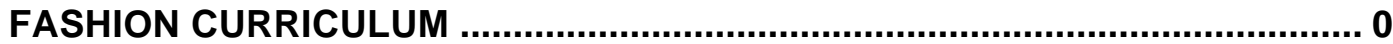

MARK O'CONNELL

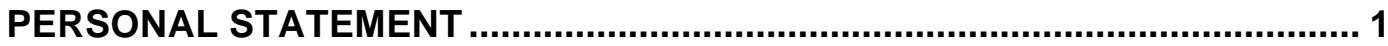

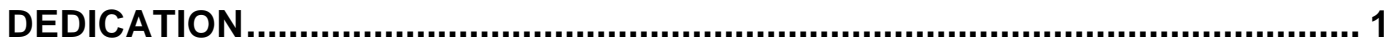

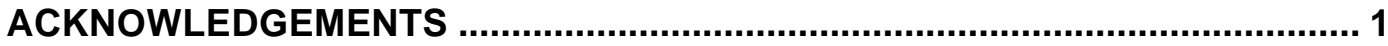

CHAPTER 1: INTRODUCTION..................................................................... 


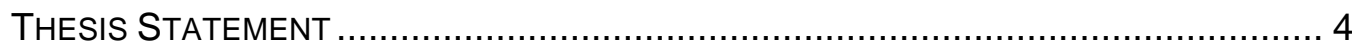

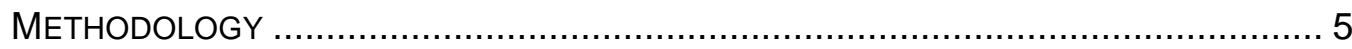

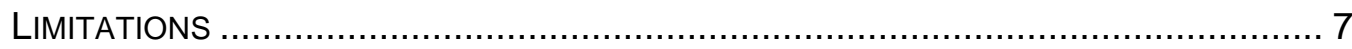

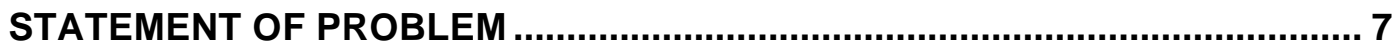

PURPOSE OF RESEARCH........................................................................ 10

DEFINITION OF TERMS.......................................................................... 11

CURRENT STATE OF SUSTAINABILITY, AND THE ENVIRONMENTAL AND SOCIAL

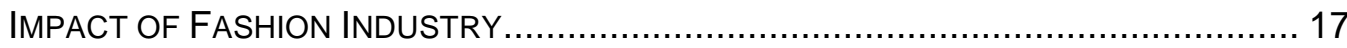

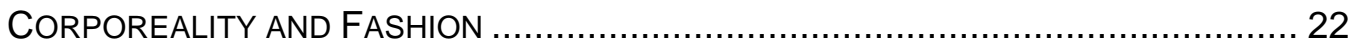

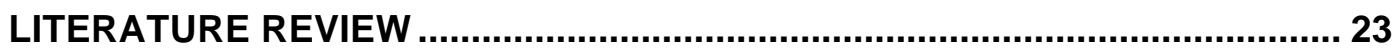

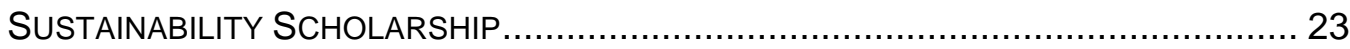

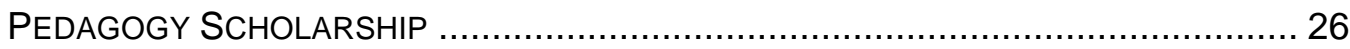

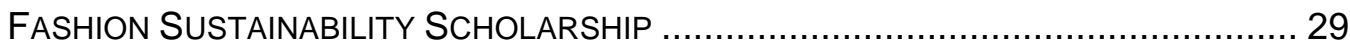

SUSTAINABILITY PEDAGOGY SCHOLARSHIP ................................................ 30

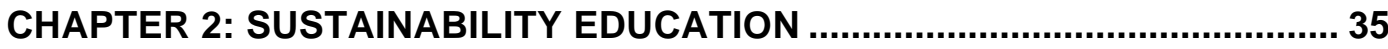

EXAMPLES OF SUSTAINABILITY IN FASHION EDUCATION .............................. 35

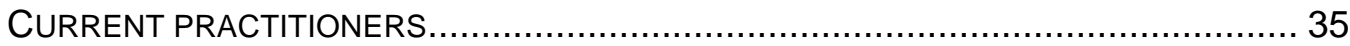

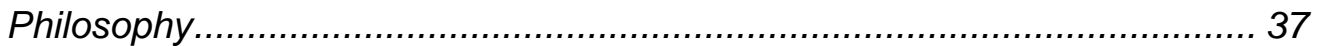

Definition of Sustainability ............................................................. 39

Information Sources and Theoretical Inspiration.................................... 41

Curriculum Management................................................................ 43

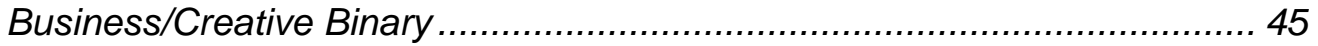

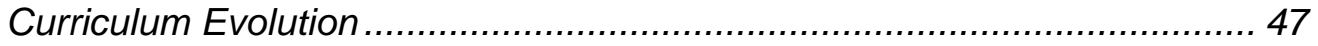

Integrating Ethical Content............................................................ 52

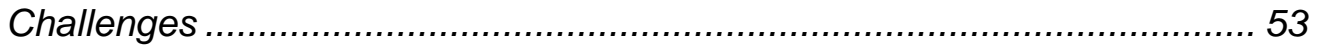

ACADEMIC LANDSCAPE: FASHION SUSTAINABILITY .................................... 56

THE DOOM FACTORY ........................................................................ 59

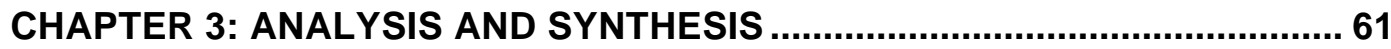

STRUCTURAL CHANGE V. CURRICULUM EVOLUTION ................................... 61

CHAPTER 4: THE NEW PROGRAM: FASHION/ SUSTAINABILITY BA.......... 62

NEW PARADIGMS IN FASHION SUSTAINABILITY PEDAGOGY................................. 62

Vision for an Ideal Fashion Program .................................................... 63

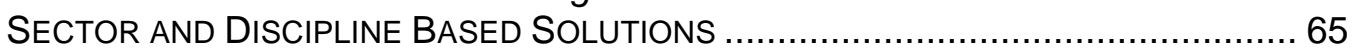

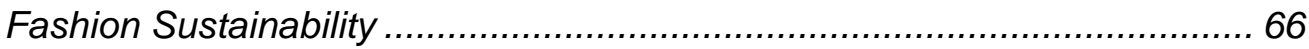

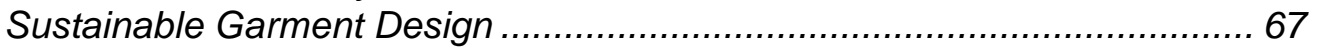

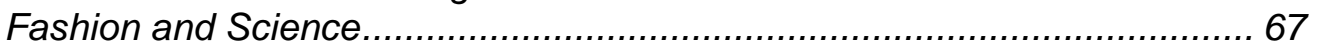

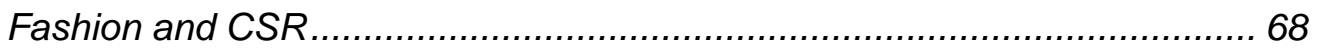

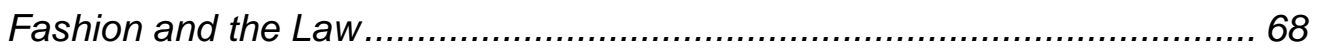

Transnational Fashion Education......................................................... 71

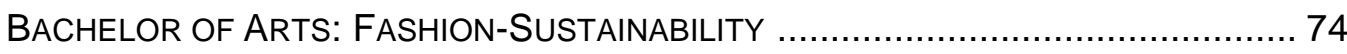

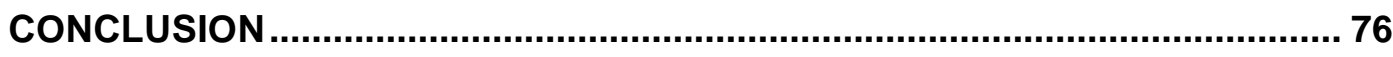

APPENDIX 1: FIT RESIDENCY ................................................................... 93

APPENDIX 2. DESIGN COLLEGES OFFERING SUSTAINABILITY ................ 102

DESIGN COLLEGES OFFERING SUSTAINABILITY ......................................... 102

APPENDIX 3: DECLARATIONS, ORGANIZATIONS, UNESCO CHAIRS AND

UN ORGANIZATIONS FOR ETHICAL FASHION ........................................ 109 
Certification, StandaRdizATION AND INSTITUtIONAL CHANGE ..................... 110

SUSTAINABILITY DECLARATIONS IN HIGHER EDUCATION.................................. 111

UNITED NATIONS: HIGHER EDUCATION SUSTAINABILITY INITIATIVE ................... 112

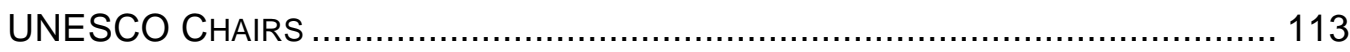

PRINCIPLES FOR RESPONSIBLE MANAGEMENT EdUCATION (PRME) ................ 114

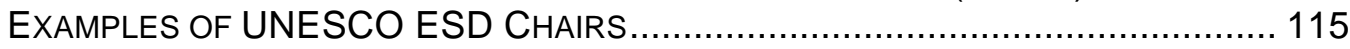

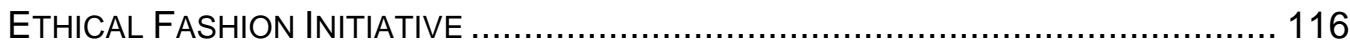

\section{APPENDIX 4: CAMPUS GREENING VERSUS CURRICULUM INTEGRATION}

CAMPUS GREENING VERSUS CURRICULUM INTEGRATION ........................... 116

APPENDIX 5: INTERVIEW QUESTIONS .................................................... 117

APPENDIX 6: ETHICS REVIEW .............................................................. 118

BIBLIOGRAPHY ...................................................................................... 120 


\section{CHAPTER 1: INTRODUCTION}

...If clothing came with warning labels like cigarette packets...you know: this dress was made by a twelve year old or it was made by somebody who was denied bathroom breaks or was sexually assaulted, or works in a dangerous facility because of, health or building codes, or it polluted a river in Java in the dyeing process, then I don't think anyone would be buying fast fashion anymore. And actually l've got to stop using that word 'fast fashion' because it's not necessarily fast fashion...it's cheap clothing.

Sass Brown, FIT interview on May 26, 2015.

\section{THESIS STATEMENT}

Fashion is powerful; if you do not think it is important, look down at what you are wearing. Every person on this planet wears clothes or adorns their body in some way. 80 billion pieces of clothing are produced in a year (Siegle, 2011); $9.3 \%$ of the world's employees are employed in the fashion industry; totalling 40 million workers and constituting $4 \%$ of global exports (Caniato et al 2012: 659; Hurley \& Miller 2008) and consumers spent one trillion on clothes in a single year (Allwood et al., 2006 in Obregon 2013). How those clothes are designed, produced, manufactured and distributed has a massive global impact. There are brightly coloured rivers in Asia that correspond to the trendy hues of the upcoming season's fast-fashion offerings, or look to the collapse of Rana Plaza ${ }^{1}$ in Bangladesh: the modern incarnation of the Triangle Shirtwaist Factory fire that claimed ten times as many lives as the original disaster ${ }^{2}$.

\footnotetext{
${ }^{1}$ Rana Plaza: Was an industrial accident in Bangladesh that happened as a result of a poorly -built factory collapsing. Described in the New York Times as: "A horrendous building collapse last April in Bangladesh (that) killed more than 1,100 garment workers." (NYT Editorial Board 2013: n.p.)

${ }^{2}$ Triangle Shirtwaist Fire: "On March 25, 1911, the Triangle Shirtwaist Company factory in New York City burned... Within 18 minutes, it was all over. Forty-nine workers had burned to death or been suffocated by smoke; 36 were dead in the elevator shaft and 58 died from jumping to the sidewalks. With two more dying later from their injuries, a total of 145 people were killed by the fire...It is remembered as one of the most infamous incidents in American industrial history, as the deaths were largely preventable-most of the victims died as a result of neglected safety features and locked doors within the factory building. The tragedy brought widespread attention to the dangerous sweatshop conditions of factories, and led to the development of a series of laws and regulations that better protected the safety of workers." http://www.history.com/topics/triangle-shirtwaist-fire
} 
Clothing is also not being held onto and valued anymore, as a result of cheap, poor-quality goods flooding the marketplace; the life cycle of a consumer product dropped 50\% between 1992 and 2002 (Niinimäki \& Hassi 2011: 1878). In addition to all of this, fashion also disseminates didactic toxic images and messages around body and class in an ongoing way. In fact, there seems to be no sector of contemporary life that it does not currently impact negatively. Truly, the global fashion industry can be identified as one of the dirtiest and most destructive forces on the earth.

The fashion classroom is a logical place for teaching both social justice and responsible practices in fashion to counter these negative impacts (Fletcher et al 2015; Armstrong \& LeHew 2014; Obregon 2013; Orr 2000; Pilatowicz 2000). At the moment however, the structure and content of fashion education is largely a reflection of existing industry practices; where sustainability is taught, it is presented as a stand-alone subject or an extra-curricular add on (Armstrong \& LeHew 2014: 68). This research explores pedagogical opportunities for social justice, as they relate to fashion education at the higher education level, and also potential larger applications of these ideas either at the departmental, institutional or for governmental policy generation.

\section{METHOdOLOGY}

Research methodology consisted of interviews of contemporary practitioners-both in Toronto, Ontario, Canada and New York City-to ascertain to what extent sustainability content is currently integrated. Also included was an exploration of what relevant philosophies exist in the areas of fashion sustainability, pedagogy, and ethical fashion in general. In addition to this, a month-long visiting scholar residency was undertaken at the Fashion Institute of Technology (FIT) in New York City during the month of May 2016. This residency constituted an examination of the sustainability pedagogical practices that are currently in place at FIT, and also at the possibilities are for further integration of these practices within a 
large public post-secondary institution. Interviews with key practitioners in sustainable design education were undertaken. In addition to this, the research involved an analysis of the current landscape of sustainability within fashion curriculum; looking both for exemplars and strategies for integrating content into existing curricular streams.

The methodological frameworks employed for this research are "qualitative" and "grounded theory". According to Strauss and Corbin, qualitative research is defined as:

...Any type of research that produces findings not arrived at by statistical procedures or other means of quantification. It can refer to research about persons' lives, lived experience, behaviors, emotions, and feelings as well as about organizational functioning, social movements, cultural phenomena and interactions between nations. Some of the data may be quantified as with census or background information about the persons or objects studied, but the bulk of the analysis is interpretative (Strauss \& Corbin 1990: 11).

They define "grounded theory" as:

...Theory that was derived from data, systematically gathered and analyzed through the research process. In this method, data collection, analysis, and eventual theory stand in close relationship to one another (Strauss \& Corbin 1990: 11).

Regarding the value of this type of research: "Grounded theories, because they are drawn from data, are likely to offer insight, enhance understanding, and provide a meaningful guide to action" (Strauss \& Corbin 1990: 12). Noting that: "...The researcher begins with an area of study and allows the theory to emerge from the data" (1990: 12) which ensures this methodological framework does not come with theoretical preconceptions. 


\section{LIMITATIONS}

The interviewees are all based in Toronto or New York City, and were selected for having demonstrated innovative pedagogy in their area. All of the research involves pedagogical practices at the postsecondary level. This research is not intended to function as a comprehensive overview of the current state of sustainable fashion education internationally. The findings of this paper were also limited by the time and extent of the research undertaken.

\section{Statement of Problem}

Fashion is an art form certainly, displaying sublime aesthetic beauty at times, but like most art objects it also has a capital value attached. Profit is what drives the trillion-dollar business we graduate our students into. If the product does not generate revenue, the designer won't be in business for very long, and any environmental or ethical impact they might have had is negated. Universities and colleges are the centres of dynamic intellectual and creative solution generation in many sectors; however fashion pedagogy is not serving well within this capacity at this time. This Master of Arts (MA) Major Research Paper (MRP) will argue that education can provide sustainability solutions, and the classroom can be ground zero for progressive change: a feeling shared by Carolina Obregon in her paper "Sustainable Fashion Education: From Trend to Paradigm?":

Design schools are the logical locus for advocacy and potential change. If students graduate with a strong framework of solutions they will be able to effect changes great and small as they progress in their careers... (graduating) future-oriented designers that have as their priority a concern with the environment; the society and the economy would be achieved through sharing and understanding concepts during their university education (Obregon 2013: 1).

Academically, sustainability need not be taught as a stand-alone accessory to the design process (Armstrong \& LeHew 2014). It needs to be incorporated into the fundamental generative systems that guide a product 
from concept through to marketplace delivery.

Fashion also has to be creative, functional, and within the fashion sector: attractive to the consumer. As Bjarke Ingels said in a CNN interview: "sustainability can't be like some sort of a moral sacrifice or political dilemma or a philanthropical cause. It has to be a design challenge" (Ingels 2012). It does not matter how ethically produced a product is, without aesthetic consideration it will sit on a shelf unsold. Further to this, Amy Williams of California College of Arts (S.F.) says:

...We don't feel that the first thing you notice about sustainable clothing is that it is sustainable. We want to make beautiful clothing. But it should be a given the clothing is mindfully crafted, and has sustainability embedded inside of it, rather than screaming it on the outside. (Williams quoted in Phelan 2012: n.p.).

And zero-waste design visionary Timo Rissanen of Parsons The New School speaks to this point as well:

It should look good because, thankfully that kind of era where sustainability was an excuse for ugly things is over [laughs]. Because I remember a time when somebody would show me something and it's like "So, what is it?": "It's organic cotton" and, "Yeah but what is it?" [laughs] That doesn't justify its existence. In fact it's a waste of organic cotton...that is thankfully I think behind us...there is no reason why sustainability can't look beautiful, and it should (Rissanen 2015).

Fashion business is currently operating for the most part exclusively on a revenue-generating model. As such, it does not have the wherewithal to fabricate and implement the sweeping systemic change needed to streamline, clean up or even create ethical production policy (Fletcher, Grose \& Hawken 2012; Siegle 2011; Orr 2002). Regarding the possibilities for transforming fashion systems, Fletcher and Grose in Fashion \& Sustainability, Design for Change identify that: 
Many environmental and social problems in the fashion sector have no purely technical or market based solution: rather their solutions are moral and ethical (values that are not captured by business and the market) and require us to take a step back from business as usual and look at what shapes, directs and motivates the bigger systems (Fletcher, Grose \& Hawken 2012: 75).

Currently, the benchmarks for what is considered "profitable" do not accurately factor in all of the impacts of fashion production.

The fashion industry knowledge that educators provide in the classroom can shape the opinion and processes of future designers, and business practitioners; thereby providing blueprints for larger systemic change. A designer with a set of sustainable design skills can influence and affect the eventual environmental impact of a product, as $80 \%$ of a product's environmental impact is set within the design stage (Grose 2013: 134). Low-harm, green considerations can be incorporated into the genesis of a design resulting in enormous benefits later. Buyers and product developers armed with this knowledge can also be influential and directive with their orders, favoring sustainable fashion.

At this time however, the majority of fashion curriculum offered does not reflect this progressive potentiality (Armstrong \& Le Hew 2014). This is unfortunate, because the transformative power of sustainability is immense, and due to the comprehensive nature of production, every stage contains a useful critique of industry practices: everything from the growing of fibre, design and production, distribution methods:, right through to the consumption by consumers. Even its eventual discard has profound impacts: socially and environmentally (Fletcher, Grose \& Hawken 2012: 8). However, the "system-transforming nature" inherent in fashion is not a pedagogical focus, and the philosophy of fashion as an agent of progressive change is not being taught at the school level. 
Anthony Cortese speaks to the need for institutional reform in his article "The Critical Role of Higher Education in Creating a Sustainable Future ":

The greatest evidence of the need to transform education is the state of the world and the tremendous effort being made by thousands of nongovernmental organizations (NGOs) and schools in environmental and sustainability education to "fix" the traditional educational system (Cortese 2003: 15).

The formation of NGOs, and specialized grassroots initiatives are needed to counter what is being perpetuated out in the world, as a direct result of what is taught in educational institutions.

\section{Purpose of Research}

The purpose of this research is to examine the current landscape of the integration of sustainability and ethics into existing fashion curriculum, and look for ways that larger inclusion of sustainability and ethical content can be incorporated; thus resulting in a new curricular model that actively supports and advances sustainable principles.

In my experience as an educator, the primary delivery models are ineffective. Teaching everything to a small group of students in an elective model is inadequate. Unfortunately, the data that is currently available points to this model as the predominant structure for communicating fashion sustainability content, and has even been described as "haphazard' and "scattered" (Armstrong \& LeHew 2014: 68). Presently, issues of ethics and sustainability are offered as a "centralized" standalone class containing all of the program's sustainability content, or offered through extra-curricular events like conferences (2014: 68). This is problematic because the topic is both vast and amorphous, resulting in information overload and forcing students to tackle content that may not be relevant to their discipline.

Certainly, the deeper and richer the experience of any information is for 
a student the better, but realistically in an already overloaded curriculum, the addition of discipline-irrelevant content is not conducive to retention and is also, clearly not an example of effective curriculum management or good pedagogy.

Another goal of this research is to aid educators who may not have strong institutional support for their own pedagogical reform ambitions; educators who may feel isolated, and lacking in resource and peer, or institutional support for the incorporation of sustainability principles.

Through the sampling of diverse educational styles and effective methodologies, there is much that can be incorporated into course materials and also used in advocating for this inclusion. Just because something has not been done at a specific institution does not mean that it cannot be. As will be discussed in relation to industrial reform, it is difficult to implement new content and structures in a system that seeks to streamline, and homogenize. Solid, tested examples of effective practices can legitimize and lend strength to the argument that this content is both relevant and of critical importance.

\section{DEFINITION OF TERMS}

Fashion brings together creative authorship, technological production and cultural dissemination associated with dress, drawing together designers, producers, retailers and all of us who wear garments. (Fletcher, Grose \& Hawken 2012: 8).

After a read through the contemporary literature on fashion sustainability, at times, it feels like the discourse around fashion sustainability as a whole, is being conducted within the Tower of Babel. The diachronic evolution of the nomenclature of fashion sustainability vis-à-vis business and design, has seen new terminology introduced that reflected changes in the world and the broader scope of factors for consideration. This was necessitated by a widening focus on what the term engendered, and an accommodation 
of a greater focus on social responsibility. Unfortunately with the inclusion of new terminology, there was no concurrent removal of terms previously used. This has resulted in the plethora of terms currently in common parlance regarding fashion sustainability. The broad swath of definitions covered by "sustainability" at first seems daunting, and this is only exacerbated by the variety of interpretations at the classroom level. This is partly a result of the scope of the need for sustainability within the fashion industry, which is equal parts vast and amorphous, and by necessity must incorporate specific terminology that is unique to various sectors of the industry.

The wide scope of descriptors is a reflection of the scope of the problem itself. The residual agglomerate vocabulary that has accumulated as a result of the multi-layered theoretical and practical discussions happening simultaneously, and independently in all of the component streams of fashion. As well as the constant adjustment and re-adjustment to new variables and re-definitions of what sustainability can entail (Serrat 2010). Also, the relatively recent introduction of ethical criteria into the definition of what sustainability can entail offers a new perspective with which to judge the sustainability of a product or its' marketing (Siegle 2011) add yet more layers of complexity.

Another complicating factor is that many terms are poly-words and are therefore unavailable for reference in a standard dictionary (Glavič \& Lukman 2007), or are so new that they are not defined at all. Gam \& Banning note that the existing terms themselves are vague to begin with: eco-friendly, green, environmentally friendly etc... (Gam \& Banning, 2011: 205).

If you throw in sleazy greenwashing that attempts to sell product that may have one component that is environmentally sound, but also may 
incorporate toxic processing-some bamboo textiles for example ${ }^{3}$-as "sustainable" then the picture gets even more blurred. Mitchell and Ramey identify the seven "sins" of greenwashing as set out by Canadian environmental marketing and consulting firm TerraChoice: “...The hidden trade-off, no proof, vagueness, irrelevance, lesser of two evils, fibbing and worshiping false labels." And conclude that: "...More than $95 \%$ of the 4,744 green products identified in the (TerraChoice) report were guilty of at least one of the seven greenwashing sins" (Mitchell \& Ramey 2011).

Comparable to the issue of greenwashing is the problem of controlled content and censorship by omission. As Sibbel identifies in "Pathways Towards Sustainability Through Higher Education":

Generally, information about products and services delivered through the media are prepared by public relations or marketing teams. By no means does this filtering lead to a systematic and balanced presentation of all the facts needed to make informed decisions (Sibbel 2009: 72).

And that:

In many instances, consumers receive information which has been selected by stakeholders for its potential to encourage purchase, to improve the public image of a company, or perhaps for political reasons, rather than for its contribution towards providing a balanced perspective (Sibbel 2009: 72).

This lack of reliability in information is particularly problematic in fashion media where voices of dissent are even less likely to be broadcast. Dissenting voices that either expose corporatist culpability in pollution or human exploitation, or propose alternatives are not featured in the corporatist controlled oligarchies of fashion media.

\footnotetext{
${ }^{3}$ Bamboo requires toxic chemical processes to render it soft enough to extrude into fibre, which results in:

"... High-impact waste emissions to both air and water". This negates the prolific and fast growth of the material (Fletcher, Gorse \& Hawken 2012:14).
} 
Fashion media has evolved into an 'omni-media' of print/digital and video, whose content is affected by the advertising budgets of the manufacturers who are responsible for the destruction wrought by fashion (Rinallo \& Suman 2009). As Gloria Steinem says in "Sex Lies \& Advertising":

...I was thinking especially of women's magazines. There it isn't just a little content that's devoted to attracting ads, it's almost all of it. That's why advertisers-not readers-have always been the problem for Ms. As the only women's magazine that didn't supply what the ad world euphemistically describes as 'supportive editorial atmosphere' or 'complimentary copy' (for instance, articles that praise food/fashion/beauty subjects to 'support' and 'complement' food/fashion/beauty ads), Ms. Could never attract enough advertising to break even. 'Oh women's magazines,' the journalist said with contempt. 'Everybody knows they're catalogs-but who cares? They have nothing to do with journalism.'... If Time and Newsweek had to lavish praise on cars in general and credit General Motors in particular to get GM ads, there would be a scandal-maybe with a criminal investigation" (Steinem [1990] 2014:180).

Although the journalist directed vitriol only at women's magazines, it is dangerously naïve to think that other news portals are not having their content mediated by corporate influences as well. This is not only true of magazines but of any media outlet that is supported by paid advertising: "Opinion, marketing, advertising, information, and news will weave together so seamlessly, in the on-line environment, that the public will no longer be able to distinguish objective reporting from promotional messages" (Williams 1998: 31). Information around fashion sustainability has largely been propagated through the relatively unregulated blogosphere, which is refreshing for its lack of corporation mediation, but as with Wikipedia and any user generated content (UGC) is the unreliability and unverifiability of the information communicated. 
Adding further confusion is Ehrenfeld's observation in Flourishing, A Frank Conversation about Sustainability regarding the relational nature of the term "sustainability" itself: "... The most important characteristic of sustainability is that the word, by itself, refers to nothing in particular. It gathers meaning in a practical sense only when the output is named." And that: "...This dissonance has serious consequences because it leads to a term that can mean different things to different people depending on the static outcome they seek. It has lost any real meaning" (Ehrenfeld and Hoffman 2013: 16); all of which has produced an imbrecated and at times confusing amalgamation. Especially for progressive educators who want to incorporate sustainability content into their curriculum, confusion abounds.

A good basic definition of sustainability is offered by Landgren and Pasricha in "Transforming the Fashion and Apparel Curriculum to Incorporate Sustainability" when they quote Hethorn and Ulasewicz:

Sustainability within fashion means that through the development and use of a thing or a process, there is no harm done to people or the planet, and that thing or process, once put into action, can enhance the wellbeing of the people who interact with it and the environment it is developed and used within (Landgren \& Pasricha 2011: 187).

One of the most significant definers of the parameters of sustainability was the Brundtland Commission Report: "Our Common Future" It was cited by Sass Brown,Grazyna Pilatowicz and Timo Rissanen during their interviews (Brown 2015, Pilatowicz 2015, Rissanen 2015). Brundtland states that we are: "...providing equitably for the needs of the present generation without jeopardizing the needs of future generations" (Brundtland Commission 1987). And: “...Emphasized the importance of cooperation among the various stakeholders at the regional, national and global level as a precondition towards a sustainable future (WCED, 1987)" (Karatzoglou 2013: 44). However, some feel that Brundtland does not go far enough in defining a truly holistic philosophy towards sustainable living (Rissanen 
2015; Ehrenfeld 2013) and that: "This definition rests on the same economics-based paradigm that created the situation it aims to correct" (Ehrenfeld \& Hoffman 2013: 20); questioning whether a "sustainable" solution can be generated within the economic construct that created the problems.

In "An In-depth Literature Review of the Evolving Roles and Contributions of Universities to Education for Sustainable Development" Karatzgolou cites the need for "extensive collaboration among diverse partners to effectively pursue (sustainable development) originates from the three dimensions of the term, namely the ecological, economic, and sociocultural" (Karatzoglou 2013: 44). The wide variety of terms and philosophies currently applied to fashion sustainability: "...Demonstrates the tension...between theoretical and practical" (Thomas 2008: 526). A comprehensive "Lexicon" is necessary to unify terminology, which can in turn clarify and define what is actually being discussed. We need to "...Know the clear meaning of the language we use" as languaging can profoundly affect the "immediate social, economic, and environmental impact of decisions" (2008: 526). Language can be a powerful tool for galvanizing support, fostering resistance and creating unified, dynamic movements for progressive change. Since:

\footnotetext{
Semantics and content analysis enable the researcher to better describe and understand sustainable development concepts. Consequently, communications within the scientific community, organizations, agencies and stakeholders can be improved. A hierarchical classification and relationship of the terms needs to be developed in order to achieve better and easier understanding. Glavič \& Lukman 2007: 1)
}

This is a good reason to break down the discussion into sector-based solutions: a cohesive and clear vocabulary and well-defined set of terms would provide a stronger framework to build sustainability initiatives upon. The added specificity of sector terminology reduces the need for blanket 
terms that cannot define elements and principles that have nothing in common.

\section{CurRent State of SustainabiLity, AND the EnVIRONMENTAL AND Social IMPACT OF FASHION INDUSTRY}

Speed and efficiency are not in themselves signs of intelligence or capability or correctness. They do not carry with them any moral value. They don't necessarily make any social contribution. The most horrifying, violent moments of the twentieth century have centered around regimes wedded to efficiency and to speed (Saul, 2013: 260).

John Ralston Saul, Voltaire's Bastards: The Dictatorship of Reason in the West

The fashion industry creates myriad problems; these occur locally but can have global impacts. Production in its current configuration consists of a product being designed in the West and produced in the East through an intricate web of sub and further sub-subcontracting activity (Fletcher, Grose \& Hawken 2012). As Collins says in Threads: Gender, Labor, and Power in the Global Apparel Industry:

The practice of subcontracting shapes the labor relations of the apparel industry in many ways. Contract shop owners serve as intermediaries between branded manufacturers and workers and organize labor process on behalf of the 'absentee' apparel firms. In reality there are often several 'layers' of subcontracting involved" (Collins 2003:160)

The lack of control or even awareness of what happens during the production of fashion is a by-product of transnational fashion production. This creates a supply chain structure that is both vulnerable to exploitation and lacks any real accountability frameworks. The most obvious culprits are the high-volume, low quality, "Fast Fashion" producers like Sweden's H\&M, Zara from Spain, Britain's TopShop and Primark, America's Gap and Canada's own Joe Fresh (whose product was found in the rubble of Rana 
Plaza alongside the workers who died there). However it is also the luxury brands who employ a similar model; Marie Claire Deveau, the Chief Sustainability Officer and Head of International Institutional Affairs of luxury conglomerate Kering ${ }^{4}$ said recently during the Ethical Fashion Initiative Lecture series at FIT that only $6 \%$ of their production was within direct corporate control, which means that a staggering $94 \%$ of the operations of their brands are subcontracted. Fletcher and Grose speak of this mode of production:

Most modern commercial artefacts are sourced internationally, based on what is the most economical production route for each processing step and material component. Though direct costs are certainly balanced with service, reliability, quality and retail timelines, economics is the logic of production and distribution. This logic makes the bottom line the most powerful factor motivating choices about where to produce garments - a factor that takes no account of the knock-on effects on environments, communities and culture; conventional economics simply counts these effects as costs 'external' to a corporation's activity (Fletcher, Grose \& Hawken 2012: 106).

This results in a fashion system that is left wide open for abuse, as there are no regulatory bodies to govern the conduct of multi-national conglomerate fashion production.

A terrible incident like Rana Plaza clearly illustrates the human impact of the current system of production, and it has since become synonymous with unsafe transnational labour practices:

Bangladesh has more than 5,000 garment factories, handling orders for nearly all of the world's top brands and retailers, and is second in

\footnotetext{
4 Kering brands are as follows: The Luxury division consists of Gucci (100\% share); Saint Laurent Paris (100\% share); Sergio Rossi (100\%); Boucheron (100\% share); Bottega Veneta (100\% share); Balenciaga (100\% share); Stella McCartney (50\% share); Alexander McQueen ( $51 \%$ share); Brioni ( $100 \%$ share); Sowind Group ( $51 \%$ share) with Girard-Perregaux and JeanRichard, Queelin; Pomellato Group with Pomellato and Dodo; Christopher Kane (51\% share) and Tomas Maier and Ulysse Nardin (100\% share). The 'Sport \& Lifestyle' division comprises Puma (86\% share); apparel brand Tretorn and golf equipment specialist Cobra Golf; action sport brand Volcom (100\% share); and Electric. http://www.kering.com/en/brands
} 
garment manufacturing output behind China. It has the lowest wages for garment workers in the world, and the collapse at Rana Plaza drew attention to unsafe practices in the industry (Manik \& Najarjune 2015: n.p.).

The business of low-wage, unethical production is not unique to Bangladesh. In the ongoing quest to find the cheapest, least regulated production environment, the industry is currently expanding into East Africa and Burma among other locations (Ellsworth, FIT interview 2015).

Fashion is also one of the largest polluting industries globally (Caniato et al 2012: 659) both in the fabrication of natural and synthetic textiles (Luz 2007: A450). The race-to-the-bottom processes of fast fashion manufacturing are fundamentally unsustainable and dangerous both locally and globally (Fletcher, Grose \& Hawken 2012; Orr 2002). Resulting in unethical offshore production and labour practices, environmental abuses, and poor industrial practices like superfluous sample production, wasteful cutting, as well as sky-high minimums that guarantee dumping product at steep markdowns. This high volume flow of badly made garments cheapens the whole process of fashion design and distribution:

The speed and volume with which industrially produced products flow through the fashion system has resulted in their depersonalization. We no longer know the makers, or the source of the materials; they no longer speak of our myths, communities or societies. Our garments have become inanimate objects, mainly providing a means for delivering on commercial goals. Poetic meaning has been reduced in importance in favour of efficiencies of production, and a garment's aesthetic reflects a bare minimum appeal, developed primarily to secure the initial sale (Fletcher, Grose \& Hawken 2012: 85).

Fast fashion also translates to fast design pressures, and innovation is pushed out during industrial production by the pragmatic demands of product development and delivery to market, therefore: "What innovative 
thinking is edited out in industry and in product development is also edited out in the designer, the wearer and the market." (Fletcher \& Grose 2013: 76). There are many challenges presented by non-standard design processes, as by their very nature they challenge the status quo of current fashion design and production.

The "variety and pluralism" of the modes of production-both in the conceptual stage and in subsequent production-required when developing fashion product that is made from low-harm fibre and produced and distributed ethically, is intrinsically challenging for an industry that is currently grooved into low-cost, high volume, mass distribution models. This is "...Challenging for industry, but also for designers and consumers transforming the way all stakeholders create and experience fashion" (Fletcher, Grose \& Hawken 2012: 76). The reductive forces of large-scale production and speed-to-market pressures are stimuli that diminish the possibilities and creativity offered by a pluralistic design environment:

For industry and in particular the segment used to designing large volumes of similar products for mass-manufacture...the challenge of adaptability is to foster heterogeneity in thinking and garment design that accommodates varying circumstances (Fletcher \& Grose 76-77).

There is an obvious and pressing need to change things, since we live in a contained environment with finite resources: "Issues of power, distribution of wealth and real reasons for pollution and economic instability will necessitate a willingness to dialogue" and the need to: "...balance current growth with long-term social viability" (Landgren \& Pasricha 2011:188). Progressive change can have an ever widening impact since: "...Fashion also has a complex relationship with larger systems; with economics and society" (Fletcher, Grose \& Hawken 2012: 11). Changing thinking around fashion can change much larger structural philosophies since sustainability brings with it not only transformative vocabulary, but the paradigm-altering 
conceptuality: "...Of thinking about the world in which our businesses operate and in which we practice design" (Fletcher, Grose \& Hawken 2012: 11). Current models are not good enough because: "The growth model used for technological and industrial development is incompatible with sustainability" (Landgren \& Parischa 2011:187). And further to this: "For the current fashion industry, and the consumer economy in which it operates, are human constructs founded on the belief that unlimited growth is possible" and current modes of production are: "...Utterly dependent on degrading finite material resources and ecosystems to produce saleable goods to fuel that growth" (Grose 2013: 135). We therefore need new thinking that can reverse the "...Take, make, waste" philosophy that: " ...Frames production and consumption activities as separate and consecutive and the linear view of how resources flow through the supply chain" (Fletcher, Grose \& Hawken 2012: 11). Ultimately: "...we need a second industrial revolution that eliminates the very concept of waste" (McDonough \& Braungart [1998] quoted in Orr 2002: 21).

When considering the: "...Moral and ethical (values that are not captured by business and the market)" (Fletcher, Grose \& Hawken 2012: 75), albeit ephemeral, they still need to be introduced somewhere, and having sustainability taught in-class is a logical place for this. As Barak Cakmak the new Dean of Fashion at Parsons was quoted as saying in the recent Business of Fashion article: "Under New Direction Parsons puts Sustainability First":

Graduates play a key role in driving the fashion business. They have the biggest opportunity to do things differently, because, unlike large companies and brands, they're not constrained by their existing environments,' he says. 'This is when we are able to really influence a designer, because once they get into the industry, it's harder to make those changes (Cakmak quoted in Chitrakorn 2015).

Educational institutional change can also cause social change since: 
...When humans have designed with ecology in mind, there is greater harmony between intentions and the particular places in which those intentions are played out that preserves diversity both cultural and biological; utilizes current solar income; creates little or no waste; accounts for all costs; and respects larger cultural and social patterns (Orr 2002: 27).

We as educators need to turn our thoughts and efforts as to how to effect these changes: in our classes, learning outcomes, program outcomes and structurally within our institutions at a policy level. If we teach with the goal of educating students who: “...Don't confuse what they have with what they are” (Orr 2002: 27), we are also helping: “...Create a better balance between the real needs of society and the pace and kind of knowledge generated" (Orr 2002: 41). Students who graduate with a strong framework of solutions will be "future oriented" designers (Fletcher, Grose \& Hawken 2012: 2) and will be able to effect changes great and small as they progress in their careers as they encounter them.

\section{CORPOREALITY AND FASHION}

Curriculum and laws were changed once the built environment was identified as having a negative impact on health by the interior design industry (Pilatowicz 2015). But our clothing, which is in constant physical contact with our bodies, is largely considered benign. Wearing something is far more intimate than sitting near or on top of it. This omission is dangerously naive when one considers the formaldehyde, fungicide and surface treatments required to get a transnational produced garment that is going to sit on a boat for three months to market. These surface treatments all have toxic impacts (Burke 2015). In fact, that: "new clothes smell" is a combination of these chemical additions (2015). Add to this the detergents that are used for cleaning that are in constant contact with our skin, and also the negative impact of dry-cleaning solution on health-both on 
practitioner and those living within the vicinity-has been well documented ${ }^{5}$ (Seldén \& Ahlborg 2011; Schreiber et al 2002; Ruder, Ward \& Brown 2001; Solet, Robins \& Sampaio 1990). The potential for harm from our clothing is real. I would argue that clothing due to its proximity to the body needs greater attention. We may be experiencing health repercussions that we do not yet know about. Even the plastic based clothing made from recycled bottles contains: “...Antimony, catalytic residues, ultraviolet stabilizers, plasticizers, and anti-oxidants..." and were never meant to be near skin (McDonough \& Braungart 2010: 58). The belief that clothing doesn't pose any health concerns is patently false, and should not be perpetuated within any fashion classroom. Within the context of fashion, the awareness around the physicality of our wearables has not been given adequate consideration, and would be good exploratory content for a science-based textiles subject.

\section{LITERATURE REVIEW}

Any research inevitably builds on a particular ontology (i.e., how the world is), epistemology (i.e., how the world can be known), methodology (i.e., what methods to use in the world's inquiry), and etiology (i.e., what are the world's underlying causes). Every scholar and researcher holds to diverse extents those assumptions...(Sousa 2010: 456)

\section{SUSTAINABILITY SCHOLARSHIP}

Tracing the history of the sustainability movement, one can see that it has gone through various evolutions and widening of meanings comparable to those of the corresponding nomenclature. Arguably, Malthus could be considered the first eco-pioneering theorist with his essay from 1798: "Population, The First Essay" whose predictions ran counter to the propopulation sentiment of his era and instead foresaw: "darkness, scarcity,

\footnotetext{
${ }^{5}$ Examples of workplace related illness due to exposure to dry-cleaning chemicals include: "Elevated SMRs for tongue, bladder, esophagus, intestine, lung, and cervical cancer, pneumonia, and diseases of the stomach and duodenum" and because of this:... Dry-cleaning workers have excess cancer mortality..." (Ruder, Ward, Brown 2001).
} 
poverty and famine...(McDonough \& Braungart 2010: 45). Wordsworth and Blake, in the UK and Thoreau in the United States wrote about the value of spending time in nature (2010: 46). However it was with her seminal text Silent Spring that Rachel Carson catalyzed the nascent modern environmental movement in 1962. As a result of her science based observations: "...Silent Spring led to the banning of DDT in the United States and Germany and sparked continuing controversy about the dangers of industrial chemicals" (48). A movement that was initially about environmental concerns, has since evolved to encompass much larger issues around ethical and economic concerns. In Sustainability: A History, Caradona talks about the creation of the term "environment" as a holistic delineator for many of the philosophical principles that sustainability encompasses:

Perhaps the most significant achievement of the environmental movement in the 1960's was establishing "the environment" as a conceptual prism through which to view the world and humanity's place in it. The word "environment" dates back to the seventeenth century, but as a specialized ecological connotation dates only to 1956; the term then entered common parlance in the 1960's. Thinking in terms of an allencompassing, interconnected environment was an innovative act because it transcended the conceptual boundaries of "nature", which had been the ordinary way of reckoning air and water and dirt and animals since antiquity and which functioned as one half of an elementary binary that structured much of western thought: the supposed opposition between nature ("out there") and human civilization ("in here")1. The ecological sense of environment collapsed that binary and showed that humans and the built environment functioned as part of a broader ecosystem, defined as a community of living organisms and nonliving entities that interact in myriad ways and through which nutrients cycle and energy flows. No longer did it make sense to think of the natural world as simply "out there". Humans are the environment, both in the sense that we act as components of ecosystems and that ecosystems 
act upon us (via nutrients, pollutants, micorbes, etc.) (Caradonna 2014:

90).

In "Exploration of the Meaning of Sustainability in Textiles and Apparel discipline and prospects for Curriculum Enhancement" Pasricha traces the evolution of the sustainability movement beginning with Carson and also Tragedy of Commons by Garret Hardin (1968), which "initiated public concern for environmental problems", then gives a chronology of significant public declarations on sustainability: The first Earth Day: (1970); the Stockholm declaration (1972); Tblisi Declaration (1977); Brundtland Report 1987; Talloires Declaration (1990); Doha Declaration (2001), United Nations launch of the "Decade for Education" (2005); and identifies during the late twentieth century the rise of "ecologism" a form of ecological activism, and ends with the "Sustainability Revolution" 2005 (Pasricha 2010:18). She identifies the Brundtland Report as an outcome of the UNCRED Rio de Janeiro Conference (2010: 18), and notes that Talloires was also significant as it was an: "...Epiphany for higher education" in that it "recognized that universities have a compelling responsibility to increase awareness and knowledge in preparing future leaders and professionals for creating an environmentally sustainable future" (Calder and Clugston 2003, in Pasricha 2010: 19). Landgren and Pasricha describe the genesis and impact of the "sustainability revolution" as follows:

The 'Sustainability Revolution', a term coined by Edwards (2005), is like many previous revolutions in that it started at the periphery of power and wealth; it differs from other revolutions in that it requires a new value system, consciousness and worldview (p. 5). The revolution is international in scope; it can, should and will encompass every facet of social, economic, political, educational, environmental and technological discourse and action (Landgren \& Pasricha 2011:189).

As Marcuse says in "Sustainability is not Enough" environmental sustainability criteria does not adequately address the human costs of 
unethical fashion production, social justice must form part of the consideration for how "programmes are judged" (Marcuse 1998: 104).

Since its inception the discourse around sustainability has grown from a focus on eco-policies to one that also takes into consideration the economic and human impacts of production. The prism through which we view the issues of sustainability has now broadened and expanded exponentially. This has in turn necessitated evolutions in what needs to being taught in-class.

\section{Pedagogy Scholarship}

Pedagogy scholarship is a fascinating field; effective rubrics and classroom delivery are only the tip of the iceberg, when considering what pedagogical theory can entail. An exploration of the ontology of pedagogy is illuminating due to the myriad elements that can constitute "good" pedagogy. As Watkins, Noble and Driscoll identify in "The Unsaid of Socio-Cultural Theory" pedagogy is both "under-defined and under-theorised" Watkins, Noble \& Driscoll 2015: 2). The term 'Pedagogy' can refer to: “...Teaching style, classroom management and instructional" but can also encompass the philosophy of education, context within institutional structures, and even the: "...Relationship between formal education and the wider social world." They identify pedagogy within a matrix of terms: “...Education, teaching, learning, instruction, training, curriculum, and so on-and a wide range of more 'sociological' notions-socialisation, transmission, reproduction, acculturation" (2015: 2) which generate both ontological and classificatory questions. They put forth their reasoning on why it is necessary to broaden the definition of pedagogy:

On the one hand, clearly what goes on in schools is not just the overt or formal acquisition of specific skills. As Philip W. Jackson (1968) argued in the 1960s, schools entail a 'hidden curriculum' through which particular values are covertly transmitted - an idea taken up by radical education critics who used it to analyse the ideological dimensions of schooling. 
Pierre Bourdieu and Jean- Claude Passeron (2000: 46-47) made a comparable distinction between implicit and explicit pedagogies, and Bernstein (2003: 68) likewise distinguishes visible from invisible pedagogies (Watkins, Noble \& Driscoll 2015: 2).

It is imperative to identify the overt and covert messaging in fashion curriculum. What we teach and how we teach it speaks volumes. The isolated stand-alone subject with encyclopedic content crammed into itwith no other mention of it anywhere else in the curriculum-clearly identifies and communicates the (low) institutional and program priorities accorded to sustainability. If content is not presented as important, the message conveyed to the student is obvious: learn once and discard. Uncomfortably close in fact, to the fast-fashion model found in the marketplace. A holistic incorporation of sustainability throughout the curriculum both communicates the gravity of the problem, and the imperative need for solutions.

\section{Fashion Pedagogy Scholarship}

At the moment, fashion curriculum for the most part is just a replication of the unhealthy business and environmental practices of the fashion industry (Armstrong \& LeHew, 2014: 63). Where it is taught, fashion as it relates to sustainability has evolved from ecofriendly to encompass ethical labour practices (2014: 63); reflecting the broadening of the definition across the board. Regarding fashion sustainability pedagogy, there has been limited scholarship in the area. Pedagogical explorations in the fashion discipline have been around curriculum reform and best practices (Sidiropolous 2014; Gam \& Banning 2011; Cao et al 2006; Leeburg, Riisberg \& Boutrup 2010; Pasricha 2010).

In "Barriers and Mechanisms for the Integration of Sustainability in Textile and Apparel Education: Stories from the Front Line" Armstrong and LeHew have done the most extensive survey of textile and apparel (TA) teacher's pros and cons, challenges faced, and innovations implemented 
within fashion curriculum. They also explore the marginalized status and corresponding lack of structure or framework around sustainability content that results in sustainability content being taught in many different schools in many different ways:

...The TA discipline educators reflect a diverse array of specializations, the curriculum often segmented by specializations like design, marketing, merchandising, textile science, and production. The widely varied educational priorities among these emphases constrains consensus (Armstrong \& LeHew 2014: 61).

Of the educators surveyed: $95 \%$ of participants modified course materials to include sustainability, $50 \%$ reported that content was centralized (contained in a single course) and $45 \%$ employed extra-curricular projects. Regarding perceived barriers to integration, $80 \%$ reported a lack of resources and support. And $80 \%$ also felt that external pressure would accelerate integration of sustainability content (Armstrong \& LeHew 2014: 67). Their study focused on the obstacles and barriers educators face in the introduction and teaching of sustainability, but did not go into specific detail of what is actually being taught.

The largest concerted effort to consolidate current research that includes teaching collateral and rubrics used in fashion sustainability education, is the 2009 book: Sustainable Fashion: A Handbook for Educators. In this ambitious project Parker and Dickson have assembled a voluminous collection of sample projects for "Educators for Socially Responsible Apparel Business" (Parker \& Dickson 2009: n.p.). Their goal in publishing this agglomerate of fashion assignments was for educators to introduce ethics and sustainability into their teaching, and through this process encourage students to consider environmental and human impacts as a part of their decision making process as mature designers (2009: n.p.). They have divided the Handbook into six chapters: "Design, Marketing, Business, Cross-curricular, Pedagogy and Institutional 
Approaches, and Interactive Activities" and have drawn upon the shared expertise of the teaching of ethics and sustainability from 45 educators from "around the world" (2009: n.p.). Although this is a very handy resource, there is no consideration given to larger pedagogical theoretical dialogues, or strategies for inclusion of this information into existing curriculum.

\section{FASHION SUSTAINABILITY SCHOLARSHIP}

Regarding fashion sustainability in general, there has been more scholarship. Kate Fletcher and Lynda Grose were the most frequently cited by the educators I interviewed. In addition to this: Sandy Black, Lucy Siegle, Sass Brown, and Timo Rissanen have all written in thoughtful and innovative ways about Economics, zero-waste, ethical practices, global production and about possible solutions within the fashion discipline (Rissanen \& McQuillan 2016; Fletcher 2013, 2010, 2007; Fletcher \& Grose 2012; Siegle 2012, 2011; Brown 2010). Mcdonough and Braungart have extensively explored the philosophy and practicalities of zero-impact, and zero-waste design in their 2010 book: Cradle to Cradle: Remaking the Way we Make Things (although not specifically related to fashion).

There is also a quantitative body of research that includes data and formula analysis, as well as survey-based studies done in the business and production areas of fashion supply chain and product development: (Fletcher G., Greenhill, Griffiths \& McLean 2016; Curwen, Park \& Sarkar 2015; Dickson \& Chang 2015; McNeill \& Moore 2015; Kulatunga, Karunatilake, Weerasinghe \& Ihalawatta 2015; Romli, Prickett, Setchi \& Soe 2015; Choi 2014, 2012; Johansson \& Sundin 2014; Prendeville, O'Connor \& Palmer 2014; Lim, Kim, Woo \& Park 2013; Caniato, Caridi, Crippa, \& Moretto; Farrer \& Fraser 2011; Hilletofth \& Eriksson 2011; Niinimäki \& Hassi 2011; Bhardwaj \& Fairhurst 2010; Garber, Hyatt \& Boya 2009; Beard 2008; De Brito, Carbone \& Blanquart 2008 ; Hustvedt \& Bernard 2008; Grayson 2007; Toklati 2007; Valor 2007; Waage 2007; 
Tyler, Heely \& Bhamra 2006).

There is also quantitative research on consumer decision making as result of sustainability criteria: (McNeil \& More 2015; Manchiraju \& Sadachar 2014; Kim, Choo, \& Yoon 2013; Gam 2011; Dickson 2000). Content from any of these areas could be easily added to fashion business curriculum.

\section{Sustainability Pedagogy Scholarship}

In 2009 a Google search for "Education for Sustainable Development" yielded 215,000 websites (Karatzoglou 2013: 46), clearly illustrating the breadth and diversity of scholarship in this area. Describing the evolution of sustainability pedagogy in "Revolutions and Second-Best Solutions: Education for Sustainable Development in Higher Education" Cotton, Bailey et al say:

Reflecting international political commitments to sustainable development (SD) since the Rio Earth Summit in 1992, Education for Sustainable Development (ESD) has gained an increasingly high profile within higher education over the past two decades. The first major step in this direction came in 1990, when university leaders from over 320 Higher Education Institutions in 47 countries signed the Talloires Declaration, committing to environmental sustainability in higher education (University Leaders for a Sustainable Future, 2005). Moreover, the UN Decade for ESD (2005 to 2014) provides a major opportunity for educational institutions worldwide to engage with ESD (see ARIES, 2005). A similar chain of commitments to ESD can be observed in the UK, where in 1993 the Toyne Report emphasised the need to improve environmental responsibility in the higher education (HE) sector. In 2005, coinciding with the UK government report, Securing the Future: delivering the UK sustainable development strategy (HM Government, 2005), the Higher Education Funding Council for England produced an ESD strategy and action plan, Sustainable Development in Higher Education (HEFCE, 2005). This was followed in 2006 by the Department for 
Education and Skills' Sustainable Schools Strategy (DfES, 2006). The potential impact of these initiatives on the HE sector is highly significant both in terms of curriculum content and pedagogical approaches. The HEFCE strategy provides a vision of higher education as 'a major contributor to society's efforts to achieve sustainability - through the skills and knowledge that its graduates learn and put into practice, and through its own strategies and operations' (HEFCE, 2005, 1). Amongst other things, the strategy seeks to encourage the sector to, '... develop curricula, pedagogy and extra-curricular activities that enable students to develop the values, skills and knowledge to contribute to sustainable development' (HEFCE 2005, 2). According to Sterling (2004a), SD is 'not just another issue to be added to an overcrowded curriculum, but a gateway to a different view of curriculum, of pedagogy, of organisational change, of policy and particularly of ethos' (50). (Cotton, Bailey, Warren \& Bissell 2009: 3-4).

Regarding academic scholarship Karatzoglou noted in "An In-depth Literature Review of the Evolving Roles and Contributions of Universities to Education for Sustainable Development" that both qualitative and quantitative methodologies were used in scholarship around the roles of universities for education in sustainable development; and identified four clearly distinct types of papers in higher education institutions (HEI) concerning education for sustainable development (ESD):

(1) Researched original case-studies, collecting and presenting detailed information, mostly of a qualitative nature, about a particular HEI or ESD initiative, including the accounts of subjects themselves, with the emphasis placed on exploration and description.

(2) Literature reviews, presenting the current state of knowledge on theoretical and methodological contributions to ESD and providing insights into aspects of the ESD field, worthy of further exploration,

(3) Conceptual papers of a rather abstract (non-factual), philosophical, 
normative nature, with the focus on understanding theoretical distinctions, and

(4) Mixed papers which equally blended elements from more than one type. (Karatzoglou 2013: 47).

Karatzoglou also details the evolution of sustainability scholarship: “...In the earlier years the published papers were mostly theoretical and prescriptive, while literature review papers became frequent later and an increasing number of case-studies and research papers followed" (Karatzoglou 2013: 47). Of the 123 papers from 2003 to $2011^{6}$ that were surveyed, 77 were empirical and descriptive which outlined case studies and the like, compared to 24 which were prescriptive which explored the larger ontological and philosophical role of $\mathrm{HEl}$ in sustainability with a goal of providing policy and evaluation models to successfully transition to new models of academic structure (both institutional and pedagogical) (Karatzoglou 2013: 47). The wide variety of methodologies reinforces the poly-dimensionality of the discipline of ESD, and the wide variety of scholarship taking place. However the lower ratio of papers addressing policy and criteria for the evolution of institutional frameworks speaks to the lack of integration of sustainability as a core institutional foundation.

Research around methodology and curriculum development for sustainability education has been conducted by: (Sidoropoulos 2014; Palomo-Lovinski \& Hahn 2014; Boman, \& Andersson 2013; Dickson, Eckman, Loker, \& Jirousek 2013; Lambrechts, Mulà, Ceulemans, Molderez \& Gaeremynck 2013; Lozano, Mulder, Huisingh \& Waas; Pappas, Pierrakos \& Nagel 2013; Downing 2012; Gam \& Banning 2011; HaBrookshire \& Norum 2011; Landgren \& Pasricha 2011; Jordan 2011; Savalyeva \& McKenna; Wals, 2011, 2007; Cortese \& Hattan 2010;

\footnotetext{
${ }^{6}$ Karatzoglou chose to analyze the years from: 2003 to 2011 as they correspond to the UN Declaration of: the Decade of Education for Sustainable Development (Karatzoglou 2013: 44).
} 
Leeburg, Riisberg \& Boutrup 2010; Pasricha 2010; Cotton \& Bissell 2009; Cao, Frey, Farr \& Gam 2006; Jones, Crier \& Richards 2008; Bonnett [2002] 2006; Barnes \& Lea-Greenwood 2006; Howarth \& Hadfield; Lidgren, Rodhe \& Huisingh 2006; Lozano 2006; Appel, Dankelman \& Kuipers 2004; Cortese 2003; Warburton 2003; Jucker 2002; LaBat \& Sokolowski 1999; Sterling 1990) among others.

Research methodology and curriculum development for sustainability education has been written about by: (Sidoropoulos 2014; Palomo-Lovinski \& Hahn 2014; Boman, \& Andersson 2013; Dickson, Eckman, Loker, \& Jirousek 2013; Lambrechts, Mulà, Ceulemans, Molderez \& Gaeremynck 2013; Lozano, Mulder, Huisingh \& Waas; Pappas, Pierrakos \& Nagel 2013; Downing 2012; Gam \& Banning 2011; Ha-Brookshire \& Norum 2011; Landgren \& Pasricha 2011; Jordan 2011; Savalyeva \& McKenna; Wals, 2011, 2007; Cortese \& Hattan 2010; Leeburg, Riisberg \& Boutrup 2010; Pasricha 2010; Cotton \& Bissell 2009; Cao, Frey, Farr \& Gam 2006; Jones, Crier \& Richards 2008; Bonnett [2002] 2006; Barnes \& Lea-Greenwood 2006; Howarth \& Hadfield; Lidgren, Rodhe \& Huisingh 2006; Lozano 2006; Appel, Dankelman \& Kuipers 2004; Cortese 2003; Warburton 2003; Jucker 2002; LaBat \& Sokolowski 1999; Sterling 1990). Faculty development research has also been done by: (Barth \& Rieckmann 2012; Kim, Pedersen \& Cloud 2007). Angela McRobbie in British Fashion Design: Rag Trade or Image Industry? Examines the tension between creativity and commercialism in fashion education, as well as the progression of postgraduate British designers.

David Orr has written prolifically, and eloquently about the designsustainability-pedagogy trinity. Orr has explored these philosophies in depth in his collection of essays: The Nature of Design: Ecology, Culture, and Human Intention. Orr speaks of a need to: "...Harmonize the human enterprise with how the world works as a physical system and how it ought 
to work as a moral system" (Orr 2002: 3). Regarding how we need to view and re-structure industrial production he says: "The goal is not total mastery but harmony that causes no ugliness, human or ecological, somewhere else or at some later time (2002: 4). And engaging in an ongoing reflective practice that incorporates consideration of: "...a closer fit between human intentions and the ecological systems where the results of our intentions are ultimately played out (14). Orr comments that "Ecological design, in other words, is the careful meshing of human purposes with the larger patterns and flows of the natural world and the study of these patterns and flows to inform human actions" (20). He also speaks to the interdisciplinary nature of sustainability pedagogy and says that it cannot: "...Take place within the safe and comfortable confines of any single discipline." Elaborating that it: "...Is as much a conversation about ethics, politics, economics, and sociology that affects how knowledge is used in the world as it is about biology, chemistry, geology, or physics." Adding that it is also about what is "Worth knowing and what's not" (137). His macro and micro explorations of sustainable concepts and solutions are a good framework to build new programming upon. He also has had one of the most highly visible campus sustainability initiatives realized in the School of Architecture building at Oberlin college: the Adam Joseph Lewis Center, which according to the Oberlin website is: "One of the most advanced examples of Green building in the United States" and was: “...Named by an AIA panel in 2010 as 'the most important green building of the past 30 years"', and is also considered to be: "One of 30 milestone buildings of the twentieth century by the U.S. Department of Energy" (Oberlin Website: n.p. n.d.). Synthesizing both the philosophical and the practical within an academic setting, the project is a prime example of the didactic use of an institutional structure to communicate philosophies that are literally embedded into the bricks and mortar of the building where the educating is taking place. This could be mirrored in fashion curriculum by introducing no-waste projects and resource conservation within classroom 
activities (Lafrenz 2015). Thereby reinforcing student learning throughout their program experience.

\section{CHAPTER 2: SUSTAINABILITY EdUCATION}

A worthy goal for fashion educators is to: "...Harmonize the human enterprise with how the world works as a physical system and how it ought to work as a moral system" (Orr 2002: 3); resulting in new philosophies in fashion pedagogy that can incorporate "Ecological Design". A principle which can be defined as: "... The careful meshing of human purposes with the larger patterns and flows of the natural world and the study of these patterns and flows to inform human actions" (Orr 2002: 20). A new model for fashion academics where all of this can take place needs to be envisioned. Regarding what the effects of implementing this type of philosophy can be, we can through education, help students to become: "...People who don't confuse what they have with what they are" (Orr 2002: 27). And ultimately create educational opportunities for our students that allow for integration of broader environmental and ethical principles.

\section{EXAMPLES OF SUSTAINABILITY IN FASHION Education}

It is possible...to practice chemistry as if evolution, ecology, and ethics do not matter, but it is impossible for them not to matter (2002: 138).

David Orr The Nature of Design: Ecology, Culture, and Human Intention

\section{CURRENT PRACTITIONERS}

Through a series of interviews, exemplary practices in sustainability education were explored. Leading educators from very different sectors shared their experience in teaching fashion sustainability at a postsecondary level. The educators consulted were based in Toronto and New York and represented wide range of multidisciplinary skills and philosophies. Through the interviews and exploration of their respective approaches, the individualities, and unique methodologies of the educators were revealed. Questions explored the following themes: research focus; 
definitions of sustainability; how ethics, social responsibility and sustainability issues were incorporated into their curriculum; how the binary between business content and creative content is managed; the identification of industry evolutions that have been incorporated into curriculum; philosophy and theorists whose work has proved inspirational for them; and in an ideal world what the perfect undergraduate fashion program would look like and how sustainability would be incorporated into it. The answers proved fascinating and for some questions were very divergent-as one would expect given their varying viewpoints on the subject-but for others there was a remarkable synergy.

Interviewees consisted of the following: Dr. LuAnn Lafrenz, who along with her teaching practice also coordinates the undergraduate fashion program at Ryerson University in Toronto: her specialty is pedagogical research and institutional approaches towards sustainability in fashion education. Rachel MacHenry, who has taught at Sheridan College, developed the sustainability class for the Fashion Studies program at Seneca College and is currently teaching at OCADU. She uses a grassroots model in her work and has among her entrepreneurial endeavors created a line of sustainable decorative trims: Botanica Tinctoria, coloured with organic dyes and created by collectives in Haiti and India ${ }^{7}$. Tarah Burke is a professor at Ryerson University and teaches the sustainability subject in the Fashion Studies program at Seneca College. Burke approaches her research in sustainability education from a business perspective exploring examples of how sustainable manufacturing models can in fact, prove more cost efficient than traditional

\footnotetext{
7 Botanica Tinctoria: According to their website Botanica Tinctoria is "Reviving historical practices and implementing current environmental ideas, both organic and conventional cotton trimmings are dyed with BioDye India in a closed loop process. BioDye uses dyes, mordants and auxiliaries that are environmentally safe. Dyestuffs are obtained from sustainable sources such as leaves, fruits, by-products and regnerative stems, and all waste materials are biodegradable. In fact, waste products, including compost and irrigation-quality water, are used to grow dye and medicinal plants and food crops for in-house consumption. Through collaboration with village women's groups, dyeplants are collected and firewood is obtained from renewable plantations and then used in fuel-efficient stoves in the dye house. BioDye also works with local farmers to support the re-introduction of indigo in agriculturally depleted regions, thus contributing to sustainable livelihoods" (n.p. n.d.).
} 
ones.

In New York the following were interviewed: Dr. Mary Davis Dean, School of Graduate Studies, Fashion Institute of Technology (FIT): Sass Brown Acting Associate Dean, School of Art and Design FIT: Pamela Ellsworth, Associate Professor and Chairperson, Global Fashion Management, FIT: Michael Renzulli: Professor of Fashion Design-Apparel, and founding member of IFFTI ${ }^{8}$, FIT: and Timo Rissanen, Assistant Professor of Fashion at Parsons, who is known for his pioneering work in zero-waste fashion. Through examination of their unique approaches, philosophy and strategies regarding sustainability, relevant and classroom tested can be gleaned, and can be used by educators to incorporate into their existing fashion curricula.

\section{PHILOSOPHY}

In regards to their personal philosophies of sustainability the answers were divergent; Rissanen spoke about his initial engagement with sustainability principles:

I was eleven when Chernobyl happened back in Finland and I think that impacted my thinking in many ways because I remember the day at school; we were told at recess to stay inside, but we weren't really told why. Everybody knew that something was wrong and then it was in the news that night. It was said that the radiation levels had skyrocketed that day but nobody knew why, because the Soviet Union hadn't made the news. I think it took them two or three days before they actually admitted that they had a problem; you know it blew up and that whole summer of 1986, I think it happened in April, Spring...it had a huge impact on the country...Finnish people go into the woods; we pick berries, mushrooms and we eat things from the woods as part of the culture, and that year we couldn't do that. And that's where it becomes, you know, the natural world, and the environment stops being an abstract concept; it's very real 
(Rissanen 2015).

Brown felt that it was an individual responsibility:

Each and every one of us is responsible to make significant change and to constantly continue to make a significant change. You know I think that this is one of those opportunities in the history of the world where we get to be change makers and we get to make a significant difference and I think all of us have that responsibility. So whatever that is, whatever capabilities each of us individually have and whatever strengths we have, I think it is our individual responsibility to make that change (Brown 2015).

Davis also uses a deeply personal framework for her philosophy:

I have come to understand the role humans play in sustainability. So that when you talk about sustainable fashion or sustainable food or ...sustainable design, eventually you come back to treating people in a way that is ethical and responsible. So if you want to follow the sustainable fashion chain all the way back to how garments get made; how things get distributed across the world, eventually you come down to looking at one worker, in one place, and in the way that worker is compensated, the working conditions for that person. You're confronted with a moral dilemma about how something that is labeled sustainable or considered to be sustainable relates to one individual (Davis, 2015).

\section{Burke was more pragmatic:}

(Sustainability)... can't be done at the sacrifice of profit. You have to do the best you can from a responsibility point of view and as a by-product you should be sustainable; you shouldn't have to change your habits to be sustainable if you are doing everything correctly and responsibly; you should just be sustainable. It shouldn't be something you have to sell, market, or charge more for (Burke 2015).

And provided an example of a company where: 
They managed to eliminate all of their waste; they looked at all forms of waste. As a by-product they were more sustainable; they were more responsible and they were more profitable. It took an initial investment of time, manpower and money but the by-product was sustainability (Burke 2015).

And closes with: "We have to stop looking at it as a green flag that we wave; it just needs to be the naturally responsible thing to do." (Burke 2015).

Lafrenz felt that sustainability should:

Be embedded throughout all of our (academic) programs and our courses...(and) we have to be as consumers, cognizant of how the Fashion Industry is impacting the environment, people, planet, and profit (Lafrenz 2015).

MacHenry takes the most creative approach in her philosophy:

I am interested in modes of production that are subtle, clever and beautiful, and that contribute to the wellbeing of the environment; and that have humane and ethical practices in terms of (impact on) human beings (MacHenry 2015).

\section{DEFINITION OF SUSTAINABILITY}

As stated earlier, the topic of sustainability is vast and amorphous. With terminology specific to various sectors of the industry: manufacturing, design, business, policy, media and communication, and education. When asked to tackle the difficult task of defining the concept of sustainability, answers range from Lafrenz who feels that sustainability is:

Anything related to creating products without harming people or the environment and creative ways that we can reduce waste...preferably within a closed loop system (Lafrenz, 2015). 
MacHenry felt that it involved:

Creating systems that do not deplete or harm our natural world, and don't exploit human beings. It's also about balancing various needs, since at this point; we can't produce fully sustainability products. Balancing off the pros and cons of sustainability in different areas (MacHenry, 2015).

However Burke categorizes her definition as "slightly different":

I look at sustainability from a corporate social responsibility perspective. If you are doing the best you can ethically and responsibly and keeping in mind all of your waste and profit margins and productivity rates, then as a by-product you should naturally be sustainable, so sustainability should be the result; it doesn't necessarily have to be the goal. I think the goal should be doing business ethically and responsibly" (Burke, 2015).

Brown references the Brundtland Commission in her definition of sustainability:

We don't pollute just through extraction of materials, through process and production, through the end of life, through the throwing away component. So it means not polluting, whether it is planetary wise, or people wise-so you can't be using up people and throwing them away at the end of the process-as well as resources. (The Brundtland Commission) talks about how production mustn't be at the cost of the next generation, so, that's pretty straightforward. As for terms like green or eco, there it really is a matter of opinion...(Brown, 2015).

Rissanen also references Brundtland, but takes a larger view:

I am aware of the different definitions...the Brundtland Commission definition from 1987; it's probably the best known and there's different critiques of that...like there's sustainable development that meets the needs of the present without comprising the needs of the future generation, or something along those lines. But the critique that a number of people have directed towards (Brundtland) which I seem to 
agree with is: it's sustainability in the economic context primarily; in that, it's about development, and when I think about sustainability, it really does include, you know every aspect of humanity. Not just economics, because I think measuring our well-being purely from an economic point of view, actually gives a very skewed view of human life. And so for meand I get that I am an idealist in many ways-but, sustainability for me encompasses all aspects of human culture, including the arts and really creating an environment where of all that can be looked at, all that is kind of amazing about humanity can survive (Rissanen 2015).

The wide variety of interpretations reinforce the ongoing dialectical negotiation that is fundamental to fashion sustainability. And points to larger ontological considerations, and the ongoing need for firmer definition.

\section{INFORMATION SOURCES AND THEORETICAL INSPIRATION}

Regarding their information sources: In the area of sustainability, which is constantly growing and evolving, accessing good data is an imperative for educators. All the educators immediately identify reading as their primary mode of gathering new information. And go on to cite a wide variety of sources when queried about the methods that they used to develop curriculum. Burke describes herself as a "journal junkie" who searches the academic publications for new research. She also follows $\mathrm{BoF}^{9}$ and is on the Board of FTA ${ }^{10}$ the latter of which curates articles and distributes them directly to members on a daily basis (Burke, 2015). MacHenry relies more on information gained from travel and collaboration "with people on projects" and characterizes a lot of her research as "first hand" (MacHenry 2015). Lafrenz mentions conferences, MA graduate student research, and

\footnotetext{
${ }^{9}$ Business of Fashion: "Fashion News, Analysis and Business Intelligence from the leading digital authority on the global fashion industry. https://www.linkedin.com/company/the-business-of-fashion

${ }^{10}$ Fashion Takes Action is Canada's premier non-profit organization that focuses on sustainability in the fashion industry. We work with both industry and the general public, with the goal to shift behaviour toward more positive social and environmental impacts. http://fashiontakesaction.com/about/mission-vision/
} 
like Burke has served on the board of FTA. Brown cites a vast range of information sources:

Eco Salon, Ecouterre, my site on Eco Fashion Talk; Future Fashion which is a German one; Inhabitat to a lesser degree because their focus is much broader...the Ethical Fashion forum and then there are particular undertakings; Coco Eco magazine would be one of them. Above used to be, but they are no longer in that space, so a lot of it happens you know with Facebook pages and individual designers websites. Redress...in Asia has been doing great work too. Individuals, Fashion Revolution of course, and amazing work has been done through that...the UK is so far beyond what we have managed to undertake in the U.S. thus far. So I think that a lot of it comes from almost individuals who have gone at following, so whether that's Carry Summers, or Orsola (Dicastro), or myself, or Lucy Siegle, or Sandy Black, or Kate Fletcher, or Timo Rissanen, or Holly McQuillan for Zero Waste. You know there are all of these players in individual spaces that have a lot to say that... (who) are connectors, actors, bridges between all of these people...We communicate but we also act as a bridge to lots of other people, because we are always sharing each other's content as well. And I think that's so in the digital space whether it's groups Facebook pages, websites, ezines or webzines, etc, really are the best communicators and means of communicating and getting information, for sure...(also) the Sustainable Power Coalition and the Higg Index.

In addition to sources of information, notable theorists mentioned by the educators include: Kate Fletcher, Jean Baudrillard, Naomi Klein, Elizabeth Cline, Lewis Perkins, William McDonough and Michael Braungart, Alan Hunter, Joanne Entwhistle, Marsha Dickson, Connie Ulasewicz, Sandy Black, and Sass Brown. With Lafrenz citing educational theorists: Albert Bandura (Social Learning Theorist) and educational theorist David A. Kolb, and Rissanen is a strong proponent of the work of John Ehrenfeld and in particular his book: Flourishing. 


\section{CURRICULUm MANAGEMENT}

As curriculum space is always at a premium, the introduction of new material must by necessity force the removal of something else. Regarding the addition and removal of course content, Burke said:

I inherited the course from someone else so it's doom, doom, doom, bright story at the end. For the first few weeks you could see the students were feeling a little depressed when they were leaving the classroom. I almost wonder if you need to intermix the negative and the good together, so that we can talk about how 'this is the problem, this is the solution'; this is someone who found a solution. So that they aren't seeing all wrong with a bright spot at the end and they are not connecting the two. l'd like to see it a little more intermixed going forward (Burke 2015).

MacHenry says that she is:

Constantly revising the material that I teach...I'm adding and deleting all the time. I want to keep the material very current and really alive, so I try to always use very current examples where it's applicable and I am constantly researching what is happening and bringing that new research into the classroom, as the field is changing very rapidly because of the scientific and technological advances that are being made and also consumer demand. l'd say the biggest change over the past 20 years is that sustainability was a very fringe area that very few people were interested in when I did my MA in 1998 (at Central St. Martin's, London). I did it around using artisans, craft production and natural dyes and sustainable eco-materials and my advisor said 'this will never catch on, I don't even know why you are bothering.' In that short time there has been a huge change of interest and I think it ties into broader changes in society. People's interests for example, (in) organic foods and natural medicines, (and) in environmentalism. In general there is a much broader knowledge, kids are growing up in a school system with more exposure to ideas about environmentalism, so it's not seen as a fringe thing, it is 
seen as a critical question... we are (also) experiencing the effects of climate change now so people are much more aware (MacHenry, 2015).

And Lafrenz said:

The Introduction to Fashion course I teach is based on introducing students to, and touching upon all of the elements of fashion that the students will be covering in their 4 years. I added one week for sustainability over the past 5 years, so I had to remove some of the less exciting information that the students can access in other ways. They needed to at least understand or be exposed to sustainability of design, environmental concerns, and social responsibility related to the fashion industry. I survey the students during orientation regarding their interests and the number of students interested in sustainability increases every year so the importance of embedding sustainability throughout this course is imperative. Also, sustainability is one of the University's mission (objectives) so we will be including more of these issues throughout our curriculum (Lafrenz 2015).

Rissanen spoke of one hot topic in particular:

Should we ban students from working with fur? And my take on that is that I don't think we should make those decisions on behalf of students. What we do have a responsibility to do, is to provide as balanced and accurate information as possible, so one of the things that we did for a while, because we used to have a relationship with a fur company, who used to sponsor a number of student projects, and then every time we did anything around sustainability, we would get angry emails from people saying: "Yeah, but you do this thing with fur". So one of the things we did for a while, was that students who wanted to work with fur also had to attend an information session with the Humane Society. Which was actually incredibly useful because the Humane Society were great to work with, in that they were respectful of the relationship that we have with the fur company. The fur company was also aware that the human society would come, and so there was this nice dynamic and mutual 
respect and it was interesting, because even the students who chose to continue using fur, they had a different point of view and a different kind of respect for where things come from (Rissanen, 2015).

Integrating new information and removing content that is less relevant is an ongoing aspect of good pedagogical practice. The gradual inclusion of sustainability need not be a radical upheaval; it can be incorporated in a holistic way throughout the curriculum and built upon incrementally.

\section{Business/Creative Binary}

There is an inherent binary inherent in teaching sustainability and this is between creative design considerations, and pragmatic business concerns. When asked how this was addressed in their curriculum, Rissanen said that:

(At Parson's) ...we tend to focus more on the creative content and it's an ongoing conversation because there is a constant criticism that we should teach more of the business side and I do think that we probably could. I think it's important, like you can't teach sustainability without talking business because sustainability is completely intertwined with Economics-and because of that, with business-so I actually talk about business all the time (Rissanen 2015).

Rissanen elaborates on this point:

In order for me to talk about sustainability, not so much to designers but certainly to the people who are running the companies, I need to have some understanding of economics and of business...I think every fashion program around the world has tackled: do we teach them creative design or do we teach them business?... I try not to approach it from a binary but rather present that, in order to design well from a sustainability perspective, you do need to understand the business side of it because it is very easy to design less sustainable product, if you ignore business completely. You do need to have an understanding of the business side, 
and maybe it is a kind of literacy where you are able to work with the people who are more responsible for the business side of things; but being able to work with them in a new way, so that, everybody's objectives are met (Risannen, 2015).

Burke used her fourth year Ryerson Communication students as an example:

Show me the price point, show me why the consumer is going to buy it, what's your offering difference? So for them because they are in fourth year and they are heading out to do this maybe in a few months, I want that realistic business case from them...(students) have all of these creative ideas, but if they can't implement them with the proper business model it's not going to happen...how do you apply it in a way that will actually work? (Burke 2015).

MacHenry has chosen to:

Focus more on the creative and the systems and processes than on business per se, but I do think the business structures are very important because they are the structures that deliver the product to market (MacHenry 2014).

MacHenry does however, discuss the "corporate structure that most fastfashion is delivered to the consumer through" and contrasts that with "fair trade ethical trade and community trade structures" and "social enterprise as an alternate business structure, going across the continuum from more socially aware responsibility and then the more corporate structure" (MacHenry, 2015). Here the importance of a fundamental knowledge of business practices is reinforced. Even design students need to be aware of the consequences of their design decisions. As Burke says: "... How do you apply (ethical business principles) in a way that will work?" (Burke 2015). A fundamental pragmatism is essential either for business or design streams. This is larger than sustainable principles; it's a fundamental of good 
fashion production.

\section{Curriculum Evolution}

When asked to identify some new industry evolutions that had to be incorporated into their curriculum, MacHenry noted that:

In the last 7 years there has been a really big evolution in corporate social responsibility, mostly due to media pressure and the public. That is an area that is changing quickly and it also... is an area that I have to be constantly researching to see what people are doing. It is a very slippery area though because it is very hard for corporations to actually know what is happening in their supply chain, but it is interesting to see what kind of structures they are attempting to put in place to monitor their supply chain. The success of it is not always evident, but it is interesting to see what work is going into trying to develop that. There was recently an international conference with representatives of different garment producing countries to try and come up with a fair living wage standard across all of the garment producing countries. And that is a really interesting concept that l've tried to introduce, it's a really new idea (MacHenry 2015).

Burke identified innovations that were aiding her teaching practice:

As a new teacher, a lot of the programs that I have been working with are already in place, and in many cases I am one of multiple teachers, so thus far there has not been a lot of room for me to make changes to the curriculum. In a difference from my own education, the availability of videos and research on the Internet has brought a lot of depth to each program I teach. I find sharing videos helps to place the lecture content into a more relatable perspective that is often more engaging than the traditional school videos. I follow a lot of the new developments and technologies in relation to sustainability, and while they are not tools that I can use in the classroom, I like to share them with my students to demonstrate that a negative aspect in the industry is really just a problem 
that is waiting to be solved. For example I am sharing an article this week about a new 3D printing fabric pen that will allow you to create a patch for holes in your clothing that matches the colour and feel of your fabric repairing a garment instead of disposing of it. While a lot of this new technology is not in wide use and is too expensive, I think it serves as inspirational for how far they can go with their own ideas. Partnerships, looking at collaborations looking at companies and NGOs and other offerings, some of the apps that are coming out a lot of it comes to communication and l've been trying to find new content, I'm using Youtube videos more which I never used to do. I'm finding so much media and stakeholder information that is out there right now that I find I'm pulling from so many different sources now. Where it used to (just) be from journals and factual documents from companies now there's is so much (Burke, 2015).

\section{Lafrenz felt that:}

(Over the)...last ten years, Rana plaza had a huge impact. The organic food movement has heightened that whole issue of going green, you see more and more in Social Media, and broadcast media, and more companies like H\&M that have their own eco division, all of those things have impacted teaching and we are moving towards that direction, evolving from grassroots movements. The students wanted and asked for: ethics, to fabric choices, to low waste we just keep incorporating more of those ideas into projects. Everything is moving in that direction. Education is a powerful tool to impact the fashion world; (and one) that can take them forward if they are empowered. The Revolution fashion show $^{11}$ showcases innovative design as it relates to sustainability; whether it is: recycle, deconstruct/reconstruct, zero waste, or showcasing creative solutions for sustainability issues. We've had a Diversity Now Conference, which dealt with issues of size, ethnic groups or age. Present sustainability as a big splash, bring in a Kate Fletcher to come in and inspire students to think in ways that they can become more

\footnotetext{
${ }^{11}$ Revolution Fashion Show, an annual exhibition of student fashion design described as: "an ecoconscious \& diversity-oriented fashion show" https://twitter.com/rev2015show
} 
sustainable as an individual, a consumer, or as a career person going into and impacting the industry. Have breakout groups where they can figure out what they can do collectively or as individuals to change industry. Work on ways to engage students because they are our future.... We will never be $100 \%$ sustainable...(however) speakers, projects, and excited faculty and student organizations will bring us closer and closer to being sustainable... that is the goal (Lafrenz, 2015).

Rissanen cites how digital media and:

The internet has transformed the industry completely...and trends are an area where the internet again has just, by having people access everything immediately, changed the pace of information. And so those are the kind of things that we are constantly trying to be on top of in the curriculum and sometimes we succeed; and sometimes we succeed later [laughs] (Rissanen 2015).

Brown talks about: Fashion Positive, a Cradle-to-Cradle certified operation, which is the most comprehensive program in the world:

That guides designers and manufacturers to make products in fundamentally better ways. Their standards of certification ensure that companies achieve the highest criteria in quality fashion and begin to harmonize with existing industry measurements and programs, like the Sustainable Apparel Coalition's Higg Index, Environmental Profit \& Loss and Natural Capital Accounting." Fashion positive also connects creatives, has an innovation fund, and is building a resource library that will "index inventive fabrics, dyes, trims, thread...making it easier for fashion brands and designers to source trusted, certified materials (Brown, 2015) $)^{12}$.

On the importance of design, the experience of an entrepreneurial artisan

\footnotetext{
${ }^{12}$ Using the Cradle to Cradle $\AA$ design framework developed by Michael Braungart and William McDonough and the requirements of the Institute's Cradle to Cradle Certified ${ }^{\text {TM }}$ Product Program, Fashion Positive brands and supply chain partners can develop truly innovative products and materials to transform the fashion industry and the world. http://www.fashionpositive.org/news/2014/11/13/g-star-bionic-yarn-loomstate-saitex-stella-mccartneyand-others-join-fashion-positive-to-revolutionize-the-fashion-industry
} 
like Rachel MacHenry can offer valuable insight. The scope of creative exploration allowed for in her experiential, tactile approach, allows for a holistic design process, but one that will generate product that is beautiful without having harmful environmental impacts. Of this, MacHenry says:

I think that this such an essential component, not just for fashion designers but for anyone going through creative education at this point and I really hope to see much more of this kind of thinking breaking out of being sustainability design and really just being the way we think and make everything, because I don't think we can afford to fool around. And young people feel that way too and they want the tools to move ahead (MacHenry 2015).

Avoiding the reductive, stultifying design influencers that dictate that sustainable design need be utilitarian or valuable only because it has been produced sustainably. MacHenry has created the Botanica Tinctura line of zero-impact trims and accessories. This endeavor clearly demonstrates that sustainable product can also be attractive, unique, and market ready. Rissanen speaks to the consideration of materials in the design stage, and:

How design can facilitate different strategies for end of life (of the garment). So for example, if you design the polyester garment, if everything from the thread, the zips, every trims is also polyester, you can, you know potentially recycle that garment without having to rip anything out of it. There's no component that can't be recycled" and "you know a landfill overflowing with organic cotton is still an overflowing landfill (Rissannen, 2015).

Rissanen also proposes a new look at traditional practices, and references the research work of Alexandra Palmer of the Royal Ontario Museum (Palmer 2001):

...The idea of quality and timelessness and heritage, and I don't mean it in sort of backward looking; I am very much a futurist in the way that I am always looking forward...But by heritage I mean making sure that all of 
the things that we do well, we continued to do...Bespoke tailoring (for example), because I don't think of it as an arcane craft; I actually think it could have a vibrant future...Even haute couture, I mean there's the excessive part of haute couture that, we can put it in the category of art, and excuse it that way. but there is also a whole side of haute couture that most people don't even know about .You know the Canadian Dior customers who would send their garments back to Dior in Paris to have them repaired or remodeled. I think there is potentially in both bespoke tailoring and haute couture practices that can be adopted at any level of the market like remodelling, repairing and so forth. Those are the positive aspects of the luxury market that I think that can counter the deappreciation of craft... (Rissanen 2015).

Brown also discussed artisanship, and related it to the pressures of modern business production. Saying that it has:

...Always been one of my great loves, and I think it's one of the great tragedies of our world that so many artisanal techniques are being lost and relegated to history books instead of retained and honoured, and so that is my current quest: I'm hoping to communicate some of those incredible techniques (and thereby) bridging the gap between some of the designers and artisans to help sustain communities that are sustaining those traditions and techniques. And I really think it's the future of the industry. (Countering) the history of luxury (brands) that sold their souls when they all went public, and had to start answering to quarterly reports and continuously growing (their) business. I mean being a global brand that continuously grows is not a sustainable model; there is a finite planet and a finite number of consumers out there. So I think that reigning luxury industry back to its real roots of artisanship, but broadening that to not just the artisanship produced in Florence and Paris, but also incorporate global artisans and their traditions and their heritage and skill set. I think if we are to salvage the luxury industry (artisanship) is the future... (Brown 2015).

All of these ideas could be worked into existing curriculum, matching 
content to epistemological streams.

\section{INTEgRating Ethical Content}

When asked about how issues around ethics and social responsibility are addressed in their respective curricula, Lafrenz provided some effective examples as to how sustainability can be embedded into curriculum that have come about as a result of a recent program review of the entire Ryerson undergraduate fashion curriculum:

These are big issues we need to cover, and this is how we are going to address them: we are taking the existing curriculum out of the discussion and starting from the outcomes and working through what has to happen in foundation, then second and third year and finally capstone... how are we going to incorporate key concepts and into which course. Ethics could go through all the courses, but others don't translate into every class. History subjects can look at how recycling and re-using were a cultural phenomena in the past, for instance my mother re-used and recycled everything. I don't think we are doing enough, it's better if we can engage students even earlier, like FTA going into the high schools and grade schools, and teaching children about being sustainable future consumers who can bring those messages back home and then when they come to us, hopefully we are already doing it (Lafrenz 2015).

Burke's answer was that:

Within my Seneca first year class we talk a lot about...how companies have established codes of conduct and whether they stick to them and how are they arranged, and who is responsible for bringing them about. This morning we discussed the news about Bangladesh ${ }^{13}$ and the fact that even though all of these codes of conduct are being talked about and (are) being brought in, we see a government facility have the same issue only two years later (after Rana Plaza). With my 4th year Ryerson

${ }_{13}$ Cement Factory collapse: On March 12, 2015, five people were killed and another about 100 feared trapped after a cement factory collapsed in Bangladesh http://www.cbc.ca/news/world/bangladesh-cement-factorycollapse-traps-about-100-workers-1.2991633 
students we start talking about ethical choices and reasons and we relate it back to the business model because they are entering a field where they are going to be the business practitioners. In a first year subject it's about the idea or concept, with 4th years it's about practical and practice and putting it into place. Yes I want to do all of these (creative) things but where is the profit, where do we start? The way I present ethics to them usually is 'make your wish list of ideas and figure out what you can do at your level', and then stand behind that. So nobody is saying that every company has to be perfect, but say: 'this what we can do, this where we are at, this is the best we can do and we are looking to do better moving forward and just be transparent and honest about that' (Burke 2015).

And MacHenry said that:

We look at labour conditions in the fast fashion industry, and how Codes of Conduct have been developed in response to consumer demand and media coverage. We also look at Fair Trade (e.g. FairWear), Community Trade, Social Enterprise and Social Responsibility (in both corporate and smaller brands) (MacHenry 2015).

Ethics is one of the most pressing issues in sustainable fashion and can be introduced to both design and business streams. As such, the philosophy could be incorporated into shared course material and then practical exploration and application can be conducted in discipline-specific curriculum.

\section{Challenges}

There are always challenges when delivering information to students, and sustainability content is no different. Regarding this, Burke feels that:

In many cases because we are looking solely at sustainability it can be a very negative feeling class if you are not careful I can feel like the doom and gloom queen sometimes (Burke, 2015).

And elaborates further upon: 
The 'doom factor'...there are so many horrible things that have happened in the age of sustainability... as much as we have all of this awareness and all of these watchdogs now, there is still so much damage happening and...many of the companies that (the students) love are still doing it (Burke, 2015).

MacHenry highlights:

Overload, it's a huge field and I think in one's enthusiasm (for the subject) it is easy to give them too much...l am always trying to pack in too much and I know that people can't take it all in. so trying to provide the information in a really useful way and enough and not too much....with opportunity for people who are interested to go on. I think that's a big challenge in this area as it is vast and connects in to so many other areas (MacHenry, 2015).

Lafrenz noted technology and: "an obstacle to our students, and on the design side it is not having access to organic fabrics" (Lafrenz, 2015). Rissanen feels that:

Sometimes the response is cynicism and...I can get cynical as well, but the thing with cynicism is it kills possibility very quickly. And I do think that, it's funny because I thought this before I read the book (Flourishing by John Ehrenfeld), Ehrenfeld says something about possibility, he says something like how the word possibility is one of the most potent words in our language; because it does leave the door open for so much potential and without necessarily any constraints of the past put on it. ...Sometimes I just have to sort of listen to-like when I am faced with cynicism-is try and hear what is underneath the cynicism and acknowledge...whatever is there for the student and then have a conversation with them too. Hopefully that leads to them to see things in a new way. Sometimes-actually most of the time-l do succeed. Sometimes I don't...(Rissanen, 2015).

Brown says one of her biggest challenges is: 


\begin{abstract}
Always preaching to the converted... within eco fashion we are always preaching to the converted: the people that find the website, who are subscribed to the newsletter, the people that come to the talks or the workshops, and that buy the books. The same people who are already interested, and I want to further that agenda, getting that information out to people who aren't necessarily interested, or who are affected, but think that they aren't. So it's really getting the information to a much broader and greater audience and helping them understand why this is important...(Brown, 2015).
\end{abstract}

This idea of communicating only to other sustainability minded practitioners is particularly relevant in an academic setting, where colleagues may not have a sustainability background. The dialogue needs to expand to include everyone. Knowledge is what changes opinions and can help further sustainability agendas.

Although the answers provided by the educators were directed by the specificity of the questions (which were all designed to fall within larger thematic categories) (Appendix 5: Interview Questions). They also allowed for individualized interpretations that reflected the diverse experience and philosophies of the practitioners. The transcript analysis was not entered into with pre-determined outcomes, or an existing theory that needed be proven or disproved. Instead, I drew on the understanding of this group of stakeholders, letting the interviewees speak and guide me to better understand their experiences and challenges. Insights emerged from these interviews and larger connections were made during the coding of the interview transcripts. Key patterns in answers became apparent, as well as convergences and divergences in philosophy and experience, and from this, strategies were formulated that were incorporated into the final recommendations

Taken as a whole, the combined wisdom and experience of these educators offers invaluable theoretical and practical resources for teaching 
fashion sustainability. All felt strongly that rather than treating sustainability as a topic for a conference, panel or stand-alone subject, it should be one of the fundamental principles guiding pedagogy in all fashion curriculum, whether it be design-based material explorations, or theoretical fashion business subject matter. A lot of their ideas are innovative, but there is a grounding in common sense that underpins their unique approaches across the board. Unfortunately there is not a corresponding manifestation of common practice in the majority of fashion education or integration of this content in a holistic way in fashion curriculum (Armstrong. \& LeHew, 2014: 78). Formalized integration of these ideas that are being practiced; into both course and program outcomes is a first step towards a truly sustainable fashion curriculum.

\section{ACADEMIC LANDSCAPE: FASHION SUSTAINABILITY}

In spite of the wide variety and creativity of the content being offered by the educators interviewed, in reality, there is a general lack of sustainability content in existing standard fashion curriculum. At this point, the creation and implementation of sustainability pedagogy is marginalized. Armstrong, and LeHew in "Barriers and Mechanisms for the Integration of Sustainability in Textile and Apparel Education: Stories from the Front Line" conducted a survey of sustainability educators where they discovered that: "There is increasing pressure in higher education to integrate sustainability holistically in the curriculum, though confusion abounds as to how to go about it" (Armstrong \& LeHew 2014: 60). They state that educators must help students to:

...Navigate attributes of the discipline seemingly antithetical to sustainability, such as unlimited growth, profit, and scale perpetuated by unbridled consumerism. Unfortunately, language associated with these attributes is inherent in the curricula and impossible to avoid, making the integration of sustainability very challenging (Bowers 2001) (Armstrong \& LeHew 2014: 60-61). 
Another issue is the wide variety of teachables that a fashion education can comprise. The specializations necessary for teaching sector-relevant content require fundamentally different course materials as it is: "Segmented by specializations like design, marketing, merchandising, textile science, and production" (Armstrong \& LeHew 2014: 61). In his chapter "Design as Pedagogy" from The Nature of Design: Ecology, Culture, and Human Intention, David Orr talks about the academic silos that are a feature of the institutional educational landscape, saying that there are currently "armies of specialists" who are "studying bits and pieces of the whole as if these were separable", and further relates this to the greater community of the ecosphere (Orr 2002: 29). It can also relate to fashion education, as the broad coverage our teachables must encompass is encyclopedic and not realistically applicable within a single subject. Brown addressed this universal need for sustainable design considerations in her interview:

That it will become much more integrated into everything, because it's not a matter of if you have an interest in it, let's specialize in it and not if you don't. I think sustainability should be incorporated into everything at this stage. It is relevant whether it's art and design, fashion clothing or accessories, or whether it's business, or sourcing or any type of product development, I think it's absolutely integral. You know we are talking about a planet with finite resources; some of which are due to run out. And whether that's oil or extraction for material production or, whether that is water use for growing fibres and what the ethics are of growing fibres over feeding people etc. etc. You know I think that sustainability has to be incorporated into every project, into every discussion, into every field (Brown 2015).

To further complicate this I would add the layered specificity within fashion design itself: clothing, bags, shoes, jewelry, and all of their attendant packaging and promotional materials have different production flows and supply chains. Solutions are different for different parts of the design and 
business of fashion, even for different market categories of the same product.

Curriculum for the fashion business students is equally fraught with complexities as: "...Their central impediment being the conflict between sustainability and an emphasis on profit maximization" (Armstrong \& LeHew 2014: 62). The focus now shifts as to how can we as educators assume greater responsibility for what is being taught within our programs and institutions. And regarding the receptivity of the population to these ideas of sustainability, Landgren and Pasricha identify that Millennials have been indoctrinated into the concepts of sustainability through their cultural milieu. They maintain that for the Millennial, sustainability is about being community oriented, supporting socially conscious and small local businesses and being aware of the social responsibility track record of companies they buy from: "Today's students and future professionals have the power to change social, cultural, environmental, economic and political practices worldwide (Landgren \& Pasricha 2013: 120). They also feel that this generation is poised to act as agents of change, and that the industry is ready for change along with them, citing sustainability as a strategic initiative in $44 \%$ of retail companies surveyed, and survey of industry practices categorized as 'anti-ecology' (2013: 119). So how do we engage these students?

The scope of the information that needs to be covered is problematic because it creates information overload and forces students to tackle content that may not be relevant to their discipline; of course, the deeper the experience of this information, the better. But realistically, in an already overloaded curriculum, the addition of content that may not be relevant to a graduate's required skill set and to the program outcomes is not ideal, and not an example of effective pedagogy.

At the moment when sustainability is offered, it is as a stand-alone 
subject, or presented within a conference setting (Armstrong \& LeHew 2014). If we are to effect real change we need to embed this philosophy and examples of practice into core curriculum. If students graduate with a strong framework of solutions they will be able to effect changes great and small as they progress forward in their careers.

Once the value of change is recognized in the fashion school framework, then how do we as educators undertake to effect this change? Fashion pedagogy as it relates to sustainability has evolved from just a consideration of eco-friendly concerns to a larger scope that encompasses ethical labour practices and the larger comprehensive network of concept through to consumer processes:

...The consumer economy in which it operates, are human constructs founded on the belief that unlimited growth is possible and they are utterly dependent on degrading finite material resources and ecosystems to produce saleable goods to fuel that growth" (Grose et al 2012: 135).

However, this evolution has not been reflected in the fashion industry at this time.

\section{THE DOOM FACTORY}

Edmund O'Sullivan said at the World Congress for Education and Communication on Environment and Development: "As educators, despair is not our business" (O'Sullivan 1992 quoted in Kool \& Kelsey 2005: 2). This may be true, but there is also a fatigue associated with the term sustainability, and there is an inherent "doom factor" that comes with any discussion about environmental and ethical concerns (Burke 2015; Kevorkian 2004; Kool \& Kelsey 2005; Leddy 2015; MacHenry 2015; Ochoa-Ochoa et al 2015; Orr 2002, 2004; Rissanen 2015). The individualizing of responsibility only exacerbates this, instead of introducing "collective, corporate or political" approaches (Kool \& Kelsey 2005: 2). This does not negate the gravity of the problems associated with this umbrella 
term. As unpleasant as it may be to some, the discussion must be continued and I would argue that resistance to sustainability principles may stem in part from a sense of futility that people face when confronted with the scale of issue.

In "Dealing with Despair: The Psychological Implications of Environmental Issues." Kool and Kelsy speak of the three "P"'s of Seligman's theory of Learned Helplessness: "Personal", they may have internalized the problem; "Pervasive"- problem affects all aspects of life and "Permanent"- the problem is seen as "unchangeable" (Kool \& Kelsey 2005: 2). This personalizing process is not helped by institutional indifference to integrating core sustainability principles into pedagogical directives (see Appendix 4: Campus Greening Versus Curriculum Integration), both for student and educator alike.

In "Distanciation: a key challenge for 21st Century Conservation" Ochoa-Ochoa et al describe the process wherein an environmental crisis when represented by media saturation causes "despair and denial" and thereby limits an individual's participation in "societal-level conservation interventions" and decrease the "effectiveness of conservation actions" (Ochoa-Ochoa, Nogué, Devillamagallón, Ladle, 2015: 207). They call this phenomena "Distanciation", and say that countering the phenomenon of:

....Distanciation requires societies to realize that even though humans have a negative effect on ecosystems, they also have the skills to successfully conserve and manage nature. Conservation success stories (and there are many) demonstrate that to a large extent; we can choose the survivor (Ochoa-Ochoa et al 2015: 210)

Webb says in: "Engineering Hope" that to: "Plant a single tree is a positive step that results in a forest that is one tree larger than it would be had we not acted." And expands on this: "To help a single student become fascinated with aspects of nature is to add one to those who do care in 
some small way about the biosphere's future" (Webb 2005: 277). And feels that:

...We need sometimes to knowingly manufacture new outlooks that help us act positively. After all, nearly all beliefs about our place in the world contain elements of self-delusion. Despair and cynicism are not friends of nature. They prevent us from succeeding at what many of us have always wanted from the start: to make a difference. We need to move beyond mourning, create a renewed hope, and share it among ourselves (Webb 2005: 277)

And to continue to do this: "Even if we are skeptical about the capacity for public opinion and international relations to effect change at local levels" (Webb 2005: 277).

\section{CHAPTER 3: ANALYSIS AND SYNTHESIS}

...After all of the costs of fast knowledge are subtracted, the net gains in many fields have been considerably less than we have been led to believe...we need no more fast knowledge cut off from its ecological and social context (Orr 2002: 40).

\section{Structural Change V. Curriculum Evolution}

However worthy the motivation for an evolution in curricular delivery, program-wide fashion sustainability does not require a new classroom model for introduction and implementation at this time. The reforms needed to influence industry can be implemented within existing curricular structures. We are already aggressively teaching our students how to destroy the planet through unsustainable production and distribution of fashion product; we can change the message to include healthy manufacturing and delivery models. One obstacle for change is that the argument for curricular evolution can be conflated with the debate around delivery models. The sample population of educators surveyed by Armstrong and LeHew bring in this other variable into the discourse 
(Armstrong \& LeHew 2014: 64). Experiential, and transformative practices are mentioned several times by their interviewees. However, given the obstacles against incorporating sustainability already in evidence (Armstrong \& LeHew 2014), bundling the process to include comprehensive institutional change is counter-productive.

Certainly, the evolution of classroom educational models is an admirable goal, and an important for social justice and equality in the classroom (Freire 1970, 1990; Hooks 2014, 2002), however the two points are divergent and the insistence that one must come with the other is an impediment to implementation of pedagogical reform as it relates to fashion curriculum today.

\section{Chapter 4: The New Program: Fashion/ Sustainability BA}

Originating with Descartes and Galileo, the foundations of the modern worldview were flawed from the beginning. In time, those seemingly small and trivial errors of perception, logic and heart cascaded into a rising tide of cultural incoherence, barbarism, and ecological degradation...this tide will continue to rise until it has finally drowned every decent possibility that might have been unless we choose a more discerning course The Nature of Design: Ecology, Culture, and Human Intention (David Orr 2002: 20).

\section{New Paradigms in Fashion Sustainability Pedagogy}

We are currently reflecting the desires and direction of industry, but not all of them and not where they are relevant to sustainability. Granted, the ontological ambiguity of fashion sustainability is at first confusing and difficult to grasp. Seeing as it: “...Encompasses a labyrinth of stakeholders, from plants and animals to farmers and production workers to product developers and retailers to primary and secondary consumers, all with diverse global and regional characteristics" (Armstrong \& LeHew 2014: $60)$. But once it has been studied for a while-both the dichotomy of content 
and diversity of approaches required to deliver it, sustainable principles can actually lend themselves very well to the teaching of fashion.

As fashion is itself an agglomerate of fundamentally polarized disciplines, encompassing both extreme creativity and the most conservative pragmatism through a fashion product's journey: from conceptualization and manufacture, on to exhibition on the runway and worldwide dissemination though social media and retail portals; virtual and brick and mortar; through to the ignominy of the final retail markdown and eventual deposit in a landfill. Analysis of a product can also be a lens through which a multitude of contemporary and historical information can be discerned: social mores, economic initiatives, even the rise and fall of civilizations can be read through the possessions of a population. With growing public awareness and demand for corporate responsibility (Dickson \& Chang 2015; Gam 2011; Dickson, Eckman \& Loker 2009; Dickson \& Eckman 2006; Dickson 2001, 1999) the graduate with a firm knowledge of sustainable principles and what their true implications are, is actually a more attractive hire than one who has no real-world grounding in their knowledge and practice.

\section{VISION fOR AN IDEAL FASHION PROGRAM}

In light of this: "It is important to consider the practicality of developing programs of study which can actually prepare graduates with the necessary knowledge and values..." to successfully manage sustainable criteria within their work. Graduates who will carry with them: " ...A capacity for critical thinking and the motivation to deal with the multitude of diverse problems associated with non-sustainable states" (Sibbel 2009: 75). In light of this, when asked to consider what a perfect undergraduate fashion program might look like, and how would sustainability be incorporated into it, Burke suggested:

More industry involvement and assessing student waste and make better 
use of that waste, properly reincorporate and recycle it. A cradle to cradle model can be applied where we evaluate student wastage of fabric and materials and where we have more industry input and involvement, like if you look at textile connect and the schools in South Carolina where the schools are actually holding classes in factories, where the students learn their production and manufacturing and some of their sewing classes in an apparel factory (Burke 2015).

\section{Machenry said:}

Wow, that would be fun to design. Gitte (Hansen, Chair of the School of Fashion at Seneca College) told me (that) when she was an undergrad in Copenhagen, they spent the first week out in the land gathering their own natural dyestuffs and cooking them up in pots ...I like that (laughs). I think experiential learning is really key for creative people, and I feel strongly that we shouldn't dismiss the way we learn and process things and the things we make. And I don't think the academic model of education does the same things as the experiential and creative model. I think (students) can learn from each other and share elements. I feel that for people working in creative areas, they have to learn how to research in a way that works for their brains and their skill sets. Research is very important, but when I talk about research I don't mean purely academic research: I mean materials research, and visual research. I mean it could be poetic research, it could be looking at other artists and writers and filmmakers perhaps. I think it's enriching your process in a whole variety of ways. So I think that is really important, especially at the beginning levels to open those things up for people; but I also feel that there has to be a rigor to the ideas. I think it's important for people to learn how to refine their ideas into as clear and expressive and explainable and defendable as possible. So I guess (when) thinking about sustainability in fashion, l'd like to open up a whole area of sustainability materials and processes to students in a really hands-on way, like the idea of being out on the land and collecting your own plants or growing your own dye garden, or going somewhere and seeing how flax is processed, (to see) that people actually do it. Carrying that through into sampling and 
materials research, and then backing that up with a good understanding that's technological and scientific (MacHenry 2015).

And Lafrenz felt that:

We wouldn't have a sustainability class at all; it would be embedded all through the program. I wouldn't have a lecture on sustainability; it would flow through the class. Early on we would talk about social responsibility and later on the design process, and then organic fabrics, and here is a marker: how would you (use it to) save on waste. That would just be part of what you would talk about, for example they would do a marker for all of their designs so when they are purchasing the fabrics, they are purchasing for the least amount of waste, and then having a way to deal with that little bit of waste whether it's to get a fiberator to make it into fluff. Using the body scanner and showing ways you can customize. Sustainability would just flow through all of the courses, I don't know if I would even have to identify it... when you take all of this research and everyone else who is doing similar work can be amalgamated, (then) there wouldn't need to be textile class, organic v non-organic, (or) natural dye versus industrial. Talking to a greater extent-and providing a way for students to experiment with-things marked for producing less waste. (At the present time) we don't talk about greenwashing, or more industry comparisons of corporate responsibility. If you leave the (Ryerson) school of fashion and you never work in the industry, you will still be a better consumer and know quality and what things are harmful, (you) will be better at making choices. And that will be shared with your children (Lafrenz 2015).

All of these ideas could be implemented immediately and don't require massive institutional upheaval. It is more of a conceptual shift than anything else.

\section{Sector and Discipline Based Solutions}

The one sure way to ensure adoption and retention of sustainability and ethical principles into the working process for our graduates is by focusing 
on sector-based curriculum that is integrated into the core foundations of fashion design and business programs. The current model of the satellite course that is an overview of everything and realistically, can only be taught by a sustainability subject expert is inadequate. There is nothing wrong with it per se; unfortunately it is limited by who is able to teach it, and how much can be taught in a single subject. Incorporating sustainability content specific to the sector studied, content that can be delivered by the subject area experts and does not require extensive retraining and curricular restructuring, is easier to implement. And arguably reflects a better pedagogical model. Business students can be taught supply chain and ethical production content and designers explore zero waste, and sustainable materials in their work (Burke 2014, Lafrenz 2014); Providing students a tool kit or knowledge bank that can be drawn upon when design or business decisions are being made. Possible material for study and inclusion into the proposed curriculum can come from the following disciplinary areas: Fashion Sustainability; Sustainable Design; Fashion and Science, Fashion and CSR; Fashion and the Law; and Transnational Fashion Education.

\section{FASHION SUSTAINABILITY}

Clothing has been de-valued by technology of capitalism. What was once so valuable that it was left to others in their wills and was a significant portion of income expenditure is now expendable (Lemire 2012; Palmer \& Clark 2005). In fact textile production was once the most important industry in the ancient world, surpassing even food production (Barber 1995, 2000). How do we now change our ways of production and consumption to reimbue value to clothing? Change something that is so fundamentally a part of our human condition and experience, and has now become so cheapened? Focus could be re-shifted to the recycling, re-use, re-adoption processes. Not just devising ever more technologically advanced processes for pumping out endless product to fill up landfills. Or go even 
further to envision an entirely harm free system, ask the question: "What would it mean to be 100 percent good?" (McDonough \& Braungart 2010: $67)$.

\section{Sustainable Garment Design}

Currently: "...The entire fashion industry-jobs available to designers, the way collections are built, store layouts, the criteria for (industry) awards and, not least, undergraduate fashion education-is organised to support and reward the narrow role of fashion designer as a stylist" (Grose 2013: 134). The designer-as-stylist is a reductive framework for creative analysis: "...The role of design being perceived as simply shaping commercial goods for sale, with the designer focused on the product, its materiality relevant to function, feel and style and its prominent positioning in the marketplace" (Grose 2013: 134). The true role of a designer is much larger than this and students need to be taught this from the beginning. The potential role of "designer as communicator-educator" (Fletcher, Grose \& Hawken 2012: 157) has yet to be embraced and communicated to the fashion student. Introducing low to zero-waste projects, and adding ethical sourcing research criteria to proposed materials used would be beneficial.

\section{FASHION AND SCIENCE}

These ideas are based on a California College of Art (CCA) initiative to "..Implement scientific instruction into the studio curricula" (Grose 2013: 141). Students explore examples of how raw materials like cotton, flax and wool are made into fabric, and also the industrial fabrication of synthetic fibres as well. This subject helps fashion students:

...Develop a comfort in working alongside scientists as peers and felt bolstered in delivering quantitative research with scientific rigour; and they experienced how their own skills complement the methods of science-linking data to wearer behaviours and giving visual form to desirable new ways of living within nature's limits (Grose 2013: 141). 
Allying fashion students with science students to create new knowledge informed by research from both sectors.

\section{FASHION AND CSR}

Fashion business curriculum currently employs case study analysis. Adding Corporate Social Responsibility (CSR) to the criteria for analysis is relatively simple and results in a more in-depth engagement with the material. In their paper: "Culture Doesn't Matter? The Impact of Apparel Companies' Corporate Social Responsibility Practices on Brand Equity" Woo and Jin analyze the corporate Social Responsibility (CSR) impact of various brands (Woo; Jin 2015). This is a logical area of exploration for fashion business students. It can incorporate explorations in "stakeholder theory" defined by De Brito et al in "Towards a Sustainable Fashion Retail Supply Chain in Europe: Organisation and performance" as when: "firms are to serve the needs of all those being affected or affecting the firm (their stakeholders), and not only maximize profit (for the shareholders) (De Brito et al 2008: 5). Using CSR as a lens, in-depth operational analyses can be conducted providing core business practices literacy in addition to sustainability-specific knowledge.

\section{Fashion and the Law}

One of the biggest obstacles to industrial change is that consumers do not want to know about these "inconvenient truths": we seem to be happier in myopic ignorance patronizing fast fashion retail outlets and using clothing shopping as a social pursuit. However as has been shown in the past, once the truth of a situation becomes clear, public will can be transmuted into public conscience and change will come. This happened during the early twentieth century when a horrific fire at the Triangle Shirtwaist Company claimed the lives of 141 garment workers most of whom were young immigrant women. With the only unlocked exit blocked by flames, the workers died either through being burnt alive; getting pushed out of 
ninth storey windows by those still inside the burning factory floor or by falling down an elevator shaft trying to escape the flames (Pence et al 2003).

McEvoy states in his article "The Triangle Shirtwaist Factory Fire of 1911: Social Change, Industrial Accidents, and the Evolution of Common Sense Causality" that: "The fire symbolized the helplessness of industrial workers in the face of dangers over which they had little control and to which the law had hitherto, for the most part, simply abandoned them" $(1995,622)$. When the details of this horror became a part of the pubic conscience massive labour reform swept through New York state legislature, and went on to have much larger repercussions:

By focusing on and making tangible causal theories that had been in circulation for some time but never embodied successfully in the law, the Triangle fire destroyed longstanding ideological barriers to factory legislation. It thus played a significant role in laying the epistemological foundation of the modern regulatory state $(1995,621)$.

Public reaction to the fire also galvanized the growing societal dissatisfaction with intolerable working conditions, and catalyzed widespread unionization within the garment industry and many others.

Just over the centenary of the Triangle Shirtwaist fire, we are confronted with another horrific garment factory disaster that was nearly tenfold in its destructive capacity. The Rana Plaza factory collapse on April 24, 2013 claimed the lives of over 1,100 Bangladeshis, and once again the majority of them were young women. This has raised public awareness and has helped educate everyone about the vital importance of ethical production not just locally, but globally (Yardley, 2013; Burke, 2013). However, I would argue that the geographical distance and the PR machinations of the companies implicated in the disaster have diminished the reaction. The Triangle fire was blocks from Union Square and no 
contemporaneous New Yorker could have remained ignorant of the appalling facts for long. However Rana Plaza is half a planet away, and the news agencies never dwell on any story too long, as such it has slipped quickly off the collective radar of the media. A self-imposed fund set up by the retailers to great fanfare after the disaster has so far proven unsuccessful. The Business of Fashion reported in the article Unfilled Rana Plaza Fund exposes fashion's lack of accountability that: "The Rana Plaza Arrangement estimated that the fund would need to collect $\$ 40$ million to cover the expected claims. As of 4 August 2014, the current total is just under $\$ 17.9$ million; the fund is not yet half-full" (2014). The article also speaks to comparable levels of disregard for the safety of Bangladeshi workers to the ones that were shown for the Triangle victims a hundred years previously:

The day before Rana Plaza collapsed, inspectors found cracks in the building and raised the alarm. Did these warnings reach Benetton and Primark? They certainly reached the banks operating in the Rana Plaza building, which evacuated all of their workers. The garment factories, by contrast, forced employees to return to work, their managers threatening to withhold a month's pay from those who didn't (n.p. n.d. 2014).

The outrage for the young Bangladeshis who lost their lives has not been as vocal and has not galvanized the significant positive change of the Triangle fire, and so the victims of Rana Plaza still wait for justice. The "modern regulatory state" that protects North American garment workers has not extended to our offshore partners along with the capital and production that has.

David Orr says that this kind of thinking results in power concentrated in "too few hands" and causes the structuring of an economy that then promotes: "human incompetence" and "destroys the ties that bind people together in community" (2002: 12). Regarding the checks and balances (or lack thereof) on unrestrained "predatory" capitalism that current fashion 
production modes operate within: there are none on a global level, and little operating on a national level, therefore "economic competitiveness" justifies destructive decisions made with no accountability (92). This is a fairly accurate summary of the corporate ethos of the fashion industry that uses non-Western peoples as sweat shop labour, and drives down pricing even as it demands faster production, creating a "perfect storm" labour condition, where people end up dying for cheap clothing.

\section{Transnational Fashion Education}

The flow of garments can not only be used as a tool for tracing the negative impacts transnational fashion production can have, but also where potential solutions can be found, since: "Paradoxically...societies with much less scientific information than we have often make better environmental choices" (Orr 2002: 24). We can shift the view of the third world as a site for gouging the cheapest price in material and manufacture and recognize the huge intellectual and creative potential offered by nonwestern peoples (Freire 1970). Non-Western societies can become a source of innovation and inspiration. For example Rabindranath Tagore's dialogic theories of learning and holism in pedagogical delivery structures, as well as progressive philosophies like Gandhi's homespun Khadi initiative, and ancient zero-harm dyeing arts that are being revived and updated for modern production (MacHenry 2015; Gandhi 1929; Tagore 1917). Thereby identifying non-Western cultures as a source of innovation and not a site of cheap production and lax labour laws. This is transformative for both parties: the countries of production who are feeling the negative effects first hand, and for the countries that are originating the design processes that are causing these negative effects.

The many examples of sustainable and ethical practices, as well as the culture of dialogic communication found in South Asia, can be used as examples for practical solutions. This holistic pedagogical wisdom can 
provide a new philosophical framework with which to re-think and reposition ourselves as we consider the integration of issues of sustainability and ethics into existing design pedagogy.

Transnational education can be used to subvert the economic imperialism that creates a one-way channel where intellectual property is generated in First World Countries and the Third World is used in an unregulated manner for labour. And create a bi-directional information transfer where both parties benefit, reversing the intellectual flow and sees instead the potentiality of solution-bearing fashion innovation that is being developed through NGO and entrepreneurial efforts (MacHenry 2015; Teklu 2015). These courses would naturally lend a field component to them, where travel/ study experiential learning can augment in-class content:

One of the Fashion Design ENGAGE initiatives partners with Bridging Cultures Trough Design outside expert Mimi Robinson, who takes students to Guatemala to work with indigenous communities to help support micro-enterprise opportunities. Here comprehension is facilitated through practical, experiential and reflective means. For students learn firsthand the capabilities of artisan groups and how to negotiate the opportunities and barriers to local and regional markets. But, perhaps more importantly, when working alongside and being taught by indigenous women how to weave on a back strap loom, students literally 'feel' the speed and rhythm of the 'technology', its scale and portability; they become intimately familiar with the materials and symbolism woven into the textiles and even the width of the fabric-all of which have coevolved in relationship to place and culture. It is through this first-hand experience that students more easily grasp issues of speed, scale globalisation and anonymity in the current fashion system (Grose 2013: 142).

As the fashion industry is a major global polluter, and unethical production has proven disastrous for non-Western countries at the sites where 
garments are produced, these social entrepreneurial efforts are both necessary and valuable examples for study.

As Freire says: "For the oppressors 'human beings' refers only to themselves; other people are 'things'” (Freire 1970: 57-58) and that:

The oppressor consciousness tends to transform everything surrounding it into an object of its domination. The earth, property, production, the creations of people, people themselves, time-everything is reduced to the status of objects at its disposal. (Freire 1970: 58).

Contacting and interacting with other cultures can humanize and provide a more accurate understanding of what the consequences of fashion production can be. Effectively countering the out of sight, out of mind mentality necessary for unethical transnational fashion production to flourish.

Accurate assessment and knowledge of what the true situation is "on the ground" in a country can aid the ongoing debate as to whether transnational industry functions as a force for bettering a poor country (Krugman 1991, in Collins 2009: 187), or this is just a oversimplification of an exploitive structure (Collins 2009; Sen 2002). The complexity of the question requires a deeper investigation than can be undertaken in a stand-alone survey class.

Educators and administrators need to explore the possibilities offered by transnational academic programming, whether they be project, program or institutionally based. With a potential goal of the creation of academic programming that is transcontinental, transcultural and provides multiple opportunities for knowledge creation, skill building and accreditation. Thereby creating a new pedagogical system that recognizes the huge intellectual and creative potential offered by non-western peoples. As educators, the more frequently we return attention to the destructive power we are supporting through unsustainable production, the harder it will be 
for people to maintain these practices, both within the academy and industry at large. We must recognize both our accountability and our agency as catalysts for change, and through this recognition bring a global awareness to all aspects of modern production and consumption.

\section{BACHELOR OF ARTS: FASHION-SUSTAINABILITY}

Taking all of this into consideration I propose a new form of education: an innovative hybrid educational model that offers traditional Bachelor of Arts courses, as well as object-based research, and practice-led research that is unique to our discipline of Fashion Studies; One that doesn't just touch upon sustainable and ethical content, but is guided and shaped by these principles. And one that aids in the:

...Promotion of integration, synthesis, critical reasoning, and systemthinking skills, supporting students and researchers beyond skill development to cope with the future multi-disciplinary complex challenges of sustainability (Karatzoglou 2013: 45).

These courses incorporate the Generic Sustainability Competences' which were built on the German ideas of Gestaltungskomptenz (Based on work by the German UNESCO Chair of ESD in Higher Education, Michelsen and Adomssent, 2007) (Wals 2014: 12):

Generic Sustainability Competence:

-Competence to think in a forward-looking manner, to deal with uncertainty, and with predictions, expectations and plans for the future.

-Competence to work in an interdisciplinary manner.

-Competence to see interconnections, interdependencies and relationships.

-Competence to achieve open-minded perception, trans-cultural understanding and cooperation. 
-Participatory competence.

-Planning and implementation competence.

-Ability to feel empathy, sympathy and solidarity.

-Competence to motivate oneself and others.

-Competence to reflect in a distanced manner on individual and cultural concepts (Wals 2014: 12)

The core courses of the proposed Fashion Sustainability BA consist of:

1. Methodology of Research: which provides a comprehensive overview of research methodology and research structure for both quantitative and qualitative research methods.

2. Environmental Impacts and Implications: a course which a Science Professor teaches, as is done for the FIT Interior design programs and counts as a science credit

3. Textile Consumption and Innovation: also offered as a science credit. Incorporating: "Materials that mimic the ingenuity of plants and animals/ industries that work like ecosystems/ products that become part of cycles resembling natural materials flows" (McDonough \& Braungart [1998], quoted in Orr 2002: 22). As well as explorations around the potential toxicity of clothing worn in close proximity to the body.

4. Overview of Sustainable Fashion Business Practices: taught by an economics professor, counts as a math or business credit

5. A selection of: Ethical, Post-Colonial courses offered as Liberal Arts subjects. Looking at philosophers and social activists like Gandhi, Paulo Freire, Hannah Ahrendt, Martin Heidegger and Karl Marx, The praxial motivational aspects of these philosophies are a good fit for this type of research that although highly theoretical, is ultimately intended to have 
practical implications at a pedagogical and policy level.

6. Social History Credits (History) an overview of the history of fashion, but one that also incorporates issue of representation and power; since: "...Fashion highlights the multiple intersections and entanglements among gender, race, ethnicity, national identity, social class, sexuality, and other facets of our identities" (Kaiser 2012: 4). Curriculum would incorporate culture studies into the content.

7. Sustainable Canada: heritage and cultural landscape subject

8. Object-Based Research Subject: aligned with the Fashion Resource Centre (currently in development with the Interdisciplinary BA)

9. Sustainable Design: principles of low-waste and environmentally friendly fashion design are explored. Also the $80 \%$ impact can be applied to material choices, and proposed finishes.

10. Capstone: wherein practice-based research is explored in an area of expertise of the student, which could be applied fashion design research, or fashion business explorations

All credits relate to sustainability, both business and creative. This suits the interdisciplinary nature of current scholarship in sustainability as well as the broad landscape of the subject. It also offers students a rich perspective in theory and research in relation to sustainability, as well as opportunities for applied practice-based research that formulates and tests out new ideas for sustainable fashion.

\section{Conclusion}

In many ways, 'subjectivity' (a way of being and becoming in the world) is to intersubjectivity (collective understandings of 'how things are') what style is to fashion, and truth is to knowledge. In each case, the former 
term suggests individual actions and intentions, whereas the latter implies collective negotiations and understandings.

Susan Kaiser, "Minding Appearances: Style, Truth, and Subjectivity" (2001).

Once all of the very disturbing data around the negative impacts of the fashion sector has been reflected upon, another idea begins to materialize: If the fashion industry has this kind of reach and power, then industrial reform is the best way to reverse all of these negative impacts. Fletcher \& Grose address the "system transforming nature of sustainability" and go on to say that "sustainability offers the biggest critique the fashion sector has ever had. It challenges fashion at the level of detail (fibre and process) and also at the level of the whole (economic models, goals, rules, values and belief systems)" (Fletcher, Grose \& Hawken 2012: 8). None of this is a naturally occurring phenomenon; these are human-made systems supplying a human market in an ongoing cyclical way. Treating them as if they carry some inherent inevitability is in the obvious interests of unscrupulous producers. Challenging the status quo is the first step in any process of change, unfortunately the potential power of the designer or fashion business professional to act as an agent of progressive change is under-utilized at this time.

The future of industrial reform lies in the hands of our current generation of students; however, it is not the same student who is a catalyst for change in all of these disparate sectors. In fact, it is the student of each discipline who can effect change within their respective areas and through concomitant action raise the standard of accountability across the board and subsequently effect substantial amelioration industry-wide.

There is also massive potential for change within the existing architecture of fashion education. At the moment the changes need to be curricular rather than structural because not everyone has the capacity to 
enact sweeping structural re-organizations. Those in state or provincially funded and approved program structures are not in a position to limit class size, or to re-write programs (Appendix 1: FIT). However, the inclusion of new program outcomes and course outcomes are more manageable and can be justified by existing industry and consumer concerns (Deveau 2015; Ellsworth 2015). Program and course learning outcomes are similar to a contract defining what content that needs to be included in curriculum; they do not however dictate how this content is taught, and they do not restrict the educator. An advocacy element can be introduced thematically allowing the college or university to influence student opinion rather than passively replicating the industrial status quo. Fashion pedagogical reform need not be considered as conjoined to delivery models, as the two areas are discrete. All of this can be accomplished within existing class sizes and modes of information delivery.

How we teach is an important consideration alongside what we teach. Not everything can be applied to all curricula, but that is exactly the point: it needn't be. A designer needs to be concerned with construction and materials; production managers should examine ethical practices and economical supply chain strategy; and marketers must address the messaging surrounding use, re-use and end-of-use of finished goods. Trying to singlehandedly shoehorn all of this diverse content-which although contiguous, is not necessarily homogenous-into a single subject is destined for defeat; resulting in a Sisyphean task that can only lead to burnout at the faculty level and a diminished classroom experience for the student. Instead, the focus will be on what is relevant to the subject and what is synergistic with the educator's knowledge base.

Regarding the "doom factor" that comes into effect when these very serious global threats are examined, to give in to despair is counterproductive and not factoring in all of the data. Giving our students solid examples of best practices and success stories can challenge corporatist 
media biased reporting that tries to cover up, hide or castigate the voices that advocate for reform. It is not surprising that the truth when it involves holism, social justice, and progressive change is not widely broadcast, for: "The oppressor knows intervention is not in his own interest" (Freire 1970: 52). It is a far cheaper corporate strategy to greenwash and catastrophize so that the general public is left disenfranchised and discouraged, or in willful denial.

There can be no discussion of sustainability without a clear illustration of its harmful effects, as Paolo Freire says in Pedagogy of the Oppresed: "Concern for humanization leads at once to the recognition of dehumanization, not only as an ontological possibility but as an historical reality" (Freire 1970: 44). My personal experience in the classroom is that students are already well aware that there are serious issues in the world as a result of fashion. If anything, they are disturbed by the lack of focus on these issues.

This is not however, the only truth, as Burke and MacHenry's, as well as my own research into transnational supply chains show. There is much already being done, and there is much to be hopeful for; and students need to know this.

Just to be clear, I am not advocating a pollyanna approach, or advocating dishonesty or misrepresentation of the magnitude of the issues caused by the fashion industry. I am calling for a rejection of the either-or, profit versus charity; fashion versus ethics; reductive generalized polarizations that seem to constitute the sustainable fashion dialogue at this time. There are massive problems, but there are also effective solutions, some of which are being implemented right now (Burke 2015, MacHenry 2015, O'Connell 2015). This needs to be communicated loudly and repeatedly: at the classroom, departmental and institutional level.

Educators can also fill the role of generator of innovation and solutions 
that can be adopted and applied in the industry, as it is filled in other sectors like science and engineering (Etzkovitz, Ranga \& Dzisah 2012; Etzkovitz 2006; Etzkovitz \& Zhou 2003). We do not need to passively reflect and re-create the toxic industrial practices that are part of the current fashion business model. We can introduce our students to alternative production and design methodology, and we can use our intellectual prowess to generate solutions that can be adopted by industry.

There are many opportunities and challenges when it comes to the actual integration of sustainability principles into curriculum (Armstrong \& LeHew 2014; Borman \& Andersson 2013; Dickson, Eckman, Loker 2013; Barth \& Rieckmann 2012; Tilbury \& Ryan 2011; Jones, Crier \& Richards 2008; Lidgren, Rodhe \& Huisingh 2006; Lozano 2006; Appel, Dankelman \& Kuipers 2004; Sterling 2004; Jucker 2002). And in addition to the curricular evolution that is necessitated by the goal of integrating ethics and sustainability into fashion education there are also larger philosophical ontological, and structural considerations that need to be considered alongside the pedagogical ones.

Described as the challenges of both "paradigm" and "provision" by Sterling in: "Higher Education, Sustainability, and the Role of Systemic Learning" (Sterling 2004: 49): It is imperative that progressive, discursive dialogue be integrated into faculty communication and pedagogical development resources as well: "...Faculty ought to be encouraged in every way possible to take the time necessary to broaden their research and scholarship to include its ecological, ethical and social context (Orr 2002: 41). Allowing them to: "...Create a better balance between the real needs of society and the pace and kind of knowledge generated" (2002: 41). Communication, professional development and support in learning is essential, especially as the current academic landscape includes so many part-time teachers, larger class sizes, and non-traditional academic delivery methods (online, part-time and hybrid). 
As discussed previously, we shouldn't be attempting to teach full spectrum sustainability content to all fashion students. Otherwise the message and content becomes so vague and watered down that it is rendered effectively useless. Instead, it can be broken down into various streams; tailoring content that is specific to the sector it is relevant to, and embed said content into the learning outcomes of the subject and the program. Learning outcomes need to match the epistemological streams of the programs they reflect, incorporating outcomes that are also specific to their sector of the industry. As a result we do not endeavor to teach students every aspect of fashion business and production, we teach content that is relevant to the area of the industry the student will graduate into, teach it in-depth, and build on it throughout the curriculum. Supporting knowledge all through the curriculum, so that students are given historical, theoretical as well as praxial exploration of this information.

In doing this we are broadening the student experience of who they are and the power that they have. And as for our graduates, if you look at any industry survey, the business-creative-critical thinking matrix is high-if not at the top of the list-of desirable qualities sought after in a new hire. In my own experience as a designer at M.A.C Cosmetics, when I was hiring junior designers, the ability to think creatively and to independently problem solve and manage competing demands was something I looked for specifically. The addition of sustainable course material can only lead to the education and graduation of better performing fashion professionals:

...As students' (and society's) understanding of sustainability deepens and broadens beyond materiality and processing considerations, so the directions and opportunities for sustainability practice also open up." (Grose 143)

It only makes sense that students who have been challenged to bring their deductive and problem-solving skills to the sophisticated level that analyzing sustainable fashion design, production and distribution require, 
can't help but develop into big-picture thinkers. Resulting in fashion professionals who are reflective and demonstrate the ability to handle highlevel problem solving, and who are continuously synthesizing various disparate criteria into their work. Undoubtedly they are an attractive hire for an employer, as independent thinking combined with creativity is valued at a premium within the industry.

Although historically, the topic of fashion itself has been viewed with ambivalence, and has been trivialized at times as an academic discipline (Entwistle 2015; Crane 2012; Kaiser 2001; Kawamura 2004; Lou; Craik 2003; McRobbie 2003; Wilson 2003; Barnard 2002; Taylor 2002, 1998; Steele 1998; Breward 1995); the power of fashion cannot be denied, as we are one of the largest global producers and the garment industry is one of the most destructive industries globally. Our practices are also adopted by all of the other design disciplines, and the fashion supply chain supplies the model used for furniture and product design. Globally, it is fashion trends that drive all of the other disciplines. Trend forecasting, colour and textile directions all are initiated with fashion and are modified for other sections of the marketplace (WGSN 2016 n.p. n.d.). And to address the elephant in the room which is the question of whether sustainability can be profitable, Stella McCartney spoke of her experience running a fashion business that was founded and guided by sustainability principles during a Business of Fashion interview:

There are many things that are challenging, but for me at the end of the day they are challenges that are worth taking. And we still have a healthy growing business to show for it, so you know, it can be done (McCartney 2015: n.p).

Our strategies and our solutions can be adopted by other disciplines. We can also learn from other disciplines like Interior Design that are ahead of us institutionally and in the marketplace (Appendix 1: FIT). But there can be no integration if there is no initial Promethean inspiration, no knowledge 
generation, and no theoretical exploration in this area. Fashion academics should be the leaders in this area, and we currently are not. There are a small group bravely fighting the good fight, largely on their own personal initiative and energy. Helping to counter the trivializing biases that seek to de-legitimize sustainable fashion philosophy and pedagogy. Professional development resources must be allocated in a far greater percentage, to support these individuals if sustainable pedagogical advances are to be made institutionally. With Embedded learning outcomes this expenditure can be better justified within existing program structures. As it is now, the identifying characteristic of academic institutional consideration of sustainability seems to be its superfluity and devaluation of importance (Appendix 4: Campus Greening v. Curriculum Integration). This added sustainability content may in fact "strengthen the viability of the discipline" (Armstrong \& LeHew 2014: 80) itself, as the introduction of sustainability content into the dialogic academic milieu, can add a gravity and importance to fashion research; that although innovative and highly relevant, is academically marginalized and not highly visible in the academic mainstream at this time.

Regarding introduction of the principles of ethics and sustainability into the fashion industry at large, it only makes sense that the fashion college or university function as an idea generator. We are in the idea business. We have the most experienced practitioners and the brightest students in our sector, and we do not have the burden of production and pleasing shareholders on a quarterly basis. As Porter and Van der Linde say in "Green and Competitive: Ending the Stalemate":

...The belief that companies will pick up on profitable opportunities without a regulatory push makes a false assumption about competitive reality -- namely, that all profitable opportunities for innovation have already been discovered, that all managers have perfect information about them, and that organizational incentives are aligned with 
innovating. In fact, in the real world, managers often have highly incomplete information and limited time and attention. Barriers to change are numerous (Porter and Van der Linde 1995: 129).

Unfortunately, within a pure corporatist ethos: "Money is the measure of all things, and profit the primary goal" (Freire 1970: 60). Industrial reform is not likely to be initiated by the producers themselves as the principle driver in a free market is pure profit, the accountant's ledger has no inherent conscience, it only recognizes credits and debits. This is not to say that industry is willfully resisting change, in fact industry does want change, the pragmatics of negative consumer pressure in the marketplace makes it harder and harder to maintain the status quo. It is also not true that industry does not care, it is closer to the truth that they do not have the frameworks in place to generate solutions, nor the time to focus on these issues. As Manuel Escudero, the UN PRME Secritariat (See Appendix 3.) says:

If you have a skeptic in front of you to start with, that person doesn't see CSR and sustainability as something that is part of the core of business. I would say that at this moment there is no global company in the world that doesn't consider sustainability as a point in its agenda (Escudero quoted in Alcaraz and Thiruvattal 2010: 545).

Industry is aware of the increasing pressure that is being brought about by horrific tragedies like Rana Plaza. Unfortunately they are not equipped with change-making apparatus (Deveau 2015; Ellsworth 2015; Fletcher, Grose \& Hawken 2012). Putting pure capitalist ideologies aside for a moment, we need remember that corporations are run by people, and produce for people; every corporate decision is made by a human being, not an autonomous machine. I have worked as a designer within large corporate structures and it is indeed challenging to introduce ideas that will disrupt the status quo; however I have also seen firsthand where initiatives spearheaded by a dedicated individual were supported by Executive and 
implemented. At a fundamental level, human beings do not want to be ruining our world: either through pollution or misuse of resources, or by enabling the abuse and enslavement of our fellow citizens. Let's give industry more to work with than passive acquiescence.

Regarding the threats we are facing vis-à-vis the environmental and ethical denigration wrought by the fashion industry, we need to direct students to look at the consequences of their garment design and production choices. This will help them become ethical designers and business practitioners who can examine the environmental and social impact of the production and distribution of fashion. For this to happen, the grassroots pedagogical reform that is currently taking place on the periphery of fashion education needs to be brought into the core curriculum. And then systemic change can happen, both within the fashion academy, and outside in the industry at large.

Change when driven by collective will can bring about massive action in a short period of time; as has been evidenced by many political upheavals and the trans-global social progressions and regressions both recent and throughout human history. The catalyst of how to mobilize this powerful collective will is the big question. The will for change must be both consumer-driven and effected from within the industry by vocal advocates. The sustainability efforts identified and explained by my interviews and research provide concrete examples of many ways sustainability can be incorporated into existing curricula, and can be used to formulate new academic programming that presents the principles of sustainability within a new, truly holistic manner of pedagogical delivery.

This paper is also a call to action for fashion educators to look at our teaching practice to see where change can be implemented within our curricula; and also to call upon our own creative power to generate workable solutions, and see where they can be implemented within an 
industrial setting. The alternative is to aid and abet the destruction of our environment and thereby facilitate the mistreatment of others, while we wring our hands and cast blame all around. Or to conduct research so focused and unrealistic that there can be no real-world potential for subsequent application, resulting in the Academy-as-ivory-tower scenario (Armstrong \& LeHew 2014: 68). Currently we function in an academic and industrial climate where: "Professionalized knowledge is increasingly isolated from the real needs of people..." (Orr 2002: 41). We are siloed within our institutions, and our curriculum has nothing to do with the real issues that are affecting the health of our ecology, both environmental and human. It is entirely possible to teach and act as if our actions have no impact, but it can't change the fact that they do. We end up looking down with disdain upon a dirty industry; ignoring that we are complicit in the creation and maintenance thereof, as we teach our students the same old dirty and destructive processes; and ultimately behave as if: "...We are exempt from the laws that govern the rest of creation" (Orr 2002: 4). The end result of this myopic thinking, is that fashion becomes lethal both to humans and the environment.

It could even be argued that the educational sector is as culpable as industry: after all, we trained the design and business practitioners working in the fashion industry today. Instead, we can train our students to be advocates of progressive change, and we can function in the same capacity. Either through creation of theoretical models for fashion sustainability that can be applied industrially, or through the identification and implementation of new paradigms and processes already happening, that can be adopted within industry.

The Fashion Studies program I coordinate (and co-created with the Chair of the School of Fashion: Gitte Hansen) consists of all part-time educators except for myself. Curriculum can come and go depending on who is assigned to teach the subject. Without institutional support, there 
will always be an impermanence to this content, and it will remain auxiliary. With an institutional mandate, we can create trans-disciplinary pathways for students to connect with other non-fashion, but relevant areas: economics and science for example. Allowing the exploration to synergistically build on the strengths, and fill in the gaps of the students of the disparate research areas; and thereby generate innovative theory and solutions grounded in solid knowledge.

This idea could be taken further with a radical re-contextualization of fashion pedagogy-where it is institutionally possible-embracing the interdisciplinary nature of the curriculum once it has evolved through the inclusion of sustainable principles; resulting in a corresponding relocation institutionally as proposed by Armstrong \& LeHew:

As sustainability is a broad, multifaceted issue that cannot be taught in a vacuum, some participants discussed a needed philosophical shift to better embrace the inherent interdisciplinarity of TA, making connections to fields outside the discipline. In some cases, this may include being more open to the reorganization or relocation of the discipline within the university setting (Armstrong \& LeHew 2014: 69).

I propose the exploration of a new paradigm along with this new pedagogy, a truly multi-disciplinary institutional structure that interweaves business, design, sustainability philosophy, science, economics and social justice. Since:

Traditional education has not provided the training for graduates to work towards developing solutions to the new and complex world problems emerging. These problems are multi-dimensional and cannot be addressed by a specific application of conventional scientific, economic or social theory (Sibbel 2009: 79).

Create a new discipline that builds on the overlaps, one that can avoid the pitfalls of the past: 
Developing a new discipline is one way to overcome the constraints of working within traditional disciplinary domains (McMichael et al., 2003). Researchers at Harvard University proposed the development of the field of sustainability science, which is characterised by an integration of ecological and social processes at the local and global levels, with an overall aim of achieving sustainability (Kates et al., 2000) (Sibbel 2009: 78).

Truly, a new discipline is required to address all of the conjoined issues that fashion sustainability encompasses. One that can rise above the obstacles of partisanship and silo-based thinking, by strategically and synergistically connecting previously unrelated disciplines that now come more into each other's orbit through the examination of sustainability problems that need solutions.

Our major challenge then is to: "....Harmonize the human enterprise with how the world works as a physical system and how it ought to work as a moral system" (Orr 2002: 3). We are not powerless, and we are definitely not blameless; in fact we are partners in this process and as such can change how we operate. With the end result: change that can ripple outward through the work of our graduates, and our own research and theory that can affect major world-amelioration results. Rather than trying to "Shrink and minimize our presence, our systems, our activities, and even our population to become almost invisible" (McDonough \& Braungart 2010: 66). What if instead we tasked ourselves and our students with the question: what would a fashion system that was completely benign and sustainable look like?

I love fashion: I love experiencing new collections, and I love to buy new clothes. I always have and I imagine I always will. What I can't stand is the massive pollution and mismanagement of resources, and that people are even dying just to make cheap clothing. What would it be like though, to be able to have a functional fashion system that caused no harm; not in 
fibre, not in dye processes, not in production or retail, and whose products could be returned to the ecosystem in a beneficial way? I do not have the answer presently, but I know my students can figure it out, if they are given the opportunity and the knowledge base to do so.

"You gotta have a dream, if you don't have a dream, How you gonna have a dream come true?"

Captain Sensible "Happy Talk" Rodgers \& Hammerstein, South Pacific [1949] 1982.

\section{FURTHER AREAS FOR RESEARCH}

...A real design revolution must aim to foster a deeper transformation in human intentions and the political and economic institutions that turn intentions into ecological results. There is no clever shortcut, no end-run around natural constraints, no magic bullet, and no such thing as cheap grace (Orr 2002: 23-24).

This research focused on pedagogical opportunities for social justice, as they relate to fashion education at the higher education level and beyond. It argued that education can provide solutions to the negative impacts of the fashion industry currently felt globally, and that the fashion classroom can be ground zero for progressive change. Further to this goal, the research focused on current best practices in fashion sustainability education, within both design and business streams. As well, strategies for implementing curricular change to accommodate these innovations into existing curriculum were explored, and what a truly progressive model for incorporating ethics and sustainability into a Fashion Bachelor of Arts (BA) program could look like. Some recommendations as a result of this research are as follows:

- Implement the Sustainable Fashion BA 
- Fashion sustainability needs to be written into course and program outcomes, so that it is consistently and thoroughly taught and assessed

- Sustainability Pedagogical reform needs to be given the same attention as campus greening

- Sustainability pedagogy needs to be given a more precise definition. Perhaps through the work of an organization like IFFTI or ITAA in collaboration with design colleges and universities, a review agency could be formed to set parameters and define terms as was done with the discipline of architectural preservation. This could lay the foundation for an organization that could influence policy and industry wide standardization

- Conduct shared research into further integrating sustainability and ethics into existing curriculum. This endeavor could include academic partnerships between the FIT undergraduate fashion programs, Ryerson University undergraduate and MA programs, and the School of Fashion at Seneca College. Building on existing research and mutual successes, a heightened focus can be brought to the process of sustainability pedagogy. Also, the university and college environment can become a generator of innovation that can supply industry with solutions and offer guidance

- Explore the creation of an MA or Graduate Certificate in Sustainable Fashion Practices that covers all of the principles of ethics and sustainability, but whose deliverables can be individualized and applied to the fashion discipline of each student. multi-disciplinary institutional structure that interweaves business, design, sustainability philosophy, science, economics and social justice This can open up opportunities for cross-disciplinary exploration and foster greater cohesion in the discourse around sustainability industry-wide. 
- Create trans-disciplinary pathways for students to connect with other non-fashion, but relevant areas: economics and science for example. So the exploration can synergistically build on the strengths and fill in the gaps of the students of the disparate research areas, and thereby generate innovative theory and solutions grounded in solid knowledge.

- Explore the creation of a four-year Bachelor of Science (BSC) degree in Technical Design. Incorporating elements of textile chemistry and low waste principles.

- Set up better information portals and textbooks: information sources that do not have sustainability as a discrete final chapter at the end, or a sidebar on a page, but instead have sustainability principles woven through and as foundational tenet underlying all of the content.

- Lobby for inclusion to be included as a fundamental program outcomes at the ministry level for all Ontario fashion programs.

Further uses for this MA research could be implemented at the college, university or graduate level. Also, the concept of integrating sustainability into outcomes is not unique to fashion, any design discipline will have an environmental impact. Most design programs have sustainability and ethical considerations as a part of the product they are designing, whether they be supply-chain, resource-use or pollution based. Embedding sustainability principles into them could be done using the model of sectorspecific content as it relates to end-use. Institutionally, taking sustainability into the realm of curriculum and pedagogical ethos still has to happen in order to elevate the integration of this philosophy at a larger than operations level (appendix 4). This research can also be of use at a governmental level to formulate larger plans for initiatives at a provincial or federal level for using sustainability educational information, whether they be for educational ministry guidelines for new program creation or for consideration of how grants are dispensed; educating the various levels of 
government to the magnitude and impact our fashion operations are having internationally.

Mark O'Connell 2016 


\section{APPENDIX 1: FIT RESIDENCY FASHION INSTITUTE OF TECHNOLOGY RESIDENCY, MAY 2015}

During the month of May 2015, I was a visiting scholar with the School of Graduate Studies at the Fashion Institute of Technology (FIT) in New York City. During my time there, I attended capstone events and year-end exhibitions of various programs, interviewed scholars and administrators, and experienced what it is like to study at FIT, one of the premier universities of fashion in the world. My goals for this residency were two-fold: firstly, I wanted to connect with educators and administrators within the School of Graduate Studies and see how issues around ethics and sustainability are handled within fashion education and use this information as research to support my MA thesis. Secondly I was interested in the ways a large State school creates and implements curricular innovation. Seneca College where I work as a design professor and coordinator of the Fashion Studies program is also a large institution with many areas of teachables offered and therefore the areas for comparison were numerous.

The majority of the research undertaken during this residency was used for my MA thesis (May 2016). In addition to this, further research will involve the authoring of a paper that examines the implementation of sustainability principles within Interior Design programs to see where that can be applied to fashion curriculum.

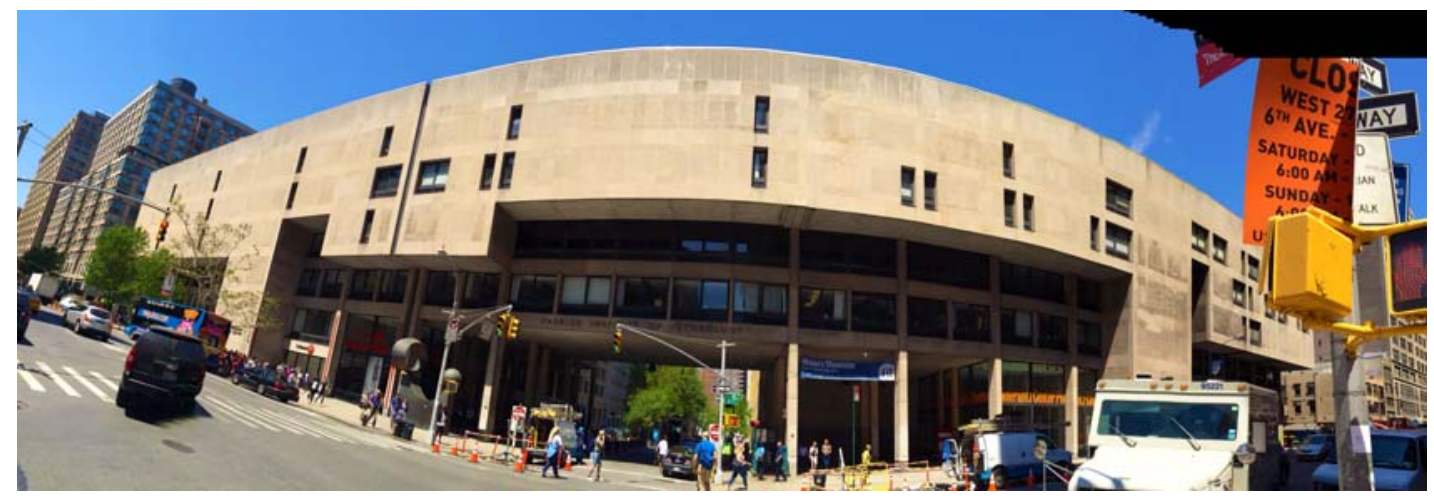

Emerging out of the $28^{\text {th }}$ street subway station from the West $27^{\text {th }}$ street exit, one is immediately engulfed and dwarfed by the FIT campus. A massive façade fronts $7^{\text {th }}$ Avenue and spans 26th to $28^{\text {th }}$ street. Described as "two great limestone megastructures in an entirely new idiom at either end of the campus, the one on the Seventh Avenue side completely bridging 27th Street." (Gray, 2015), it is necessary to cross the street to fully take in the sheer brutalist magnitude of this building. Passing underneath the archway, and walking down $27^{\text {th }}$, the atmosphere of the FIT campus is one of overwhelming urban biped activity, facilitated by the closed off $27^{\text {th }}$ street that bisects the two-block long configuration of conjoined buildings on either side. I would concur that: "This walk down 27th Street during the day is a strange and refreshing delight in a city where much of the public way is given over to free vehicle storage." (Gray, 2015). May is a lovely time in Manhattan and the end of term mood around campus is ebullient. Students are everywhere, chatting, laughing in the spring sunshine; they pour out and back into the university buildings in a constant stream. Occupying the many tables outside and perched all over the steps are students, and this milieu is clearly identifiable as one that focuses on fashion: the majority are very stylish with a downtown edge. As it was the end of term, the migration out of residence was also in full force. Students surrounded by their boxed belongings waiting for parents to pull up and load out their possessions.

\section{FIT AND SUNY}


Founded in 1944, FIT is a division of SUNY which is the State University of New York. Originally established in 1816 the SUNY has "grown to include 64 individual colleges and universities that were either formerly independent institutions or directly founded by the State University of New York." And now "...comprise the nation's largest comprehensive system of public higher education." with a total enrollment of 459,550 students in 2014" (http://www.suny.edu/about/fast-facts/: 2015). Curriculum must be proposed and vetted through Albany, NYC. Therefore the process for introducing new academic programming and altering existing curriculum is more labour intensive than it would be at a private institution. In light of this, the scope of innovation and creative programming evident at FIT is admirable. In this case, the partnership between state and faculty has created opportunities for creative and dynamic curriculum generation and new program creation.

\section{FIT DEGREes OfFered}

FIT offers Associate of Applied Science Degrees, Bachelor of Science Degrees, Bachelor of Fine Arts Degrees, Master of Professional Studies Degrees, Master of Arts Degrees, and a Master of Fine Arts Degree.

\section{Fit Mission StATEMENT}

FIT prepares students for professional excellence in design and business through rigorous and adaptable academic programs, experiential learning and innovative partnerships. A premier public institution in New York City, FIT fosters creativity, career focus, and a global perspective and educates its students to embrace inclusiveness, sustainability and a sense of community.

\section{FIT VISION STATEMENT}

FIT will be globally celebrated as the institution where students, scholars, and teachers cross traditional disciplinary boundaries to stimulate innovation, partner with creative industries worldwide, and develop innovative design and business solutions. By focusing on the three major goals, FIT will become stronger by conscious design and be known as a strategic organization-one that applies available resources to greatest effect to achieve its vision:

Academic and Creative Excellence: FIT will provide a rigorous learning experience built on the highest standards of academic and scholarly excellence; an environment that promotes creativity and experimentation; and diverse experiential learning with a variety of industry partners.

An Innovation Center: The College will work with industries worldwide to help address key challenges, build an even stronger culture of innovation and entrepreneurship at FIT, and establish collaborations that translate creative ideas into action.

An Empowering Student Community: FIT will build an inclusive community in which students engage with, learn from, and inspire each other-discovering how their differences and similarities promote creativity, intellectual and personal growth, and understanding.

\section{FACULTY AND ENROLMENT}

There are 240 Full-time faculty and 704 Part-time. In the fall of 2012 there were 7,270 Full-time students enrolled and 2,782 Part-time, with $98 \%$ at the undergraduate levels 
(Source: SIRIS).

\section{Majors AND Certificates}

FIT offers 37 Majors and 12 Certificates, some of these include: Accessories Design, Advertising Design, Communication Design, Computer Animation and Interactive Media, Fabric Styling, Fashion Design, Fine Arts, Graphic Design, Illustration, Interior Design, Jewelry Design, Menswear, Packaging Design, Photography, Textile/Surface Design, Toy Design, Visual Presentation and Exhibition Design, Advertising and Marketing Communications, Cosmetics and Fragrance Marketing, Direct and Interactive Marketing, Entrepreneurship, Fashion Merchandising Management, Home Products Development, International Trade and Marketing for the Fashion Industries, Production Management: Fashion and Related Industries, Technical Design, Textile Development and Marketing, Art History and Museum Professions, and Film and Media.

\section{INTERVIEWS}

A major component of my residency involved interviewing key practitioners in sustainability education. The following were generous both with their time and their experience:

Dr. Mary Davis: Dean, School of Graduate Studies, Fashion Institute of Technology

Barbara Campagna: Acting Chair \& Assistant Professor, Sustainable Interior Environments, Fashion Institute of Technology

Sass Brown: Acting Associate Dean, School of Art and Design, Fashion Institute of Technology

Michael Renzulli: Professor Fashion Design-Apparel, and founding member of IFFTI, Fashion Institute of Technology

Grazyna Pilatowicz: Assoc. Professor, Interior Design Department, and co-founder of the Sustainability Council, Fashion Institute of Technology

Shannon Leddy: Professor FIT Interior Design Program, Fashion Institute of Technology

Pamela Ellsworth: Associate Professor and Chairperson, Global Fashion Management

I also interviewed Timo Rissanen: Assistant Professor of Fashion at Parsons, who is known for his pioneering work in zero-waste fashion.

\section{SUSTAINABILITY NOMENCLATURE}

One of the challenges in discussing sustainability is the word itself. The definition of sustainability in the fashion industry is equal parts vast and amorphous, with terminology specific to various sectors of the industry. Gam \& Banning note that even the terms themselves are vague: eco-friendly, green, environmentally friendly etc... (205). If you throw in sleazy greenwashing that attempts to sell toxic product as "sustainable" the picture gets even more blurred. A good basic definition of sustainability is offered by Landgren and Pasricha in "Transforming the Fashion and Apparel Curriculum to Incorporate Sustainability" when they quote Hethorn and Ulasewicz: "Sustainability within fashion means that through the development and use of a thing or a process, there is no harm done to people or the planet, and that thing or process, once put into action, can enhance the wellbeing of the people who interact with it and the environment it is 
developed and used within" $(2011,187)$. Armstrong and LeHew offer this definition: "...The continual examination of the environmental, economic, and social implications of all phases of the product's life cycle, rooting out threats to long-term human well-being from pre- to post-consumption while also considering the ever-critical psycho-social needs of the end user (Allwood et al. 2006; Black 2008; Fletcher 2008; Fletcher, Grose \& Hawken 2012; Quinn 2010)" (60, 2014). Dean Mary Davis of the School of Graduate Studies at FIT offered this definition of her evolution of sustainability consciousness:

I have come to understand the role humans play in sustainability. So that when you talk about sustainable fashion or sustainable food or you know, you name it, sustainable design: eventually you come back to treating people in a way that is ethical and responsible. So if you want to follow the sustainable fashion chain all the way back to how garments get made; how things get distributed across the world, you eventually you come down looking at one worker, in one place and in the way that worker is compensated, the working conditions for that person: you're confronted with really a moral dilemma about how something that is labeled sustainable or considered to be sustainable relates to one individual (Davis, 2015).

Within the context of this research the term "Sustainability" will refer to labour issues, environmental pollution and resource depletion as they relate to garment production and consumption.

\section{SUSTAINABILITY COUNCIL}

The Sustainability Council at FIT is an ambitious college-wide initiative. Originally a grass roots organization founded and built by faculty, the council has since grown through institutional support (Pilatowicz, 2015). According to the FIT webpage: "The Sustainability Council was established by the President, to develop and foster sustainability initiatives throughout the FIT community" (2015). The Sustainability Council at FIT has the following initiatives on their webpage: No Impact Week, Multimedia, Annual Sustainable Business \& Design Conference, FIT Sustainability Guide, FIT Sustainability Council (Sustainability Grants/ Mission and Members), Faculty Senate Committee on Sustainability, Curricular Initiatives, Greening the Campus, Clinton Global Initiative University, Minor in Ethics and Sustainability. Some projects that the council undertakes are the organization of an annual conference and also manages a permanent exhibition space in the library in the Goodman building. Of particular interest were the grants that are offered by the council:

The Sustainability Council of the Fashion Institute of Technology offers an annual grantfund of $\$ 15,000$ to support creative and innovative initiatives that help to infuse various aspects of sustainability into our college culture, curricula, operations, and physical environment. Individual grants are awarded up to $\$ 5000$ each. The fund is administered by the Sustainability Council” (Sustainability Council webpage 2015).

The purpose of the fund is as follows:

The fund can support the development of a full range of potential sustainability efforts at FIT. These might include educational projects that inform our community about sustainability, scholarly research focused on sustainable issues, creative endeavors and projects, procedural changes to daily campus operations, new technology that impacts the campus in a positive and sustainable manner, new methods of operating the physical campus, or professional activities that support awareness of sustainability. "Sustainability," for the purposes of this grant award, should relate to areas of social, environmental, and economic domains of human activities. (2015)

In regards to eligibility:

All faculty, administrators, staff, and students of the College are eligible to apply for a grant, individually or in groups, by submitting a written proposal describing their program 
or initiative. (Student applicants must be freshmen, sophomores, or juniors in consultation and collaboration with faculty advisors or mentors; students must be continuing at FIT in the following year and must be enrolled at FIT during grant implementation) (2015).

Grants requests are assessed on the following objectives and criteria:

1. The project has relevance to the Sustainability Council's goals of supporting educational projects, scholarly research, creative endeavors, and professional activities that help protect the environment, sustain resources, and/or enhance an understanding of sustainability on our campus and within our community (environmental sustainability, social sustainability, and economic sustainability).

2. The project addresses one or more of the facets of sustainability: environmental, social, and /or economic.

3. The project exemplifies innovative ideas for change and has the potential to have an impact on the FIT community that will last well beyond the grant period.

4. The project provides opportunities for collaboration or outreach with other members of FIT, SUNY, or the larger community.

5. The project serves as a model that can be replicated by others at FIT, SUNY, or the larger community.

6. The project has clear and effective evaluation measures.

7. The project budget is reasonable and justified.

8. Successful projects must have minimal carbon and ecological footprints.

The Sustainability Council also offers a new interdisciplinary minor in Ethics and Sustainability that commenced in the Fall of 2014 :

The Minor in Ethics and Sustainability at FIT draws on the expertise and critical thinking of faculty across the campus in all three schools. Minoring in this interdisciplinary field of study will provide students with the knowledge and tools that will allow them to understand the concepts and depth of topics in and related to ethics and sustainability and associated philosophical, social, economic and environmental impacts. Minoring in Ethics and Sustainability will help students build a content knowledge base that will support future understanding and critical assessment of local and global environmental, economic and social responsibility and the impacts of actions. The Minor is designed to facilitate graduates' understanding of the interrelatedness of topics, information and applications related to ethics and sustainability. (Sustainability Council webpage 2015)

There are two required core courses and then a number of course from across the other schools that can be applied to the 15 credit minor.

There is also a Sustainability Council Blog which has postings on: Education and Curriculum; Events and Conferences; Green Eating; Greening the Campus; Industry; News and Commentary. This is a user-friendly way for disseminating current information around the activities of the council.

The Sustainability Council also has a dedicated space on the sixth floor of the FIT library used for exhibitions. During my visit there was a photo exhibition showcasing the FIT Green Roof initiative.

\section{FIT SUSTAINABILITY SUBJECTS}


Some of the FIT sustainability subjects are offered by the Science faculty and constitute a science credit for degree students. This is relevant as this was one of the obstacles that was articulated by a participant in the Armstrong and LeHew study:

... The lack of sustainability science knowledge of our students is definitely a barrier. They don't have that basic understanding of ecological systems at all, and how the water system works, and how, you know, where energy comes from or where electricity comes from, those sorts of things" (Armstrong \& LeHew 2014: 74).

As fashion educators may not have the background information, having a scientist teach content from this area has obvious benefits.

\section{Bachelor of Science Technical Design}

FIT has a Bachelor of Science Degree in Technical Design offered by the School of Business and Technology. Originally created as a two-year Associates diploma due to industry demand for the skill set, and it was later expanded into a four year Bachelor of Science Degree (Renzulli, 2015).

\section{Capstone Events}

Through the invitation of Dean Davis, I was able to attend the capstone events for the Sustainable Interior Environments MA and the Exhibit Design MA.

\section{SUSTAINABLE INTERIORS MA:}

the graduating cohort of the MA in Sustainable Interiors class presented their final thesis research focusing on areas like implementation of green roof principles (and the roof right outside the glassed-in boardroom where the presentations were held, was in fact a green roof), commercial urban water use (and misuse), use of foliage in office interior design, and examining the inclusion of Biophilia principles into hotel lobby design. There were many interesting and innovative ideas presented, and I was pleasantly surprised to learn during the presentations that both the Empire State building and Chrysler had been retrofit to LEED standards. Some past graduate theses were: "The Role of Delight in Furniture Longevity"; "Healing by Design: How Sustainable Design Strategies that Pertain to the Built Environment Can Be Found in the Frameworks and Principles of Complementary \& Alternative Medicine"; "Fire Retardants in Commercial Furnishings"; "An exploration of deconstruction in New York City. Main Stacks and Special Collections"; "Healing by Design: How Sustainable Design Strategies that Pertain to the Built Environment Can be Found in the Frameworks and Principles of Complementary \& Alternative Medicine"; "A Program Template for Complete Integration of Sustainability Principles into Accredited Undergraduate Interior Design Programs in the United States".

Of particular interest to me was the latter MRP, as it related to the topic of my thesis except that it focused on interior design pedagogy and curriculum. At the capstone event I was introduced to Professor Shannon Leddy who authored this research. I subsequently interviewed Professor Leddy and gained valuable information for my own research.

\section{EXHIBITION DESIGN MA}

At their capstone party, the Exhibition Design MA hosted a panel of practitioners from the field to discuss the future of the industry. The panel was a broad age range of age and expertise. It was interesting that the participants provided varying viewpoints on the topics proposed by the moderator, and added encouragement for the graduating cohort of students. All of the panelists also brought their individuality to the process, showing students that having personality is not antithetical to exhibiting knowledgeability. For 
example James Damian of James Damian Brand Integration Services returned in his answers to the value of creativity, and used the elemental principles: fire, earth, air and water to illustrate his concepts. I found this model where industry luminaries share insight about contemporary and future issues offers a broader viewpoint than just the single voice of a keynote speech. A dialogue is created as opposed to the monologue, both between the panelists and by the questions from the audience.

\title{
MA FASHION DESIGN
}

Creating new programming in the Ontario College system requires satisfying both ministry of Education requirements and several tiers of college requirements. The process at FIT is also very detailed and incremental. The school of graduate studies is in the process of launching a Master of Fine Arts degree program and Dean Davis spoke to the challenges of creating new programming within the structured environment of the New York State Public Colleges system:

\begin{abstract}
...It seems like an obvious thing that the Fashion Institute of Technology would have (an MFA Fashion Design), but in fact it's been a little bit of a political issue to get it off the ground here. And because people have very different visions of what a Fashion Design program in a school like this should be. But the challenge is for us, to go beyond those internal challenges of building consensus within our own walls. So for me, that consensus has to be gathered from the other three schools in the institution, particularly from the School of Art and Design, which offers an AAS and a BFA in Fashion Design; but also from the School of Business and Technology, and the School of Liberal Arts. Because one of the goals that we've always had here is to create a Fashion Design Masters that reflected what people call the DNA of FIT, which is our connection of business and technology, with creative work and design. So there was a lot of discussion with those stakeholders; then there was a lot of discussion with the Vice Presidents here who control things like marketing and advertising, the finances, the development potential around such a program and the needs that that program would have. .... huge issue for us, has been space. Because we are kind of locked in (at the $27^{\text {th }}$ St. campus), and out of space, and a program like this would require a lot of space. So the internal challenges alone were significant: that was a steep hill. But everything that we do, every document that we create, and the bigger one is a document called the Approval to Proceed document, has to have a massive amount of detail, because it has to pass through the State University of New York (SUNY) approval system. We are one of 64 colleges in the SUNY system and I believe there are 14 Community colleges, so we are part of that group as well; even though we are an oddball community college because we offer lots of Bachelor's degrees as well as Master's degrees. So we don't really fit into any peg or hole there. But we do have to go through the process, and one of the things that has to be established by the administrators of the SUNY system is that our new program or any new program that we offer, is not going to be a distraction or a duplication of any existing program...you wouldn't think that would be such a hard thing but in fact there are a number of city schools that are looking at fashion as a potential area... So we've had to be really thoughtful and very detailed about a curriculum: laying out the full curriculum for the program, laying out the space needs detail and laying out the costs for everything versus the revenue. So what happens is... once it has got the stamp of approval from our president... (the proposal then) goes through the SUNY approval process, and that will take the better part of nine months to accomplish. The other responsibility we have is to our accrediting bodies, and so Middle States is the general accrediting body for the college, but a program like this, a studio program is also accredited by NASAD (National Association of Schools of Art \& Design). So everything that we've done, and laid out has to conform to NASAD standards and will be vetted by NASAD along the way (Davis 2015).
\end{abstract}

The process has taken two and a half years at this point, and the estimated launch date is Fall 2016. When it is up and running, it will no doubt prove to be as dynamic as the other MA offerings at FIT. 


\section{Art \& Design Graduating Student Exhibition}

During my residency I attended the year-end exhibitions for the following programs: Accessories Design; Advertising Design; Computer Animation and Interactive Media; Fabric Styling; Fashion Design; Fine Arts; Graphic Design; Illustration; Interior Design; Jewelry Design; Menswear; Packaging Design; Photography; Textile/Surface Design; Toy Design; Visual Presentation; Exhibition Design. This large-scale group exhibition is described in the accompanying catalog as follows: "The show presents the work of over 800 students receiving AAS and BFA degrees from the School of Art and Design and is on view throughout the main floors of the Marvin Feldman Center, the Fred P. Pomerantz Art and Design Center, and the John Reeves Great Hall."

\section{FIT LIBRARY}

According to the Library website "The library holdings of more than 138,000 volumes, teamed with non-book materials such as fashion forecasting services, fashion designrelated clippings files, periodicals from around the world, reference resources and Special Collections, provide professional aspects of the fashion business and the study of design not found in conventional academic libraries" (2015). Fashion Professor Michael Renzulli says of the holdings: "There is no getting around it, our library is considered the most comprehensive fashion library in the world" (2015). The significance of the special collections are detailed on the library website:

With a collection size of 3,500 linear feet and over 3,200 titles, rare and important books and periodicals on fashion and textiles are housed, as well as unique oral histories and designer scrapbooks. Our 350 manuscript collections include more than 500,000 works on paper from primarily American designers from the late nineteenth century through the 1980s. The work of the garment industry of New York's Seventh Avenue is heavily represented along with small samples of sketches executed for Broadway and Hollywood productions. Taken cumulatively, Special Collections primary source research materials reveal developments which characterize the school of American fashion design in the first half of the 20th century. (2015)

In regards to sustainability the library has created an online Research Guide that has the following sub sections: Journals, Books \& DVD's, Government Information, Sustainable Interiors, SE541 - Sustainable Interior Environments, Sustainable Interior Environments Theses (A-Z), Sustainability.

I visited the FIT Library and spoke with Reference Librarian and Adjunct Assistant Professor Marian Weston about the challenges and strategies of collecting and cataloguing fashion sustainability content. There is an ongoing process of acquiring material suggested by faculty, and the library itself is connected to many other leading institutions digitally and through lending privileges so the range of materials available to FIT students is vast and varied. One of the challenges Ms. Weston identified was that the Library of Congress assigns subject terms to publications which may be slow to change: "clothing trade" "sustainable" etc., so search results may be limited by the parameters of these terms. This is another good reason to standardize definitions and nomenclature around sustainability in design, as it can be hard to access cross-disciplinary research if the specific terminology is not known.

\section{SUStainABLE DESign ENTREPRENEURS}

There is an innovative program offered by the Continuing Education faculty called: Sustainable Design Entrepreneurs, according to the program website "This program gives design entrepreneurs the knowledge, tools and access to resources they need to build a viable business based on sustainable design." Administered by the Enterprise Studies 
and Digital Design. And includes the following courses: Natural Dyeing; SUS 022 55A; Collaborative Designs with Artisans I; Ethical Fashion I; Ethical Fashion II; Clothing Reconstruction; Materials and Eco Labels - Interior Design.

\title{
WhitNey MUSEUM
}

On a break from research-and-writing, I visited "America is Hard to See", the inaugural exhibition at the new Renzo Piano designed Whitney museum. Situated at the foot of the Highline in the Meatpacking District. Jerry Saltz writes of his experience of the new gallery in contrast to the previous space on the Upper East Side:

\begin{abstract}
This kind of show - this kind of museum-shaping - would have been impossible in the Breuer, and the Whitney has built itself an environment much more suited to it than those the other museums have managed to. In part, this is because the Whitney has had the brilliant instinct to make the setting, not the building, the spectacle... On my first visit, I walked in and out of the building, onto roof decks and terraces, up and down outdoor steel staircases, through galleries (Saltz, 2015).
\end{abstract}

I concur, the architecture is less of a focus than the flow-through, resulting in a heightening of the multi-dimensionality of the viewing experience. One wanders room-byroom, floor-by-floor, in-gallery subdivisions and painted backgrounds contrast and categorize the artworks on display. Like old friends, artworks by Basguiat, Chuck Close, Georgia O'Keefe, and Rothko are perceived, but they are mostly pieces by the artists that I had not seen before. Resulting in a slightly surreal feeling, almost a déjà-vu. And the emergence onto sunlit patios with sculpture and up vertiginous staircases, punctuates the viewing experience. Overall, the experience was thrilling and did live up to the preceding hype. According to the feedback from my students on my Instagram images, they heartily agree.

\section{COOPER HEWITT}

I also visited the Cooper Hewitt Museum, which recently reopened after a three-year closure due to renovation. The museum collection is housed in the Andrew Carnegie mansion on $5^{\text {th }}$ av. across from Central Park and is marvelously grand. It is an interesting contrast to the Fricke down the street, and both buildings represent the aesthetic of their former occupants who were rivals in contemporanaeity. Renamed as Cooper Hewitt Smithsonian Design Museum, the results of the refurbishment are: "60 percent more gallery space for temporary exhibitions and shows of the permanent collection, which contains 212,000 objects" (Pogrebin, 2014). According to the New York Times:" The museum plans to encourage each visitor to use a special electronic pen that can collect information from works on view by tapping wall labels. The information can later be downloaded for additional study, and the system will remember patrons the next time they visit" (Pogrebin, 2014). At first I thought the pen a bit gimmicky, but I was pleased with the functionality and found it to be quite useful. My picks from that day's visit can be accessed here: https://collection.cooperhewitt.org/visits/gk0q (once a surface designer always a surface designer!)

I was delighted that one of the temporary exhibitions on display was "Maira Kalman Selects". Author and illustrator Kalman is a perennial favourtie of mine and here she has assembled a collection that ranges from: stockings, shoes, a hat, a teapot, samplers, porcelain figures of ballet dancers, vintage editions of Alice in Wonderland and Winnie the Pooh, the Gerrit Rietfeld Zig Zag chair (ca. 1934), a handkerchief memorializing Queen Victoria, Abraham Lincoln's funeral pall and gold pocket watch. According to Kalman the show evokes: "falling in love with a group of objects"; "the preciousness of time"; and the realization that "many of the most important memories in your life will be populated by the most seemingly unimportant objects. A chair. A bowl." 
(http://www.cooperhewitt.org/events/current-exhibitions/maira-kalman-selects/). favorite piece from the show is Toscanini's anti-fascist pants from Kalman's personal collection that she purchased at an auction. Described by Kalman in a VICE interview:

\begin{abstract}
What makes Toscanini's pants antifascist? "As far as I know," Kalman said, "these pants were the pants he wore, or could have worn, in 1936 to conduct the then Palestine Orchestra in their inaugural concert. He was invited by Bronisław Huberman, the man who created the Palestine Orchestra/Israel Philharmonic. Toscanini was really antifascist; he was anti-Mussolini, he wouldn't perform in Germany, he was anti-Hitler. His coming to Palestine at the time, to Tel Aviv, was really making a statement: I'm with these people, not with you" explained Kalman. "Because I'm from Tel Aviv, and mother's family came to Tel Aviv in the early 30s, I imagine [Toscanini] meeting her and falling madly in love. But I don't call them my 'Falling in Love with My Mother Pants'" (Bates, 2015).
\end{abstract}

Kalman describes her process as: "I'm not a curator or historian, so I didn't have any constraints," and says "I was just able to put things together by instinct and a sense of space"(Kalman in Bates: 2015: n.p.). The whole exhibition is suffused with Kalman's wry humour and use of quotidian objects to elucidate larger philosophical concepts.

Overall, my only criticisms of the collection on display at the Cooper Hewitt Smithsonian Design Museum were the lack of fashion on display (a solitary Miyake), and that the 3-D printing samples were really basic. One quick call to Iris Van Herpen could correct both of these issues.

\title{
CONCLUSIONS:
}

The creativity and dedication evidenced by the work of all of the professors and administrators that I interviewed is inspiring, especially given the fact the they work within a large organizational framework that is potentially a challenging environment to effect large-scale change. I would like to thank Dean Mary Davis for working with me to structure the process for this internship over the winter of 2015, for allowing me the opportunity to come and immerse myself in the FIT experience, for facilitating interviews with faculty whose knowledge and experience will advance my research, and for her kindness. Thank you to Barbara Campagna, Sass Brown, Grazyna Pilatowicz, Michael Renzulli, Pamela Ellsworth, and Shannon Leddy at FIT as well as Timo Rissanen at Parson's. All graciously took time out of their packed schedules during one of the busiest months of the year to meet with me and answer my queries at length and in depth.

I would also like to thank Gitte Hansen, Chair of the School of Fashion at Seneca College for allowing me release time from my teaching and administrative duties to pursue this valuable distance research opportunity.

FIT proved to be an inspiring and innovative institution and the knowledge I have gained from this experience will support both my MA thesis at Ryerson University as well as my teaching, curriculum creation, and administrative responsibilities at the School of Fashion at Seneca College.

\section{Appendix 2. Design Colleges offering Sustainability Design Colleges offering Sustainability}

Although sustainability is not currently offered as a core outcome of most current mainstream fashion education, there are notable schools and programs where fashion sustainability is a driving force in curriculum generation and delivery. Some of these are:

\begin{tabular}{|l|l|l|l|l|}
\hline Institution & Degree(s) Offered & Notable Faculty & Delivery & Innovations \\
\hline & & & & \\
\hline
\end{tabular}




\begin{tabular}{|c|c|c|c|c|}
\hline $\begin{array}{l}\text { Designskolen } \\
\text { kolding, Denmark: }\end{array}$ & $\begin{array}{l}\text { Radical Innovation } \\
\text { and Sustainability in } \\
\text { the Fashion } \\
\text { Industry BA Program }\end{array}$ & & $\begin{array}{l}\text { Four years / Eight } \\
\text { semesters. Classes } \\
\text { are both in Tongji } \\
\text { University in China } \\
\text { and Kolding Denmark }\end{array}$ & $\begin{array}{l}\text { industry contact with: } \\
\text { Both traditional } \\
\text { fashion industries and } \\
\text { emerging industries } \\
\text { such as innovative } \\
\text { SMEs - Small and } \\
\text { Medium Sized } \\
\text { Businesses and O2Os - } \\
\text { Online to Offline } \\
\text { Businesses }\end{array}$ \\
\hline $\begin{array}{l}\text { California College of } \\
\text { Arts (CCA) (San } \\
\text { Francisco, California) }\end{array}$ & $\begin{array}{l}\text { MBA Design Strategy } \\
\text { and BA Fashion } \\
\text { design }\end{array}$ & $\begin{array}{l}\text { Lynda Grose; Bob } \\
\text { Adams; Karen Brown; } \\
\text { John Warner, Eric } \\
\text { Wilmanns; Robert } \\
\text { Neher; Rana Cho; } \\
\text { Nathan Shedroff; Tim } \\
\text { Smith }\end{array}$ & $\begin{array}{l}\text { Full-time, two-year } \\
\text { MBA in Design } \\
\text { Strategy }\end{array}$ & $\begin{array}{l}\text { Unites the } \\
\text { perspectives of design } \\
\text { and integrative } \\
\text { thinking, sustainability } \\
\text { and systems thinking, } \\
\text { finance, } \\
\text { entrepreneurship, and } \\
\text { generative leadership } \\
\text { into a holistic strategic } \\
\text { framework. }\end{array}$ \\
\hline $\begin{array}{l}\text { London College of } \\
\text { Fashion (LCF) } \\
\text { (London, UK) }\end{array}$ & $\begin{array}{l}\text { MA Fashion and the } \\
\text { Environment }\end{array}$ & $\begin{array}{l}\text { Sandy Black; Kate } \\
\text { Fletcher, Dilys } \\
\text { Williams }\end{array}$ & $\begin{array}{l}\text { Centre for } \\
\text { Sustainable Fashion } \\
\text { (CSF) is a Research } \\
\text { Centre of the } \\
\text { University of the Arts } \\
\text { London based at } \\
\text { London College of } \\
\text { Fashion. Dir.: Dilys } \\
\text { Williams }\end{array}$ & $\begin{array}{l}\text { Shared Talent India; } \\
\text { Fashioning the Future } \\
\text { Awards, }\end{array}$ \\
\hline $\begin{array}{l}\text { Parsons The New } \\
\text { School for Design } \\
\text { (New York, USA). }\end{array}$ & $\begin{array}{l}\text { Parsons does not } \\
\text { have a specific } \\
\text { program that } \\
\text { specializes in } \\
\text { sustainable fashion } \\
\text { design preferring } \\
\text { instead to build } \\
\text { sustainability into } \\
\text { "everything they do." }\end{array}$ & $\begin{array}{l}\text { Timo Rissanen; } \\
\text { Bernard Kahn; Dr. } \\
\text { Hazel Clark }\end{array}$ & & $\begin{array}{l}\text { The new Dean Burak } \\
\text { Cakmak has a strong } \\
\text { background in fashion } \\
\text { sustainability } \\
\text { including time as CSO } \\
\text { of Kering group }\end{array}$ \\
\hline $\begin{array}{l}\text { Fashion Institute of } \\
\text { Technology (FIT) } \\
\text { (New York, USA) }\end{array}$ & $\begin{array}{l}\text { Sustainable Design } \\
\text { Entrepreneur } \\
\text { Certificate Program }\end{array}$ & $\begin{array}{l}\text { Neil Chambers; } \\
\text { Jeffrey Silberman; } \\
\text { Nathan Fleisig; Nicole } \\
\text { Schorr; Lisa } \\
\text { Hendrickson }\end{array}$ & $\begin{array}{l}\text { Continuing Education } \\
\text { offered outside of } \\
\text { normal BA structure }\end{array}$ & $\begin{array}{l}\text { A series of four-week } \\
\text { classes: non-credit } \\
\text { and open to the } \\
\text { public, conveniently } \\
\text { scheduled, and very } \\
\text { inexpensive }\end{array}$ \\
\hline $\begin{array}{l}\text { ESMOD Berlin } \\
\text { (Berlin, Germany) }\end{array}$ & $\begin{array}{l}\text { MA Sustainability in } \\
\text { Fashion }\end{array}$ & $\begin{array}{l}\text { Friederike Von } \\
\text { Wedel-Parlow; Rolf } \\
\text { Heimann; Renate } \\
\text { Stauss; Maximilian } \\
\text { Lang; Miguel } \\
\text { Adrover; Kirsten } \\
\text { Brodde }\end{array}$ & & $\begin{array}{l}\text { holistic and } \\
\text { interdisciplinary } \\
\text { approach to design } \\
\text { positioning itself as } \\
\text { ecologically, ethically, } \\
\text { socially and } \\
\text { economically } \\
\text { sustainable. }\end{array}$ \\
\hline $\begin{array}{l}\text { Central Saint Martins } \\
\text { College, University of } \\
\text { the Arts London } \\
\text { (UAL) }\end{array}$ & Material Futures MA & $\begin{array}{l}\text { Kate Goldsworthy; } \\
\text { Caroline Till; Carole } \\
\text { Collet }\end{array}$ & $\begin{array}{l}\text { MA Material Futures } \\
\text { explores the } \\
\text { intersection of craft, } \\
\text { science and } \\
\text { technology } \\
\text { encouraging students } \\
\text { to look beyond } \\
\text { existing boundaries } \\
\text { to anticipate future } \\
\text { needs, desires, and } \\
\text { challenges. }\end{array}$ & $\begin{array}{l}\text { integrate high and low } \\
\text { technological } \\
\text { materials and } \\
\text { processes, pursuing } \\
\text { relevant applications } \\
\text { across fashion, } \\
\text { architecture, product } \\
\text { design, and } \\
\text { communication \& } \\
\text { critical design }\end{array}$ \\
\hline $\begin{array}{l}\text { Chelsea College of } \\
\text { Art \& Design, UAL }\end{array}$ & $\begin{array}{l}\text { BA (Hons) and MA } \\
\text { Textile Design. }\end{array}$ & $\begin{array}{l}\text { Rebecca Earley; Kay } \\
\text { Politowicz; Lorna }\end{array}$ & $\begin{array}{l}\text { TED has used its } \\
\text { portfolio of }\end{array}$ & $\begin{array}{l}\text { Textile Environment } \\
\text { Design (TED) project; }\end{array}$ \\
\hline
\end{tabular}




\begin{tabular}{|c|c|c|c|c|}
\hline & & Bircham & $\begin{array}{l}\text { international } \\
\text { workshops and } \\
\text { lectures to create a } \\
\text { 'cradle to cradle' } \\
\text { approach to } \\
\text { sustainability in the } \\
\text { textiles and fashion } \\
\text { industry, but } \\
\text { increasingly applied } \\
\text { to wide range of } \\
\text { industries, including } \\
\text { interior, architecture, } \\
\text { and product design. }\end{array}$ & $\begin{array}{l}\text { They also have } \\
\text { outreach with the } \\
\text { industry and function } \\
\text { as a consultancy } \\
\text { called TEN }\end{array}$ \\
\hline $\begin{array}{l}\text { Otis College of Art \& } \\
\text { Design, Los Angeles }\end{array}$ & Sustainability Minor & Susan Baker & BA Minor & $\begin{array}{l}\text { Transdisciplinary } \\
\text { options for } \\
\text { sustainability } \\
\text { exploration: both } \\
\text { artistic and design } \\
\text { based }\end{array}$ \\
\hline $\begin{array}{l}\text { University of } \\
\text { Delaware }\end{array}$ & $\begin{array}{l}\text { Graduate Certificate } \\
\text { program in Socially } \\
\text { Responsible and } \\
\text { Sustainable Apparel } \\
\text { Business. }\end{array}$ & Dr. Marsha Dickson & $\begin{array}{l}\text { How apparel, textile, } \\
\text { and footwear } \\
\text { businesses address } \\
\text { the "Global Compact" } \\
\text { principles for human } \\
\text { rights, labour } \\
\text { standards, and } \\
\text { environmental } \\
\text { stewardship }\end{array}$ & Online Delivery \\
\hline $\begin{array}{l}\text { Winchester School of } \\
\text { Art, Hampshire U.K }\end{array}$ & $\begin{array}{l}\text { BA (Hons) Fashion \& } \\
\text { Textile Design. }\end{array}$ & $\begin{array}{l}\text { Zoë Olivia John; } \\
\text { Emanuelle Dirix }\end{array}$ & $\begin{array}{l}\text { As part of the BA in } \\
\text { Fashion \& Textiles, } \\
\text { Winchester offers a } \\
\text { module called } \\
\text { Introduction to } \\
\text { Responsible Design, } \\
\text { which engages with } \\
\text { ethical issues and the } \\
\text { broader concept of } \\
\text { environmental } \\
\text { responsibility }\end{array}$ & $\begin{array}{l}\text { The programme } \\
\text { specialises in design of } \\
\text { knitwear, woven and } \\
\text { printed textiles using } \\
\text { state-of-the-art } \\
\text { technology" }\end{array}$ \\
\hline
\end{tabular}

These colleges each have their unique approaches and programming. Some are pioneering online delivery, others are incorporating transnational and even multiinstitutional structures.

Designskolen kolding in Kolding Denmark offers the: "Radical Innovation and Sustainability in the Fashion Industry" BA Program. Their program website says that: "This joint fashion design programme introduced by Design School Kolding in Denmark and the College of Design and Innovation at Tongji University in China...Combines fashion design with sustainability, innovation, customization and social entrepreneurship in close collaboration with companies." and that the program trains students in "Radical Innovation" which discards traditional methods, creates new design methodology and teaches students to generate "new solutions by means of new technologies" The program is described as: "The best from Chinese business development is merged with Danish design traditions in this essential and sought-after programme that combines fashion, innovation and sustainability." They seek to provide: " sustainable solutions" identifying the industry need, but the lack of skills held currently by working designers. They seek to educate: "Designers with a thorough knowledge of sustainability; designers who know how to create and implement solutions - products as well as processes - that are 
sustainable; socially, environmentally and commercially" (n.p. n.d). Saying that: "The programme combines the essence of the design and business fields, creating a bridge between them." Noting their industry contact no involves:" Both traditional fashion industries and emerging industries such as innovative SMEs - Small and Medium Sized Businesses and $\mathrm{O} 2 \mathrm{Os}$ - Online to Offline Businesses are in the collaborative pipeline." Students learn to: "... work closely with various types of businesses and how to use design methods to make companies more sustainable in terms of their products and how they design and produce them (n.p. n.d.). They endeavor to train students "to support fashion industries and emerging businesses with a mutual understanding of sustainability, social entrepreneurship, open design and customization, new business and service and other business models of tomorrow." Providing "knowledge and tools to change the traditional ways of working in the fashion industry and provide it with new, innovative workings methods." and for students to: "assimilate sustainability as a fundamental mindset (n.p. n.d).

California College of Arts (CCA) (San Francisco, California) - MBA Design Strategy and BA Fashion design. Their "two-year MBA in Design Strategy at California College of the Arts prepares the next generation of innovation leaders for a world that is not only profitable, but also sustainable, ethical, and truly meaningful" (Phelan 2012). Their "...Curriculum mixes fashion sustainability, conceptual ideation, and interdisciplinary studio practice" (2012). CCA was the first to offer HE sustainability curriculum and has the longest running program. According to their website, the program: "Unites the perspectives of design and integrative thinking, sustainability and systems thinking, finance, entrepreneurship, and generative leadership into a holistic strategic framework." (CCA website). Key researchers and lecturers include: "Robert Neher, CEO of St Ives Laboratories; Rana Cho, communications strategy expert at Gingerworks; Chair Nathan Shedroff, co-founder of Vivid Studios; Tim Smith, Founder of All About The Future" (Phelan 2012).

Lynda Grose eco-pioneer with the first commercial line of organic clothing for Esprit in 1990 introduced sustainability principles into the CCA BA program eighteen years ago. It is also: "one of the only fashion schools where studying sustainable design is mandatory" (Phelan 2012: n.p.).

Their website states that the program: "...unites the perspectives of design and integrative thinking, sustainability and systems thinking, finance, entrepreneurship, and generative leadership into a holistic strategic framework" and that: "These themes run fluidly throughout the integrated curriculum and students develop deep, practical experience in managing today's interconnected markets and ecosystems." Aside from learning how to "... create innovative products, services, and policy..." students also learn to: "...help organizations develop new business models for the future" (n.p n.d)."

Notable Professors, Guest Lecturers, as well as courses and workshops are:

Lynda Grose, co-founder of ESPRIT's ecollection, the first ecologically responsible clothing line developed by a major corporation which set pioneering standards for the textile industry; Bob Adams, designer/farmer and IDEO Fellow; Karen Brown, creative director of the Center for Ecoliteracy; Amanda Cattermole, Levi Strauss \& Co.; Timo Rissanen, pioneer in no-waste pattern cutting and coeditor (with Alison Gwilt) of Shaping Sustainable Fashion; John Warner, founder of the Warner Babcock Institute for Green Chemistry; Eric Wilmanns, cofounder, Brown and Wilmanns Sustainability....Notable Courses and Workshops: Eco: Sustainability Seminar, Sustainability Studio, Innovation Studio, Leadership by Design (Phelan 2013: n.p.).

Grose describes the "sustainable education ethos" of CCA "consciousness, structure and agency" (Grose 2013: 139) and elaborates on its implementation: 


\begin{abstract}
...Enabling students to form an interactive relationship with ecological issues as agents for their own craft, and reflecting on the outcome, they become engaged and active, the logic of current fashion practice becomes apparent (consciousness) and as it does, it can be critically investigated through a number of lenses (structure). As idealism is tempered, students realise that ideas for sustainability are not fixed, but emergent and they begin to develop a grounded perspective regarding their own potential as fashion practitioners in furthering change (agency) (Grose 2013: 139).
\end{abstract}

According to the CCF website, the college endeavors to inculcate "Lasting Value" into their curriculum: "Create socially responsive, culturally relevant, and technologically appropriate lasting value". They also say that: "Organizations haven't always been -- and don't need to be -- focused only on money. Each semester, students develop individual and collaborative solutions to a variety of economic and social challenges". Regarding student learning they: "...Apply design techniques that include customer-centered research, prototyping, critique, and iteration as well as business strategies and metrics." And regarding evaluation: "Solutions are evaluated according to how well students serve customer and market needs for social, cultural, ecological, and economic impacts as well as long-term organizational and stakeholder value" (CCF website n.d.)

London College of Fashion (LCF) (London, UK) - MA Fashion and the Environment. Notable Professors and Guest Lecturers are: Professor Sandy Black, author of seminal book Eco Chic: The Fashion Paradox. Of particular note is Kate Fletcher, who in collaboration with Lynda Grose of CCF is author of Fashion and Sustainability, Design for Change (2012), Fletcher is also the most frequently noted fashion theorist during all of my fashion educator interviews. Notable Courses at LCF are: "New Perspectives on Fashion, Sustainability Solutions" (Phelan 2012). LCF's MA Fashion and the Environment is described on their site as: "Mixing design practices, innovative thinking and conceptual speculations, along with technology and science, the course finds strategies for the future state of fashion in ecological, cultural and social contexts" (LCF website, n.d.). It is the home to the Centre for Sustainable Fashion (CSF) which is a: "Research Centre of the University of the Arts London based at London College of Fashion". Established in 2008, their: "starting point was human and ecological resilience as a lens for design in fashion's artistic and business practices" and have grown into: "A diverse community of world leading researchers, designers, educators and communicators with an extensive network that crosses disciplines, generations, cultures and locations (CSF. n.d.). The Director of the CSF is Dilys Williams, notable for innovation in sports sustainability industry/ academic partnerships with Nike says the CSF:

...Challenges the status quo through sustainability as the ideation process for design and making fashion, working in collaboration with fashion industry leaders and change makers creates a dynamic relationship that is both imaginative and pragmatic (Williams quoted by Phelan 2012: n.p.).

Enabling them to: "Create internationally acclaimed research...Set agendas in government, business, and public arenas" as well as "Pioneer world relevant curriculum" (CSF site: n.d.). The school has an MA Fashion and the Environment program which is "Supported by the CSF--a relationship that affords opportunities for holistic, interdisciplinary, multi-levelled research which has seen numerous students go on to the PhD level" (Phelan 2012). It is involved in the following initiatives: "opening the UK's first sustainable fashion lab (in collaboration with Marks \& Spencer)...Shared Talent India, which encourages designers to exchange expertise with other protagonists across the supply chain." In addition to this, they also annually hold the Fashioning the Future Awards, which: "rewards innovative sustainable designs from students and graduates across the globe in categories such as "Unique Design Award" and "Unique Materials and Processes Award"' (Phelan 2012).

Parsons The New School for Design (New York, USA). Described as: "Known the world 
over as the former academic home of Donna Karan, Marc Jacobs, Anna Sui and Alexander Wang" (Chitrakorn 2015: n.p.) Notable Professors and Guest Lecturers include: "Timo Rissanen, zero-waste menswear designer and author; Bernard Kahn, fashion industry consultant for large companies for over 25 years; Dr. Hazel Clark, Research Chair of Fashion at Parsons and author of countless seminal publications" (Phelan 2013). Notable Courses: "Zero Waste Design, Sustainable Fashion, Ethical Fashion, EcoFashion: Sustainable Solutions" (2013). Regarding their approach to sustainability Parson' aims to incorporate ethics and sustainability curriculum across the curriculum in a holistic way. Students also focus on sustainability as a thesis topic and there are industry partnerships like a zero-waste denim project with Loomstate (an organic denim brand) (Rissanen 2015; Phelan 2013)

Parson's also has a new Dean. The Business of Fashion describes the new Dean Burak Cakmak in the article "Under New Direction, Parsons Puts Sustainability First". The new Dean has a strong background in fashion sustainability including time as the CSO of Kering group where he: "....Spearhead(ed) sustainability strategies for Kering's luxury brands, including Gucci, Stella McCartney and Bottega Veneta" (Chitrakorn 2015: n.p.). Describing the climate of sustainability at Parsons Cakmak says: "What has been positively surprising to me is how much Parsons cares about the topic of sustainability. They try to implement this across the board and in every part of their education" (Chitrakorn 2015: n.p.). Cakmak also speaks of supra-institutional initiatives:

I've begun speaking to several schools on how we can work together to better define fashion education on a global level...l'm looking beyond just creating a product. It's about your overall influence on society and how we can work together to address some of the ongoing challenges today (Chitrakorn 2015: n.p.).

It will be interesting to see what develops with both Rissanen and Cakmak working on curriculum and institutional direction.

Fashion Institute of Technology (FIT) (New York, USA). Notable Professors and Guest Lecturers: Neil Chambers, Sustainable Director, Chambers Design; Jeffrey Silberman, sustainable cotton expert; Nathan Fleisig, Social Responsibility \& Compliance Manager at Outerstuff, responsible for global compliance at Adidas/Reebok; Nicole Schorr, Founder, Zero to Sixty Communications; Lisa Hendrickson, an idea generator and a solution provider to Fortune 500 companies (Phelan 2013). Notable Courses are: "The Sustainable Organization, Sustainable Marketing, Responsible Manufacturing and Product Life Cycle, Ethical Fashion, Sustainable Design Technology: Farm to Retail (Phelan 2013). FIT also has the internationally recognized fashion sustainability pioneer Sass Brown who is currently the Acting Associate Dean for the School of Art and Design. FIT has a Sustainable Design Entrepreneur Certificate Program, that is offered on a parttime basis to professionals who are already in the industry to give: "Design entrepreneurs the knowledge, tools, and access to resources they need to build a viable business based on sustainable design practices." Offered as a series of four-week classes, the program is non-credit and open to the public, inexpensive, and offers working designers a chance to re-train and incorporate sustainability theory in their practice (Phelan 2013).

ESMOD Berlin, the Germen satellite of venerable French Fashion College: École Supérieure des Arts et Techniques de la Mode, offers an MA Sustainability in Fashion. Taught in English, the program was launched in 2011, and takes a: "...Holistic and interdisciplinary approach to design positioning itself as ecologically, ethically, socially and economically sustainable" (Vimeo n.d.) Notable Professors and Guest Lecturers are: "Friederike Von Wedel-Parlow, established sustainable fashion designer; Rolf Heimann, expert in textile ecology; Renate Stauss, expert on politics of fashion; Hessnatur's Maximilian Lang and Miguel Adrover; Kirsten Brodde, Senior Campaigner, Greenpeace DETOX Campaign" (Phelan 2013). Notable Courses are: "Sustainable 
Design Strategies, Sustainable Marketing, Sustainable Knowledge, Sustainable Production \& Textiles" (2013).

Central Saint Martins College, University of the Arts London (UAL) - MA Material Futures MA. Notable researchers and lecturers are: "Kate Goldsworthy, developing new digital technologies for recycling fabrics; Caroline Till, Founder of consultancy Franklin Till; Carole Collet, expert on resilient textiles" (Phelan: 2013: n.p.). According to their site, the MA Materials Futures: "Explores the intersection of craft, science and technology". They encourage their students to: "Look beyond existing boundaries to anticipate future needs, desires, and challenges". They take materiality as the "starting point of the design process" they encourage their students to: "...Integrate high and low technological materials and processes, pursuing relevant applications across fashion, architecture, product design, and communication \& critical design" (n.d.:n.p.). They take a larger view of sustainability and consider the: "Current and future context of design decisions...combining social, political and economic inquiry to inform future, sustainable design applications" (n.d.:n.p.).

Chelsea College of Art \& Design, UAL - BA (Hons) and MA Textile Design. The Chelsea Textile Design BA and MA have sustainability as one of the criteria for creation of designs. Some key researchers and lecturers are: "Rebecca Earley, expert in textile upcycling; Kay Politowicz, expert in conductive textiles; Lorna Bircham, expert on lowimpact dyes" (Phelan 2013). According to their website the BA Textile Design at Chelsea College of Arts: "...Allows students to take an experimental and creative approach to textile design." Students gain: "...Colour, design and materials knowledge within textile print, knit, stitch or weave." And that: "The course actively encourages a studio culture to develop alongside specialist textile workshops (n.d.). They also have the Textile Environment Design (TED) project: which was established at Chelsea in 1996, by a "...Unique collective of practising designers and educators" and is now attached to the University's Textiles Futures Research Centre. TED uses their "portfolio of international workshops and lectures to create a 'cradle to cradle' approach to sustainability in the textiles and fashion industry". The research from TED includes "...Elements of strategic design thinking about the lifecycle and aesthetic issues of a product". And have since applied these principles to a "...Wide range of industries, including interior, architecture, and product design (TED website). They also have outreach with the industry and function as a consultancy called TEN which provides sustainability solution to: "large-scale companies and small-to-medium-size enterprises (SME's) who wish to be pro-active and create real change in design and production". Recent consultancies include Stanhope PIc, PPR Home (now Kering), H\&M, The Continuity Company (TCC Global), Sloggi, Puma, VF Corporation and Gucci (TED website). The TED process is described on their website as follows:

TED has been developing a portfolio of research projects which have explored many aspects of sustainability and textile design. Staff and students work collaboratively and on individual practice-based projects. This archive of past research activity contains a range of methodologies and new thinking that we are continuing to build on and develop. The most recent collaborative projects, including Worn Again: Rethinking Recycled Textiles and the MISTRA Future Fashion project, are leading to the development of a model for practice-based research, the first of its kind within the sustainable textile design field (n.p. n.d.).

Otis College of Art \& Design, Los Angeles - Sustainability Minor. Key researchers and lecturers are: "Susan Baker, expert on manufacturing in LA fashion industry; Meg Cranston, internationally recognised artist; Laura Hoad, designer and expert brand consultant" (Ditty 2012). Their Focus is on: "Strategies and systems, which can meet the needs of current generations without compromising those of future generations, including: climate change, biomimicry, cradle to cradle, life cycle analysis (2012). 
University of Delaware, USA - Graduate Certificate program in Socially Responsible and Sustainable Apparel Business. Key researchers and lecturers are: "Dr Marsha Dickson, internationally known researcher and expert on socially responsible practices in the apparel industry; Dr Huaniten Cao, expert in protective clothing; Dr Doug Cahn, Board member of Fair Factories Clearinghouse and Verité" (Ditty 2012). The Department of Fashion \& Apparel Studies offers a graduate certificate "that addresses labour and environmental problems in the global supply chains for the apparel, textile, and footwear industries. (Ditty 2012). And describes their focus as: "How apparel, textile, and footwear businesses address the "Global Compact" principles for human rights, labour standards, and environmental stewardship and how they can more effectively address them in the future" (2012). The program is interesting in it is offered completely online, a good solution for industry professionals who wish to re-train, and as it is a grad certificate, students will bring with them the maturity needed to manage an entirely online learning environment. According to their website they offer a graduate certificate in Socially Responsible and Sustainable Apparel Business in the Department of Fashion \& Apparel Studies that: "...Addresses labor and environmental problems in the global supply chains for the apparel, textile, and footwear industries. The certificate is comprised of nine, one-credit courses that are offered through the Internet". Their objectives are to provide foundational knowledge necessary for: "...Managing international production and sourcing design, product development, buying, promotion, sourcing, and production of apparel, textiles, and footwear in ways that are socially responsible and sustainable". They identify the: "...Competencies and skills embedded in the courses are based on research with industry leaders and professionals who lead non-governmental organizations and civil society groups with a stake in the global apparel business." And the basis for curriculum generation are the principles United Nations (UN) Global Compact, a "...Voluntary international initiative bringing together companies, labor and civil society groups, and various UN agencies in support of human rights, labor, and the environment." They have created the following program outcomes that students must master before graduating the program:

Evaluate how apparel, textile, and footwear businesses address the "Global Compact" principles for human rights, labor standards, and environmental stewardship and how they can more effectively address them in the future.

Analyze the moral and ethical responsibility of business and individuals toward human rights labor standards, and environmental stewardship, and

Recommend various strategies for effecting change in the industries (UDEL website).

Winchester School of Art - BA (Hons) Fashion \& Textile Design. Key researchers and lecturers: Zoë Olivia John, Founder of Engage by Design; Emanuelle Dirix, expert in fashion history and freelance curator." and focus: "Provenance and the subjects of sustainability, the value of cultural diversity and social responsibility of design and creative practice (Ditty 2012). "As part of the BA in Fashion \& Textiles, Winchester offers a module called Introduction to Responsible Design, which engages with ethical issues and the broader concept of environmental responsibility. The programme specialises in design of knitwear, woven and printed textiles using state-of-the-art technology" (Ditty 2012).

\section{ApPendix 3: Declarations, Organizations, UNESCO CHAIRS AND UN ORGANIZATIONS FOR ETHICAL FASHION}

"To be transformative, higher education must transform itself." 
Key Principle: International Association of Universities, Higher Education Treaty for Rio+20 (Wals 2014: 12).

\section{Certification, Standardization and Institutional Change}

Even if the will is there, concrete guidance for creating and incorporating sustainability curriculum into existing programming is not there to support it at this time: "Though learning outcomes have been described with eloquence and precision, practical direction for implementation and assessment is currently lacking (Forum for the Future 2004; Landorf et al. 2008; Rode and Michelsen 2008; Svanström et al. 2008)" (Armstrong \& LeHew 2014: 63). This does not mean however that institutional goals need be left out of the progressive reformation of the fashion academic landscape. It was with this big-picture goal in mind that the International Textile and Apparel Association (ITAA) ${ }^{14}$ created a series of learning outcomes for four-year college and university textile and apparel programs: "to develop creative, knowledgeable, and effective professionals who are able to contribute to organizations in the global textile and apparel complex and to society, and who are able to continue to grow personally and professionally following graduation". Pursuant to this, the committee included four metagoals that specifically address sustainability:

1). Understand how aesthetics and the design process can support quality of life, social responsibility, and sustainability

2). Identify and evaluate issues of social responsibility, professional behavior, and ethics related to the impact of individual, organizational, and corporate decision making.

3). Analyze and evaluate issues related to environmental sustainability and environmental impact as they relate to industry activities and processes.

4). Identify and understand social, cultural, economic, technological, ethical, political, educational, language, and individual influences on industry issues (ITAA 2008: n.p.).

Lack of a common discursive framework is a hurdle for curriculum creation and implementation. Other areas of design and manufacturing have industry-wide standards: LEED for architecture, and in Europe there is REACH for chemicals use, and WEEE for electronics recycling (De Brito et al 2008: 4). There are also International organizations like the Organization for Economic Co-operation and Development (OECD), the European Environmental Agency (EEA), and the United Nations Environment Program (UNEP), but they do not have fashion-specific initiatives at this time.

Sustainability trailblazer, and Acting Associate Dean, School of Art and Design, Fashion Institute of Technology: Sass Brown comments on the lack of cohesive industry structure around sustainability.

No, we don't have anything in fashion, do we? Like in that way architects have all sorts of accreditations and boards and oversight but fashion doesn't have any of that...there's lots of certifications whether it's for fur dying... AZO free for dyes, whether it's fair trade

\footnotetext{
${ }^{14}$ ITAA: The International Textile and Apparel Association, described on their website as: "ITAA is a professional, educational association composed of scholars, educators, and students in the textile, apparel, and merchandising disciplines in higher education. ITAA welcomes professionals employed in those fields who wish to join with members of the Association in the pursuit of knowledge, interchange of ideas, and dissemination of knowledge through meetings, special events, and publications." and their work : "promotes the discovery, dissemination, and application of knowledge and is a primary resource for its members in strengthening leadership and service to society."
} 
labeling, etcetera...there are certifications but there's not an oversight as in architecture. It's a different industry, completely (Brown, 2015).

And here a comparison can be drawn to the discipline of architectural preservation during its formative years. The Acting Chair of Sustainable Interior Environments at Fashion Institute of Technology Barbara Campagna comments on this:

...(Sustainability Pedagogy is...) similar to where the preservation world was with academia about thirty years ago....All these different schools over the country, all over the world were creating preservation schools with no guidelines. Everybody had a different thing and that's what's happening right now with sustainability. And then eventually the preservation schools got together and created a kind of review agency for themselves and created guidelines for creating preservation programs" (Campagna, 2015).

LEED certification and EPA ${ }^{15}$ laws have forced curricular evolution in Interior design in the United States and it is there we can look for solutions as it is a similar discipline, but has better industry-wide vigilance and oversight.

As mentioned earlier, the lack of a clear sustainability lexicon clearly is a problem in fashion. A logical next step in the evolution of Sustainability pedagogy is that it be given a more precise definition perhaps through the work of an organization like The International Foundation of Fashion Technology Institutes ${ }^{16}$ (IFFTI) or ITAA. A review committee could be formed to set parameters and define terms, lending support to educators who are facing pressures both internally and externally when trying to implement change. Providing clear language with which progressive educators can frame and strengthen their arguments.

\section{Sustainability Declarations in Higher Education}

The potential for educational institutions and the classroom as a site for sustainability advocacy has been identified, debated and theorized about. Proposals for reform have been created by large-scale initiatives and international conferences.

In "The Evolution of Sustainability Declarations in Higher Education" Wright summarizes the key themes of the Sustainable Higher Education (SHE) declarations from the 1970's until the early 2000's:

...The ethical and moral responsibility of the university to contribute to local, regional and global sustainability; the need for public outreach and universities to become models of sustainability; the need for public outreach and universities to become models of sustainability in their own communities; encouraging sustainable physical operations; fostering ecological literacy; the development of interdisciplinary curriculum; encouraging research related to sustainability; forging partnerships with government, nongovernmental organizations and industry; and cooperation amongst universities (Wright 2004: 18)

\footnotetext{
${ }^{15}$ LEED (Leadership in Energy and Environmental Design) is an internationally recognized green building certification system, providing third-party verification that a building or community was designed and built using strategies aimed at improving performance across all the metrics that matter most: energy savings, water efficiency, $\mathrm{CO} 2$ emissions reduction, improved indoor environmental quality, and stewardship of resources and sensitivity to their impacts. http://www.bu.edu/sustainability/what-were-doing/green-buildings/leed/ EPA: The EPA is an agency of the United States federal government whose mission is to protect human and environmental health. Headquartered in Washington, D.C., the EPA is responsible for conducting environmental assessment, research and education to create and enforce standards and laws that will promote the health of individuals and the environment. http://www.investopedia.com/terms/e/environmental-protection-agency.asp

${ }^{16}$ The International Foundation of Fashion Technology Institutes (IFTTI) is an international association of leading higher education institutiona dedicated to promoting excellence in teaching and learning in fashion and fashion related programs. http://www.iffti.com/home.html
} 
The notion of educational reform and potential advocacy has been an ongoing component of sustainability initiatives globally. Notable ones are the: Halifax, Talloires, Tbilisi and the Kyoto Declarations all of which contained Higher Education Institution (HE) criteria related to Sustainable Development (SD).

In 2002 the United Nations (UN) General Assembly adopted Resolution 57/254 that declared the time period 2005-2014 the Decade of Education for Sustainable Development (DESD) (Wals 2014: 8). The DESD website defines education for sustainable development (ESD) as the following:

\begin{abstract}
Education for Sustainable Development means including key sustainable development issues into teaching and learning; for example, climate change, disaster risk reduction, biodiversity, poverty reduction, and sustainable consumption. It also requires participatory teaching and learning methods that motivate and empower learners to change their behaviour and take action for sustainable development. Education for Sustainable Development consequently promotes competencies like critical thinking, imagining future scenarios and making decisions in a collaborative way (n.p. n.d.).
\end{abstract}

What ESD actually entails is "...A learning process (or a teaching - training approach) based on the ideals and principles that underlie sustainability and is concerned with all levels and types of education (Wals, 2009)" (Karatzoglou 2013: 45). The role of Universities and ESD to tackling the issues include:

A change in the Universities' own management practices, for instance their involvement in recycling schemes, energy efficiency initiatives, or the implementation of an environmental management system (EMS);

Promotion of integration, synthesis, critical reasoning, and system-thinking skills, supporting students and researchers beyond skill development to cope with the future multi-disciplinary complex challenges of sustainability;

The assumption of a leading role in coordinating, promoting, and enhancing the engagement of local authorities and other societal stakeholders to design and implement regional sustainability plans by acting as sources of technical expertise; and

A new research and teaching agenda for Universities as centers of development of the sustainability science as an innovative scientific field defined by the problems it addresses (Karatzoglou 2013: 45).

There is also Agenda 21 from the Rio Declaration on Environment and Development which: "...Addressed the potential of the scientific and the technological community to make an effective contribution to the decision-making processes concerning environment and development and stressed the role of academia in such an effort" (Zilahy and Huisingh in Karatzoglou 2013: 44).

An oversight in many of these declarations is their absence of fashion-specific criteria. Given the massive impact of the industry there should be more specific content directly applicable to the fashion sector.

\title{
United Nations: Higher Education Sustainability Initiative
}

The largest higher education sustainability initiative is the Higher Education Sustainability Initiative (HESI). According to the HESI website, it was originally created as a partnership of UN entities: (UNESCO, UN-DESA, UNEP, Global Compact, and UNU) during the "runup to the United Nations Conference on Sustainable Development (Rio+20)". With a membership totaling nearly 300 colleges and universities globally: "HESI accounts for more than one-third of all the voluntary commitments that came out of Rio +20". HE (higher education) institutions made a commitment to incorporate the following four 
principles institutionally:

1) Teach sustainable development concepts, ensuring that they form a part of the core curriculum across all disciplines.

2) Encourage research on sustainable development issues, to improve scientific understanding through exchanges of scientific and technological knowledge.

3) Green their campuses by: i) reducing the environmental footprint; ii) adopting sustainable procurement practices; iii) providing sustainable mobility options for students and faculty; iv) adopting effective programmes for waste minimization, recycling and reuse, and $v$ ) encouraging more sustainable lifestyles.

4) Support sustainability efforts in the communities in which they reside (HESI 2015: n.p.).

With the following deliverables:

1) Sustainability programs of many cities and towns enhanced through cooperation with technical expertise at local universities. 1 Jun 2015

2) Numerous technological innovations shared with academic and scientific institutions around the world for knowledge sharing, and new partnerships formed with private sector for commercialization and diffusion of new technologies 1 Jun 2015

3) Hundreds of university campuses with resource efficient buildings, sustainable transport options, and green supply chains 1 Jun 2015

4) Thousands of university students across multiple disciplines with knowledge of sustainability concepts that can be applied in the marketplace and in living more sustainable lifestyles (HESI 2015: n.p.).

How they plan to achieve these goals is to have the university presidents, chancellors and deans "who are signatories to this initiative", implement the "sustainability strategies and implementation plans at their respective institutions of higher education" with the implementation "monitored through reporting to the various higher education networks of UN Academic Impact, UNEP, UNESCO, UN Global Compact, UN-PRME and UNU. (HESI 2015: n.p.)

\section{UNESCO CHAIRS}

Learning for sustainable development enables everyone to get back into complex and changing society by appropriating the mechanisms of thought and action, allowing it to understand the interactions between the local and the global perspective of the consumerist approach, based on our materialistic society and to envisage a lifestyle grounded on ethical conduct involving equality and solidarity.

UNESCO ESD Chair, Michel Ricard, France (Wals 2014: 12)

Set up for the promotion of ESD, the UITWIN/UNESCO Chairs Programme was: "...Conceived as a way to advance research training and programme development in higher education by building inter-University cooperation through the transfer of knowledge across borders" (Wals 2014: 12). The program has established 626 UNESCO Chairs and 60 UNITWIN Networks, involving over 740 institutions in 125 Countries" (2014: 12). There are currently eight UNESCO Chairs and one UNITWIN Network focusing on education for SD. UNESCO ESD Chairs each occupy niches and co- ordinate networks within those niches, some more nationally, others more internationally, some working more as individual chairs, some more as a community of practice. As such they contribute 
to the advancement of the conceptualization, research, practice, and, indeed, critique of ESD and the systems in which ESD is to evolve.

A particular niche that resonates well with those seeking to make education in general more competence-based is the work done by UNESCO Chairs and UN-bodies such as UNECE on sustainability competence. This work supports HEls who are seeking to understand and develop such competence (Table 3 ) in all both within and outside the higher education community through their courses, professional development programmes, community outreach activities, and post-initial education and training in both the public and private sector. Some initiatives can be observed where universities are providing resources for members of the wider university community who can be considered SD-change agents and for those who wish to pursue careers in ESD within or outside the university structure. With respect to the use of the concept of ESD competence the latest UNECE evaluation of the implementation of the ESD Strategy.

\section{Principles for Responsible Management Education (PRME)}

PRME is a: "...Global call to embed business education in international values such as those portrayed in the Global Compact framework on Human Rights, Labour, AntiCorruption and the Environment" (Alcaraz and Thiruvattal 2010: 543). Described by Alcaraz and Thiruvattal in "An Interview with Manuel Escudero The United Nations' Principles for Responsible Management Education: a Global Call for Sustainability" As follows:

The PRME initiative is to a large extent the result of efforts by the UN, AACSB International, EFMD, efforts by the UN, AACSB International, EFMD, the Aspen Institute's Business and Society Program, EABIS, GMAC, GRLI, and Net Impact. These institutions have conducted some of the major learning and educational initiatives on responsible management worldwide. The PRME project consolidates and gives new momentum to this joint initiative, framing it within international values such as those portrayed in the United Nations' Global Compact (Alcaraz and Thiruvattal 2010: 543).

And focus on the need to promote the "international values" of: human rights, labour, environment, and anti-corruption (2010: 543). The six Principles for Responsible Management Education have been created from these values:

- Develop the capabilities of students to be future generators of sustainable value for business and society at large and to work for an inclusive and sustainable global economy.

- Incorporate into our academic activities and curricula the values of global social responsibility as portrayed in international initiatives such as the United Nations Global Compact.

- Create educational frameworks, materials, processes and environments that enable effective learning experiences for responsible leadership.

- Engage in conceptual and empirical research that advances our understanding about the role, dynamics, and impact of corporations in the creation of sustainable social, environmental, and economic value.

- Interact with managers of business corporations to extend our knowledge of their challenges in meeting social and environmental responsibilities and to explore jointly effective approaches to meet these challenges.

- Facilitate and support dialog and debate among educators, business, government, consumers, media, civil society organizations, and other interested groups and stakeholders on critical issues related to global social responsibility and sustainability. 
(Alcaraz and Thiruvattal 2010: 543)

These have great potential value for the generation of fashion business projects or course/ program outcomes.

\section{EXAMPLES OF UNESCO ESD CHAIRS}

UNESCO Chair in Reorienting Teacher Education towards Sustainability. Established 1999, York University (Canada). Objectives:

-To take leadership in developing an international pilot network among existing teacher training institutions around the world, and facilitating and coordinating its work.

-To reorient teacher education towards sustainability, using an agreed upon common framework allowing for comparison of results; and

-To gain practical experience and insights that can be articulated in the form of guidelines to reorient teacher education towards sustainability.

UNESCO Chair in Higher Education for Sustainable Development. Established 2005, University of Lüneburg (Germany). Objectives:

-To promote an integrated system of research, training, information and documentation in thefields of sustainability for university education and its implementation in research and education;

-To help facilitate collaboration between high-level, internationally recognized researchers and teaching staff of the University and other institutions in Germany and elsewhere in Europe, and in other regions of the world;

-To help bring forward the concepts of inter/transdisciplinary education and research, to counterbalance disciplinary approaches which are equally needed to achieve sustainability; and

-To stimulate international debate about the meaning of sustainability as a paradigm for higher education institutions.

UNESCO Chair in Research and Education for Sustainable Development. Established 2007, Okayama University (Japan). Objectives:

-To develop the human resources needed for the creation of a sustainable society, through research and education for sustainable development.

-To foster the training and development of experts who will work to realize a sustainable society at the local level, as well as experts who will work in the international arena and contribute to the creation of a sustainable society at the global level.

-To reorient the curriculum of Okayama University so as to contribute the creation of a sustainable society locally, nationally, regionally and globally; and,

-To transfer technology and knowledge on environmental conservation to developing countries through inter-university cooperation.

UNESCO Chair on Community Based Research \& Social Responsibility in Higher Education. Established 2012, PRIA, India \& University of Victoria, Canada. Objectives: 
-Provide a space for encounter of these multiple experiences and practices in the context of CBR\&SR across institutions and actors.

-Amplify the voices of practitioners of community based research and social responsibility for policy dialogues, development and reforms.

-Support multiplication and scaling-up of capacity enhancement of actors inside and outside the institutions of higher education.

UNESCO Chair on Education for Sustainable Development and the Earth Charter. Established 2012, Earth Charter Centre on ESD and University of Peace, Costa Rica. Objectives:

-To promote transformative education experiences that cultivate the fundamental values and ethical vision necessary to move towards a more sustainable world (Wals 2014: 12)

\title{
ETHICAL FASHION INITIATIVE
}

Although not specifically addressed at fashion education, the Ethical Fashion Initiative of the United Nations focuses on social justice within the fashion sector. Based in Geneva, the EFI has operations globally. It has conducted training and is exploring using pedagogical outreach and curricular knowledge exchange as a form of social justice aid (Teklu 2016).

\section{Appendix 4: Campus Greening Versus Curriculum INTEGRATION \\ Campus Greening versus Curriculum Integration}

Unfortunately: "Relative to the transition to sustainability, institutions of higher education are underachievers" (Orr 2002: 80). At a campus level the green initiatives at an operational level far outweigh the examples of curricular innovation. As Timmerman and Metcalfe say in "From Policy to Pedagogy: The Implications of Sustainability Policy for Sustainability Pedagogy in Higher Education":

\begin{abstract}
Although universities have often had success in implementing sustainability policies in the area of operations (e.g., building codes and energy usage), implementation has proved to be much more difficult in the processes of teaching and learning (i.e., pedagogy) (Timmerman and Metcalfe 2009: 46).
\end{abstract}

Armstrong and LeHew comment on the widening gap between campus green reforms and pedagogical evolution:

A movement supported by the United Nations, education for sustainable development (ESD), has advocated for the holistic integration of sustainability in all higher education disciplines in an effort titled, The Decade for Education for Sustainable Development (DESD) (2005-14) (UNESCO 2003, 2005). Campus greening and research has flourished while pedagogical innovation and curriculum redevelopment have lagged behind (Sterling and Scott 2008)." (Armstrong and LeHew, 2014: 61)

Saveleyeva in "Campus Sustainability: Emerging Curricula Models in Higher Education" contrasts the concept of campus greening with ethical standards at a philosophical level:

Greening campuses implies infusing environmentally friendly practices in all dimensions of university operations and infrastructure. EfS refers to the set of ethical standards for academia to become sustainable (Savelyeva, 2011:65). 
She elaborates further on this idea of EfS as a driver of systemic change:

Campus greening initiatives influence the curricula by creating an ecologically sensitive academic environment and establishing a result-oriented culture of a sustainable action. They exemplify sustainability efforts and provide visions of innovation and technological advances that can be reflected in a curriculum. At the same time, the underlying knowledge of sustainability still remains vibrant within a small disciplinary circle, finding its application through the sustainability courses and the EfS capacity building workshops for faculty (2011:65).

Orr questions what effects an incorporation of sustainable principles would have on an institution and how institutions can re-educate themselves regarding the possibilities:

The question, then, is whether the institutions that purport to advance learning can themselves learn new ways appropriate for an ecological era. What would it mean for the ecological idea to take root in colleges and universities? It would mean, for one thing, that such institutions would have to become learning organizations in order to reinvent themselves. This requires rethinking institutional purposes and procedures at a higher level of generality (Orr 2002: 80-81).

Therefore, the goals should be for widening the pedagogical outreach of sustainability, so that the curricula can match the progressive sustainability initiatives enacted on the institutional level. As in other sectors, institutionally, fashion education is not where it needs to be in regards to sustainability content implementation.

\section{APPENDIX 5: INTERVIEW QUESTIONS}

1. How do you define sustainability?

2. How are you incorporating sustainability issues into your curriculum?

3. Have you had to remove content to accommodate new content on sustainability? If so, what was added and deleted?

4. How is the binary between business content and creative content handled within your curriculum?

5. Where do you feel the field of fashion and design education is evolving in regards to sustainability?

6. Can you identify some changes in the industry that you have had to incorporate into your curriculum?

7. Approximately what is the percentage of your curriculum apportioned between: creative exploration, applied design skills, business content, history, and visual culture/theory?

8. How are issues around ethics and social responsibility addressed in your curriculum?

9. What do you do in your teaching practice that connects you to your students?

10. What are the challenges you face in delivering your information to students?

11. Where do you get the information that is used to develop curriculum?

12. What are your teaching resources/ books, sites that you feel are the most useful? 
13. Are there any theorists that you have been inspired by?

14. Do you have a philosophy in relation to sustainability?

15. Is there anything you would like to add that I haven't asked?

\section{APPENDIX 6: ETHICS REVIEW}

\section{RYERSON UNIVERSITY}

Ryerson University Consent Agreement

You are being invited to participate in a research study. Please read this consent form so that you understand what your participation will involve. Before you consent to participate, please ask any questions to be sure you understand what your participation will involve

Name of Paper: Educators in Sustainable Design

INVESTIGATORS: INVESTIGATORS: This research study is being conducted by Mark O'Connell, (Supervisor: Dr. Lu Ann LaFrenz) from the MA Fashion Theory program, at Ryerson University.

If you have any questions or concerns about the research, please feel free to contact: Mark O'Connell (mark.oconnell@ryerson.ca)

PURPOSE OF THE STUDY: This paper is designed to as an examination of the teaching practices of educators in the area of sustainability as it relates to the fashion sector. This research will contribute to the knowledge base for my MRP, which relates to educational pedagogy as it relates to fashion. It also may be submitted for publication or presented at conferences.

WHAT YOU WILL BE ASKED TO DO: If you volunteer to participate in this study, you will be asked to do the following things:

Participants will be interviewed for the duration of approximately one hour. Interview questions will be provided to the participants before the scheduled interview. Participants will also be asked to bring curriculum samples that will aid in defining their philosophy and educational strategies. Participants can have access to the research findings at any time. For access to research please e-mail: mark.oconnell@ryerson.ca

You may be identified by name in the final paper

POTENTIAL BENEFITS: Potential benefits are the wider dissemination of curricular exemplars, and contributions to critical pedagogy as it relates to sustainability in fashion education, so that it may be incorporated into existing curriculums and into program wide initiatives to raise awareness around sustainability.

I cannot guarantee, however, that you will receive any benefits from participating in this study 
WHAT ARE THE POTENTIAL RISKS TO YOU AS A PARTICIPANT Potential risks of being involved with this study are being misquoted, or having your views on teaching in sustainability misrepresented. In order to alleviate this risk participants will have access to the final draft before publication, may withdraw at any time, and may refuse to answer any questions.

CONFIDENTIALITY: Interviews will be audio recorded and the files will be kept on a password-protected computer in my home office. No one other than myself, and my MA advisor: Dr. LuAnn LaFrenz will review the recordings. The recordings will be deleted after completion of the paper June 2016. A written transcript of the interview may be included as an appendix of the final paper.

COSTS TO PARTICIPATION: There are no costs to participate in this study

Compensation for Injury:

By agreeing to participate in this research, you are not giving up or waiving any legal right in the event that you are harmed during the research.

VOLUNTARY PARTICIPATION AND WITHDRAWAL: Participation in this study is completely voluntary. You can choose whether to be in this study or not. If any question makes you uncomfortable, you can skip that question. You may also choose to not have your data included in the study. Your choice of whether or not to participate will not influence your future relations with Ryerson University, Seneca College, or the investigator: Mark O'Connell involved in the research.

QUESTIONS ABOUT THE STUDY: If you have any questions about the research now, please ask. If you have questions later about the research, you may contact: Mark O'Connell mark.oconnell@ryerson.ca

This study has been reviewed by the Ryerson University Research Ethics Board. If you have questions regarding your rights as a participant in this study please contact:

Research Ethics Board

c/o Office of the Vice President, Research and Innovation

Ryerson University

350 Victoria Street

Toronto, ON M5B 2K3

416-979-5042

rebchair@ryerson.ca

Name of Paper: Educators in Sustainable Fashion

\section{CONFIRMATION OF AGREEMENT:}

Your signature below indicates that you have read the information in this agreement and have had a chance to ask any questions you have about the study. Your signature also indicates that you agree to participate in the study and have been told that you can change your mind and withdraw your consent to participate at any time. You have been 
given a copy of this agreement.

You have been told that by signing this consent agreement you are not giving up any of your legal rights.

Name of Participant (please print)

Signature of Participant

Date

I agree to be audio recorded for the purposes of this study. I understand how these recordings will be stored and destroyed.

Signature of Participant

Date

\section{BIBLIOGRAPHY}

Achillas, Ch, D. Aidonis, Ch Vlachokostas, Dimitris Folinas, and Nicolas Moussiopoulos. "Re-designing Industrial Products on a Multi-objective Basis: a Case Study." Journal of the Operational Research Society 64, no. 9 (2012): 1336-1346. >>>>

Allwood, Julian. M., Søren E. Laursen, S. N. Russell, C. Malvido de Rodríguez, and Nancy. M. P. Bocken. "An Approach to Scenario Analysis of the Sustainability of an Industrial Sector Applied to Clothing and Textiles in the UK". Journal of Cleaner Production 16 (12) 2008: 1234-46.>>>>

Allwood, Julian M., Søren E. Laursen, C. Malvido de Rodriguez, and Nancy MP Bocken. "Well Dressed? The Present and Future Sustainability of Clothing and Textiles in the United Kingdom." The Present (2006). >>>>

Allwood, Julian M., Michael F. Ashby, Timothy G. Gutowski, and Ernst Worrell.. Material efficiency: A White Paper. Resources, Conservation \& Recycling 55 (3) 2011: 36281. >>>science

Alcaraz, Jose M., and Eappen Thiruvattal. "An Interview with Manuel Escudero The United Nations' Principles for Responsible Management Education: a Global Call 
for Sustainability." Academy of Management Learning \& Education 9, no. 3 (2010): 542-550.

Appel, Geertje, Irene Dankelman, and Kirsten Kuipers. "Disciplinary Explorations of Sustainable Development in Higher Education." In Higher Education and the Challenge of Sustainability. Springer Netherlands, (2004): 213-222.

Armstrong, Cosette, and Melody LeHew. "Barriers and Mechanisms for the Integration of Sustainability in Textile and Apparel Education: Stories from the Front Line." Fashion Practice: The Journal of Design, Creative Process \& the Fashion Industry 6, no. 1 (2014): 59-86.

. "Sustainable Apparel Product Development: In Search of a New Dominant Social Paradigm for the Field using Sustainable Approaches." Fashion Practice 3, no. 1 (2011): 29-62. >>>>

Barber, Elizabeth Wayland. The Mummies of Ürümchi. WW Norton \& Company, 2000. Women's Work: The First 20,000 Years Women, Cloth, and Society in Early Times. WW Norton \& Company, 1995.

Barnes, Liz, and Gaynor Lea-Greenwood. "Fast Fashioning the Supply Chain: Shaping the Research Agenda." Journal of Fashion Marketing and Management: An International Journal 10, no. 3 (2006): 259-271.>>>>

Barnard, Malcolm. Fashion as Communication. Psychology Press, 2002.

Barth, Matthias, and Marco Rieckmann. "Academic Staff Development as a Catalyst for Curriculum Change Towards Education for Sustainable Development: an Output Perspective." Journal of Cleaner Production 26 (2012): 28-36.

Bates Rebecca. "Maira Kalman Compresses Time at the Cooper Hewitt Museum" Vice Magazine. May 2015, accessed May 26, 2015: http://www.vice.com/read/artistmaira-kalman-compresses-time-at-the-cooper-hewitt-museum-345

Beard, Nathaniel Dafydd. "The Branding of Ethical Fashion and the Consumer: a Luxury Niche or Mass-Market Reality?." Fashion Theory 12, no. 4 (2008): 447-467.

Benyus, Janine M. Biomimicry. New York: William Morrow, 1997. >>>> 
Bhardwaj, Vertica, and Ann Fairhurst. "Fast Fashion: Response to Changes in the Fashion Industry." The International Review of Retail, Distribution and Consumer Research 20, no. 1 (2010): 165-173.

Black, Sandy. Eco Chic: The Fashion Paradox. London: Black Dog Publishing. 2008.

Black, Sandy, ed. The Sustainable Fashion Handbook. Thames \& Hudson, 2013.

Bonnett, Michael. 2006. Education for Sustainability as a Frame of Mind: Reprinted from Environmental Education Research (2002) 8(1), pp. Environmental Education Research 12 (3):.[2002] 2006: 265-276

Boman, Johan, and Ulf P. Andersson. "Eco-labelling of Courses and Programs at University of Gothenburg." Journal of Cleaner Production 48 (2013): 48-53.

Botanica Tinctoria. Website. Accessed on March 1, 2016. http://www.botanicatinctoria.com/pages/about-us

Breward, Christopher. The Culture of Fashion. Vol. 1. Manchester University Press, 1995.

Brown, Sass, and Valerie Steele. Eco fashion. London: Laurence King, 2010. Interview by author. Audio interview. FIT, Thurs. May. 14, 2015.

Brundtland Commission. Accessed on Jan. 25. 2016. https://en.wikipedia.org/wiki/Brundtland Commission,

Brundtland, Gro Harlem. "Our Common Future: World Commission on Environmental Development." The Brundtland-Report Oxford University Press, Oxford, UK (1987).

Burke, Jason. "Bangladesh Factory Collapse Leaves Trail of Shattered Lives." The Guardian 6 (2013).

Burke, Tarah. Interview by author. Audio interview. Ryerson University, Wed. Mar. 18, 2015.

California College of Arts. Accessed on: Jan. 23, 2016 https://www.cca.edu/ . CCA MBA Design Strategy. website: https://www.cca.edu/academics/graduate/strategy-mba. Accessed Jan. 19

Campagna, Barbara. Interview by author. Audio interview. FIT, Wed. May. 13, 2015. Caradonna, Jeremy L. 2014. Sustainability: A History. Oxford University Press. 2014. 
Central St. Martins, Material Futures Program. Accessed Jan. 19, 2016.

http://www.arts.ac.uk/csm/courses/postgraduate/ma-material-futures.

_. http://www.arts.ac.uk/research/researching-at-ual/research-infrastructure/researchgroups-networks-and-collaborations/textiles-environment-design/

. TED http://www.tedresearch.net/Cortese, Anthony D., and Amy Seif Hattan. "Research and Solutions: Education for Sustainability as the Mission of Higher Education." Sustainability: The Journal of Record 3, no. 1 (2010): 48-52.

Caradonna, Jeremy L. Sustainability: A History. Oxford University Press, 2014.

Caniato, Federico, Maria Caridi, Luca Crippa, and Antonella Moretto. "Environmental Sustainability in Fashion Supply Chains: An Exploratory Case Based Research." International journal of production economics 135, no. 2 (2012): 659-670.

Centre for Sustainable Fashion (London College of Fashion). Accessed Jan. 19, 2016http://sustainable-fashion.com/.

Choi, Tsan-Ming. Fashion Supply Chain Management: Industry and Business Analysis Business Science Reference. 2012.

Choi, Tsan-Ming. Fast Fashion Systems: Theories and Applications. Vol. 4.; 4;CRC Press Balkema. 2014

Chitrakorn, Kati. "Under New Direction Parsons puts Sustainability First". Business of Fashion. August 26, 2015. Accessed Jan. 19, 2016.http://www.businessoffashion.com/articles/education/under-new-directionparsons-puts-sustainability-first.

Collins, Jane L. Threads: Gender, Labor, and Power in the Global Apparel Industry. University of Chicago Press, 2009. >>>

Comaroff, John L., and Jean Comaroff. "Fashioning the Colonial Subject." Of Revelation and Revolution 2: (1997) 218-73.

Corcoran, Peter Blaze, and Arjen EJ Wals. eds. Higher Education and the Challenge of Sustainability. Dordrecht: Kluwer Academic Publishers. 10 (2004)

Cortese, Anthony D. "The Critical Role of Higher Education in Creating a Sustainable Future." Planning for Higher Education 31, no. 3 (2003): 15-22. 
Cortese, Anthony D., and Amy Seif Hattan. "Research and Solutions: Education for Sustainability as the Mission of Higher Education." Sustainability: The Journal of Record 3, no. 1 (2010): 48-52.

Cotton D, Bailey I, Warren M, Bissell S. "Revolutions and Second-best Solutions: Education for Sustainable Development in Higher Education". Studies in Higher Education. 34 (7) 2009:719-33.

Cao, Huantian, Lisa Vogel Frey, Cheryl A. Farr, and Haejin Gam. "An Environmental Sustainability Course for Design and Merchandising Students." Journal of Family and Consumer Sciences 98, no. 2 (2006): 75.

Craik, Jennifer. The face of Fashion: Cultural Studies in Fashion. Routledge, 2003.

Crane, Diana. Fashion and its Social Agendas: Class, Gender, and Identity in Clothing. University of Chicago Press, 2012.

Curwen, Lisa G., Juyeon Park, and Ajoy K. Sarkar. "Challenges and Solutions of Sustainable Apparel Product Development A Case Study of Eileen Fisher." Clothing and Textiles Research Journal 31, no. 1 (2013): 32-47.

Davis, Mary. Interview by author. Audio interview. FIT, Wed. May. 29, 2015.

De Brito, Marisa P., Valentina Carbone, and Corinne Meunier Blanquart. "Towards a Sustainable Fashion Retail Supply Chain in Europe: Organisation and Performance". International Journal of Production Economics, 114(2) (2008): 534553.

Declaration of the Decade of Education for Sustainable Development (DESD). Accessed March 2, 2016. http://www.unesco.org/new/en/education/themes/leading-theinternational-agenda/education-for-sustainable-development/

Designskolen kolding. Accessed on: Jan. 23, 2016. https://www.designskolenkolding.dk/en/ba-programme-tongji-university-radicalinnovation-and-sustainability-fashion-industry.

Dickson, Marsha A. "Personal Values, Beliefs, Knowledge, and Attitudes Relating to Intentions to Purchase Apparel from Socially Responsible Businesses." Clothing and Textiles Research Journal 18, no. 1 (2000): 19-30. 
. "US Consumers' Knowledge of and Concern with Apparel Sweatshops." Journal of Fashion Marketing and Management: An International Journal 3, no. 1 (1999): 4455.

Dickson, Marsha A., Molly Eckman, Suzanne Loker, and Charlotte Jirousek. "A Model for Sustainability Education in Support of the PRME." Journal of Management Development 32 (3) (2013): 309-318. doi:10.1108/02621711311318337. http://resolver.scholarsportal.info/resolve/02621711/v32i0003/309 amfseisotp.

Dickson, Marsha Ann, Molly Jean Eckman, and Suzanne Loker. Social Responsibility in the Global Apparel Industry. Fairchild Books (2009).

Dickson, Marsha A., and Rita K. Chang. "Apparel Manufacturers and the Business Case for Social Sustainability: 'World Class' CSR and Business Model Innovation". The Journal of Corporate Citizenship (57) 2015: 56.

Dickson, Marsha A., and Molly Eckman. "Social Responsibility: The Concept as Defined by Apparel and Textile Scholars." Clothing and Textiles Research Journal 24, no. 3 (2006): 178-191.

Ditty, Sarah. "Top 10 Sustainable Fashion Programs and Courses", Ethicalfashionforum.com. May 25, 2012, Accessed Jan. 19, 2016

http://source.ethicalfashionforum.com/article/top-10-sustainable-fashion-programmesand-courses.

Downing, Kevin. "Diversity is Prosperity: Globalised Fashion and Higher Education in the Twenty-first Century." International Journal of Fashion Design, Technology and Education 5, no. 3 (2012): 151-151.

Ehrenfeld, John, and Andrew Hoffman. Flourishing: A Frank Conversation about Sustainability. Stanford University Press, 2013.

Ellsworth, Pamela. Interview by author. Audio interview. FIT, Wed. May. 22, 2015.

Entwistle, Joanne. The Fashioned Body. John Wiley \& Sons, 2015.

EPA: Accessed on March 1, 2016. http://www.investopedia.com/terms/e/environmentalprotection-agency.asp

Etzkowitz, Henry. "Innovation in innovation: The triple helix of university-industrygovernment relations." Social science information 42, no. 3 (2003): 293-337. 
Etzkowitz, Henry, and Chunyan Zhou. "Triple Helix Twins: Innovation and Sustainability." Science and Public Policy 33, no. 1 (2006): 77-83.

Etzkowitz, Henry, Marina Ranga, and James Dzisah. "Whither the University? The Novum Trivium and the Transition from Industrial to Knowledge Society." Social Science Information 51, no. 2 (2012): 143-164.

ESMOD (Germany). Accessed Jan. 19, 2016. http://www.esmod.com/en/content/esmodberlin.

Vimeo: Accessed Jan. 19, 2016. https://vimeo.com/45569431

Farrer, Joan, and Kim Fraser. "Sustainable 'v' Unsustainable: Articulating Division in the Fashion Textiles Industry." Anti-po-des Design Research Journal 1, no. 4 (2011): 1 12.

Fletcher, Gordon, Anita Greenhill, Marie Griffiths, and Rachel McLean. "The Social Supply Chain and the Future High Street." Supply Chain Management: An International Journal 21, no. 1 (2016): 78-91.

Fletcher, Kate, Lynda Grose, and Paul Hawken. Fashion \& Sustainability: Design for Change. London: Laurence King, (2012).

Fletcher, Kate. "Not one but Many: New Visions for Fashion." Future Fashion: White Papers (2007): 275-293.

_ _ "Slow Fashion: An Invitation for Systems Change." Fashion Practice 2, no. 2 (2010): 259-265.

__. "Sustainable Fashion." The Handbook of Design for Sustainability (2013): 283.

Freire, Paulo. "Pedagogy of the Oppressed, trans." Myra Bergman Ramos. New York: Continuum (1970)

—_, and Myles Horton. We Make the Road by Walking: Conversations on education and social change. Temple University Press, 1990.

(FIT) Fashion Institute of Technology Website: (http://www.fitnyc.edu/ccps/certificateprograms/noncredit/sustainable-design.php accessed on: Jan. 23, 2016

FIT Data: https://www.fitnyc.edu/1832.asp Library: http://www.fitnyc.edu/8416.asp: 
Library Sustainability Guide: http://fitnyc.libguides.com/sustainabledesign

__ Sustainability Council: http://www.fitnyc.edu/22193.asp

Gam, Hae Jin, and Jennifer Banning. "Addressing Sustainable Apparel Design Challenges with Problem-based Learning." Clothing and Textiles Research Journal 29, no. 3 (2011): 202-215.

Gam, Hae Jin. "Are Fashion-conscious Consumers More Likely to Adopt Eco-friendly Clothing?." Journal of Fashion Marketing and Management: An International Journal 15, no. 2 (2011): 178-193.

Gandhi, Mohandes. "Appeal to the Women of India” Young India. Nov 8, 1929.

Glavič, Peter, and Rebeka Lukman. "Review of Sustainability Terms and their Definitions." Journal of Cleaner Production 15, no. 18 (2007): 1875-1885.

Gray, Christoper. STREETSCAPES/Fashion Institute of Technology; A Smorgasbord Of Architectural Diversity. The New York Times. June 262005. http://query.nytimes.com/gst/fullpage.html?res=9C0DE4DA1F3EF935A15755C0A9 639C8B63. Accessed May 25, 2015.

Greyson, James. "An Economic Instrument for Zero Waste, Economic Growth and Sustainability." Journal of Cleaner Production 15 (13-14) 2007: 1382-1390. doi:10.1016/j.jclepro.2006.07.019. http://resolver.scholarsportal.info/resolve/09596526/v15i13-14/1382 aeifzwegas.

Gwilt, Alison, and Timo Rissanen. Shaping Sustainable fashion: Changing the Way We Make and use Clothes. Routledge, 2011.

Ha-Brookshire, Jung, and Pamela Norum. "Cotton and Sustainability: Impacting Student Learning through Sustainable Cotton Summit." International Journal of Sustainability in Higher Education 12, no. 4 (2011): 369-380

Ha-Brookshire, Jung E., and Jana M. Hawley. "Envisioning the Clothing and TextileRelated Discipline for the 21st Century its Scientific Nature and Domain from the Global Supply Chain Perspective." Clothing and Textiles Research Journal 31, no. 1 (2013): 17-31. >>>>

Hapke, Laura. Sweatshop: the History of an American Idea. Rutgers University Press, 2004. 
Hawken, Paul, Amory B. Lovins, and L. Hunter Lovins. Natural Capitalism: The Next Industrial Revolution. Routledge, 2013.

HESI, United Nations Higher Education Sustainability Initiative. Accessed Feb 23, 2016.https://sustainabledevelopment.un.org/sdinaction/hesi

Hilletofth, Per, and David Eriksson. "Coordinating New Product Development with Supply Chain Management." Industrial Management \& Data Systems 111, no. 2 (2011): 264-281.

Hoffman, Leslie. ed. Future Fashion White Papers. Earth Pledge, 2007.

Hooks, Bell. Teaching to Transgress. Routledge, 2014 Teaching community: A Pedagogy of Hope. Vol. 36. Psychology Press, 2003.

Howarth, George, and Mark Hadfield. "A Sustainable Product Design Model". Materials and Design 27 (10) (2006):1128-33.

Lozano, Rodrigo, Francisco J. Lozano, Karel Mulder, Donald Huisingh, and Tom Waas. "Advancing Higher Education for Sustainable Development: International Insights and Critical Reflections." Journal of Cleaner Production 48 (2013): 3-9.

Hustvedt, Gwendolyn, and John C. Bernard. "Consumer Willingness to Pay for Sustainable Apparel: the Influence of labelling for Fibre Origin and Production Methods." International Journal of Consumer Studies 32, no. 5 (2008): 491-498.

ITAA: The International Textile and Apparel Association. Accessed on Jan 26, 2016.http://itaaonline.org/

Johansson, Glenn, and Erik Sundin. "Lean and Green Product Development: Two Sides of the Same Coin?." Journal of Cleaner Production 85 (2014): 104-121.

Johnson, Kim KP, MiYoung Lee, Dooyoung Choi, Jung Mee Mun, and Nayeon Yoo. "Trends in Research Addressing Fashion and Social Responsibility." Journal of Global Fashion Marketing 4, no. 3 (2013): 145-157.

Jones, Paula, Colin J. Trier, and Jonathan P. Richards. "Embedding Education for Sustainable Development in Higher Education: A Case Study Examining Common Challenges and Opportunities for Undergraduate Programmes." International Journal of Educational Research 47, no. 6 (2008): 341-350. 
Jordan, Elizabeth. "Can We Create a Sustainable Structural Approach to Pedagogy?" (unpublished). (2011).

Joy, Annamma, John F. Sherry Jr, Alladi Venkatesh, Jeff Wang, and Ricky Chan. "Fast Fashion, Sustainability, and the Ethical Appeal of Luxury Brands." Fashion Theory 16 , no. 3 (2012): 273-295.

Jucker, Rolf. "'Sustainability? Never Heard of it!' Some Basics we Shouldn't Ignore When Engaging in Education for Sustainability." International Journal of Sustainability in Higher Education 3, no. 1 (2002): 8-18.

Kaiser, Susan B. Fashion and Cultural Studies. A\&C Black, 2012. . "Minding Appearances: Style, Truth and Subjectivity." Body Dressing (2001): 79-102.

Karatzoglou, Benjamin. "An in-depth Literature Review of the Evolving Roles and Contributions of Universities to Education for Sustainable Development." Journal of Cleaner Production 49 (2013): 44-53.

Kawamura, Yuniya. Fashion-ology: an Introduction to Fashion Studies. Berg, 2004.

Kering. Corporate Website. http://www.kering.com/en/brands. Accessed March 1, 2016

Kevorkian, Kriss. "Environmental Grief: Hope and Healing." PhD Diss., Union Institute and University, Cincinatti, Ohio (2004).

Kim, Hye-Shin, Elaine Pedersen, and Rinn Cloud. "Social Support, Research Interest, Stress, and Research Productivity of Textiles and Apparel Faculty." Clothing and Textiles Research Journal 25, no. 2 (2007): 156-170.

Kim, Hyunsook, Ho Jung Choo, and Namhee Yoon. "The Motivational Drivers of Fast Fashion Avoidance." Journal of Fashion Marketing and Management: An International Journal 17, no. 2 (2013): 243-260.

Kool, Rick, and Elin Kelsey. "Dealing with Despair: The Psychological Implications of Environmental Issues." In Paper presented at the Third World Congress on Environmental Education. 2005.

Krugman, Paul R. Geography and Trade. MIT press, 1991.

Kulatunga, A. K., N. Karunatilake, N. Weerasinghe, and R. K. Ihalawatta. "Sustainable Manufacturing Based Decision Support Model for Product Design and Development process". Procedia CIRP 26 (2015): 87-92. 
LaBat, Karen L., and Susan L. Sokolowski. "A Three-stage Design Process Applied to an Industry-university Textile Product Design Project." Clothing and Textiles Research Journal 17, no. 1 (1999): 11-20.

Lambrechts, Wim, Ingrid Mulà, Kim Ceulemans, Ingrid Molderez, and Veerle Gaeremynck. "The Integration of Competences for Sustainable Development in Higher Education: an Analysis of Bachelor Programs in Management." Journal of Cleaner Production 48 (2013): 65-73.

Landgren, Trudy M., and Anupama Pasricha. "Transforming the Fashion and Apparel Curriculum to Incorporate Sustainability." International Journal of Fashion Design, Technology and Education 4, no. 3 (2011): 187-196.

Lanier Pence, Patricia, Paula Phillips Carson, Kerry D. Carson, J. Brooke Hamilton III, and Betty Birkenmeier. "And All Who Jumped Died: The Triangle Shirtwaist Factory Fire." Management Decision 41, no. 4 (2003): 407-421.

Larsen, Val, and Sweta Chaturvedi Thota. "Truth and Consequences in the Global Village." Academy of Marketing Studies Journal 18, no. 1 (2014): 217.

Garber Jr. Lawrence L., Eva M. Hyatt, and Ünal Ö. Boya. 2009. "The Collaborative Roles of the Designer, the Marketer, and the Consumer in Determining what is Good Design." Advertising \& Society Review 10 (1). 2009: n.p.

Leddy, Shannon. Interview by author. Audio interview. FIT, Wed. May. 27, 2015.

LEED. Accessed on March 1, 2016. http://www.bu.edu/sustainability/what-weredoing/green-buildings/leed/

Leerberg, Malene, Vibeke Riisberg, and Joy Boutrup. "Design Responsibility and Sustainable Design as Reflective Practice: An Educational Challenge." Sustainable Development 18 (5) (2010): 306-317.

Lemire, Beverly. "The Secondhand Clothing Trade in Europe and Beyond: Stages of Development and Enterprise in a Changing Material World, c. 1600-1850." Textile 10, no. 2 (2012): 144-163.

Lidgren, Alexander, Håkan Rodhe, and Don Huisingh. "A Systemic Approach to Incorporate Sustainability into University Courses and Curricula." Journal of Cleaner Production 14, no. 9 (2006): 797-809. 
Lim, Seong-Rin, Yoo Ri Kim, Seung H. Woo, Donghee Park, and Jong Moon Park. "System Optimization for Eco-design by Using Monetization of Environmental Impacts: a Strategy to Convert Bi-objective to Single-Objective Problems." Journal of Cleaner Production 39 (2013): 303-311.

Lin, Yu-Sien. "Fostering Creativity Through Education-A Conceptual Framework of Creative Pedagogy." Creative Education 2, no. 03 (2011): 149.

London College of Fashion. Accessed Jan. 19, 2016

http://www.arts.ac.uk/fashion/courses/graduate-school/ma-fashion-futures/.

. (Centre for Sustainable Fashion). Accessed Jan. 19, 2016. http://sustainablefashion.com/

Lozano, Rodrigo. "Incorporation and Institutionalization of SD into Universities: Breaking Through Barriers to Change." Journal of Cleaner Production 14, no. 9 (2006): 787796.

Louie, Miriam Ching Yoon. Sweatshop Warriors: Immigrant Women Workers Take on the Global Factory. South End Press, 2001.

Luz, Claudio. Waste Couture: Environmental Impact of the Clothing Industry. Environmental Health Perspectives, 115(9), (2007) p.A448.

Manchiraju, Srikant, and Amrut Sadachar. "Personal Values and Ethical Fashion Consumption." Journal of Fashion Marketing and Management 18, no. 3 (2014): 357-374.

Manik, Julifikar \& Najarjune, Nida. "Bangladesh Police Charge 41 With Murder Over Rana Plaza Collapse" New York Times (online edition) May 2, 2015. Accessed on Jan. 24, 2016. http://www.nytimes.com/2015/06/02/world/asia/bangladesh-rana-plazamurder-charges.html? $r=0$.

McCartney, Stella. Interview BoF in Conversation with Stella McCartney. Business of Fashion (Online Edition) March 22, 2015. Accessed March 26, 2015.http://www.businessoffashion.com/articles/video/conversation-stellamccartney-building-sustainable-luxury-brand

McCall, Tyler. "Parsons Hires New Dean of Fashion With Strong Background in Sustainability, Simon Collins's Replacement Has Been Found". Fashionista. April 7, 2015. Accessed Jan. 19, 2016. [Website?] 
McDonough, William, and Michael Braungart. Cradle to Cradle: Remaking the Way we Make Things. MacMillan, 2010.

McEvoy, Arthur F. "The Triangle Shirtwaist Factory Fire of 1911: Social Change, Industrial Accidents, and the Evolution of Common Sense Causality." Law \& Social Inquiry 20, no. 2 (1995): 621-651.

McNeill, Lisa. and Moore, Rebecca. Sustainable Fashion Consumption and the Fast Fashion Conundrum: Fashionable Consumers and Attitudes to Sustainability in Clothing Choice. International Journal of Consumer Studies, doi: 10.1111/ijcs.12169. 39. (2015): 212-222

McRobbie, Angela. British Fashion Design: Rag Trade or Image Industry?. Routledge, [1998] 2003.

Maxfield, Sylvia. "Teaching Economics to Business Students Through the Lens of Corporate Social Responsibility and Sustainability." Journal Of Economic Education 42 , no. 1 (2011): 60-69.

McDonough, William, and Michael Braungart. Cradle to Cradle: Remaking the Way We Make Things. MacMillan, 2010.

McEvoy, Arthur F. "The Triangle Shirtwaist Factory Fire of 1911: Social Change, Industrial Accidents, and the Evolution of Common Sense Causality." Law \& Social Inquiry 20, no. 2 (1995): 621-651.

Mertig, A.G., Dunlap, R.E., and Morrison, D.E., 2002. "The Environmental Movement in the United States." In: R.E. Dunlap and W. Michelson, eds. Handbook of Environmental Sociology. London, UK: Greenwood Press, 448-481. New York, NY: W.W. Norton \& Company.

Mitchell, Lorianne D., and Wesley D. Ramey. "Look how Green I Am! An Individual-level Explanation for Greenwashing." Journal of Applied Business and Economics 12, no. 6 (2011): 40-45.

Niinimäki, Kirsi, and Lotta Hassi. "Emerging Design Strategies in Sustainable Production and Consumption of Textiles and Clothing." Journal of Cleaner Production 19, no. 16 (2011): 1876-1883.

Niinimäki, Kirsi. From Disposable to Sustainable: The Complex Interplay Between Design and Consumption of Textiles and Clothing. Aalto University, 2011. 
Oberlin College. Accessed on March 1, 2016: https://new.oberlin.edu/arts-andsciences/departments/environment/faculty_detail.dot?id=21065Obregón, Caßrolina. "Sustainable Fashion Education: From Trend to Paradigm?" 2012.

O'Connell, Mark. "The Fashion Museum as a Pedagogical Tool". Conference Paper: Fashion Now \& Then. 20-22 Oct., 2015, LIM College, New York, NY.

- "Two Way Street: Transnational Fashion Education as a Model for Equity and Sustainability". Conference Paper: Fourth International Conference on Asian Studies 2016: "Globalization to Asianization - Challenges \& Issues". 11-12 June, 2016, Toronto, Canada.

Ochoa-Ochoa, Leticia Margarita, Sandra Nogué, Rafa Devillamagallón, and Richard J. Ladle. "Distanciation: a Key Challenge for 21st Century Conservation." In EnviroInfo and ICT for Sustainability 2015. Atlantis Press, 2015.

Orr, David W. Earth in mind: On Education, Environment, and the Human Prospect. Island Press, 2004.

. "Hope in hard times." Conservation Biology 18, no. 2 (2004): 295-298.

. The Nature of Design: Ecology, Culture, and Human Intention. Oxford University Press, (2002).

Otis College of Art \& Design. Accessed on: Jan. 23, 2016. http://www.otis.edu/sustainability/sustainability-minor

Palmer, Alexandra. Couture \& Commerce: The Transatlantic Fashion Trade in the 1950s. UBC Press, 2001.

Palmer, Alexandra, and Hazel Clark. 2005;2004;. Old Clothes, New Looks: Second Hand Fashion. Berg, 2005. Accessed Nov. 18, 2015.

http://dx.doi.org.ezproxy.lib.ryerson.ca/10.2752/9781847888815/OCNL0008

Palomo-Lovinski, Noël, and Kim Hahn. 2014. Fashion Design Industry Impressions of Current Sustainable Practices. Fashion Practice: The Journal of Design, Creative Process \& the Fashion Industry 6 (1): 87-106.

Pappas, E., O. Pierrakos, and R. Nagel. "Using Bloom's Taxonomy to Teach Sustainability in Multiple Contexts." Journal of Cleaner Production 48 (2013): 54-64.

Parker, Liz, and Marsha Ann Dickson, eds. Sustainable Fashion: A Handbook for Educators. Labour Behind the Label, 2009. 
Parsons The New School for Design, website:

http://www.newschool.edu/parsons/fashion-school/ accessed on: Jan. 23, 2016

Pasricha, Anupama. "Exploration of the Meaning of Sustainability in Textiles and Apparel Discipline and Prospects for Curriculum Enhancement." (2010).

Pasricha, Anupama, and Sara J. Kadolph. "Millennial generation and fashion education: a discussion on agents of change." International Journal of Fashion Design, Technology and Education 2, no. 2-3 (2009): 119-126.

Pepper, David. Eco-Socialism: from Deep Ecology to Social Justice. Routledge, 2002.

. "On Contemporary Eco-socialism." In Eco-socialism as Politics, pp. 33-44. Springer Netherlands, 2010.

Phelan, Hayley. "The Top 5 Sustainable Fashion Design Programs in the World", Fashionista. April 22, 2013. Accessed Jan. 19, 2016.

http://fashionista.com/2013/04/the-top-5-sustainable-fashion-design-programs-inthe-world.

Pilatowicz, Grazyna. Interview by author. Audio interview. FIT, Wed. May. 19, 2015.

Pogrebin, Robin. June 16, 2014. Renovating the Cooper Hewitt National Design Museum, The New York Times. June 16, 2014. Accessed May 28, 2015:

http://www.nytimes.com/2014/06/17/arts/design/renovating-the-cooper-hewittnational-design-museum.html?ref=topics

Pool, Heather. "The Politics of Mourning: The Triangle Fire and Political Belonging." Polity 44, no. 2 (2012): 182-211.

Porter, Michael E., and Claas van der Linde. "Green and Competitive: Ending the Stalemate. Harvard Business Review 73 (1995): 120-134.

Prendeville, Sharon, Frank O'Connor, and Luke Palmer. "Material Selection for Ecoinnovation: SPICE Model." Journal of Cleaner Production 85 (2014): 31-40.

Rinallo, Diego, and Suman Basuroy. "Does Advertising Spending Influence Media Coverage of the Advertiser?" Journal of Marketing 73(6) (2009): 33-46

Renzulli, Michael. Interview by author. Audio interview. FIT, Tues. \& Thurs. May. $19 \& 21$, 2015.

Rissanen, Timo. Interview by author. Audio interview. FIT, Wed. May. 20, 2015. 
Rissanen, Timo, and Holly McQuillan. Zero Waste Fashion Design. Bloomsbury Publishing, 2016.

Rivoli, Pietra. The Travels of a T-Shirt in the Global Economy: An Economist Examines the Markets, Power, and Politics of World Trade. New Preface and Epilogue with Updates on Economic Issues and Main Characters. John Wiley \& Sons, 2014.

Romli, Awanis, Paul Prickett, Rossitza Setchi, and Shwe Soe. "Integrated Eco-design Decision-making for Sustainable Product Development." International Journal of Production Research 53, no. 2 (2015): 549-571.

Rosen, Ellen Israel. Making Sweatshops: The Globalization of the US Apparel Industry. Univ of California Press, 2002.

Ross, Andrew. No Sweat: Fashion, Free Trade, and the Rights of Garment Workers. Verso, 1997.

Ruben, Barbara. 1993. "Greening the Ivory Tower." Environmental Action Magazine 24, (4): 15

Ruder, Avima M., Elizabeth M. Ward, and David P. Brown. 2001. "Mortality in Dry-cleaning Workers: An Update". American Journal of Industrial Medicine 39 (2): $121-32$.

Saltz, Jerry. "On the New Whitney Museum", New York Magazine. May 2015. Accessed May 26, 2015 http://www.vulture.com/2015/04/jerry-saltz-on-new-whitneymuseum.html? ga=1.259079306.1219438589.1432830470.

Savelyeva, Tamara, and James R. McKenna. "Campus Sustainability: Emerging Curricula Models in Higher Education." International Journal of Sustainability in Higher Education 12, no. 1 (2011): 55-66.

Schreiber, Judith S., H. Kenneth Hudnell, Andrew M. Geller, Dennis E. House, Kenneth M. Aldous, Michael S. Force, Karyn Langguth, Elizabeth J. Prohonic, and Jean C. Parker. 2002. "Apartment Residents' and Day Care Workers' Exposures to Tetrachloroethylene and Deficits in Visual Contrast Sensitivity". Environmental Health Perspectives 110 (7): 655-64.

Seldén, Anders I., Gunnar Ahlborg Jr, Sahlgrenska akademin, Institute of Medicine, Department of Public Health and Community Medicine, Sahlgrenska Academy, Institutionen för Medicin, Avdelningen för Samhällsmedicin och Folkhälsa, 
University of Gothenburg, and Göteborgs universitet. 2011. "Cancer Morbidity in Swedish Dry-cleaners and Laundry Workers: Historically Prospective Cohort Study." International Archives of Occupational and Environmental Health 84 (4): 435-43.Serrat, Olivier. "Forestalling Change Fatigue." Internal Publications, Cornell (2010).

Sen, Amartya. "How to Judge Globalism." The American Prospect, Winter, A2-A6. Accessed on March 22, 2016. http://ezproxy.lib.ryerson.ca/login?url=http://search.proquest.com/docview/2011366 16 ? accountid=13631. (2002).

Sidiropoulos, Elizabeth. "Education for Sustainability in Business Education Programs: a Question of Value." Journal of Cleaner Production 85 (2014): 472-487.

Sibbel, Anne. "Pathways Towards Sustainability Through Higher Education." International Journal of Sustainability in Higher Education 10, no. 1 (2009): 68-82.

Siegle, Lucy. "Is H\&M the New Home of Ethical Fashion." The Guardian 8 (2012).

. To Die For: is Fashion Wearing Out the World?. HarperCollins UK, (2011).

Solet, David, Thomas G. Robins, and Carlos Sampaio. "Perchloroethylene Exposure Assessment Among Dry Cleaning Workers." The American Industrial Hygiene Association Journal 51, no. 10 (1990): 566-574.

Sousa, Filipe J. "Meta-theories in Research: Positivism, Postmodernism, and Critical Realism." Postmodernism, and Critical Realism (2010).

Steele, Valerie. "A Museum of Fashion is More than a Clothes-bag." Fashion Theory 2, no. 4 (1998): 327-335.

Steinem, Gloria. Eds.: Hovland, Roxanne, Joyce M. Wolburg, and Eric E. Haley. "Sex, Lies \& Advertising". Readings in Advertising, Society, and Consumer Culture. Routledge, 2014: 180-192 (1990).

Sterling, Stephen. "Higher Education, Sustainability, and the Role of Systemic Learning." In Higher Education and the Challenge of Sustainability, pp. 49-70. Springer Netherlands, 2004.

Stieg, Cathy. "The Sustainability Gap". Journal of Interior Design, 2006. 7-21

SUNY Data: http://www.suny.edu/about/history/ 
SUNY Mission Statement: http://www.suny.edu/about/mission/

Tagore, Rabindranath. My School,' Personality (London: Macmillan and Co., Ltd., 1917): 116-117

Taylor, Lou. "Doing the Laundry? A Reassessment of Object-based Dress History." Fashion Theory 2, no. 4 (1998): 337-358.

. The Study of Dress History. Manchester University Press, 2002.

Teklu, Kidest. Interview by author. Audio interview. Toronto, Friday. Jan. 2, 2016.

Thomas, Sue. "From "Green Blur" to Ecofashion: Fashioning an Eco-Lexicon" Fashion Theory, 12(4). 2008, pp.525-539

Tilbury, Daniella and Alexandra Ryan. "Today Becomes Tomorrow." Journal of Global Responsibility 2 (2) 2011: 137-150. doi:http://dx.doi.org/10.1108/20412561111166012. Accessed on March, 25, 2016. http://ezproxy.lib.ryerson.ca/login?url=http://search.proquest.com/docview/9215858 00? accountid=13631.

Timmerman, Nora, and Amy Scott Metcalfe. "From Policy to Pedagogy: The Implications of Sustainability Policy for Sustainability Pedagogy in Higher Education." Canadian Journal of Higher Education 39, no. 1 (2009): 45-60.

Tokatli, Nebahat. "Global Sourcing: Insights From the Global Clothing Industry-The Case of Zara, a Fast Fashion Retailer. Journal of Economic Geography 8 (1): 21-38. (2007)

Triangle Shirtwaist Fire. History.com. Accessed: Jan 25, 2016.http://www.history.com/topics/triangle-shirtwaist-fire.

Tyler, David, Jo Heeley, and Tracy Bhamra. "Supply Chain Influences on New Product Development in Fashion Clothing." Journal of Fashion Marketing and Management: An International Journal 10, no. 3 (2006): 316-328.

UNESCO. 2003. The United Nations Decade for Education for Sustainable Development. United Nations Educational, Scientific, and Cultural Organization. Accessed Jan. 25, 2016. http://portal.unesco.org/education/en/ev.phpURL_ID=26295\&URL_DO=DO_TOPIC\&URL_SECTION=201.html 
. Contributing to a More Sustainable Future: Quality Education, Life Skills and

Education for Sustainable Development. Paris: United Nations Educational,

Scientific, Cultural Organization. Accessed Jan. 25, 2016

.http://unesdoc.unesco.org/images/0014/001410/141019e.pdf

Unfilled Rana Plaza Fund exposes fashion's lack of accountability, (author unknown) Business of Fashion. Aug, 19, 2014.

University Leaders For A Sustainable Future: (ULSF) [Date of Access?]

http://www.ulsf.org/pub declaration parvol32.html

University of Delaware, Accessed on: Jan. 23, 2016.

http://academiccatalog.udel.edu/Pub_ShowCatalogPage.aspx?CATKEY=KEY_244

7\&ACYEAR=2013-2014

Valor, Carmen. "The Influence of Information About Labour Abuses on Consumer Choice of Clothes: a Grounded Theory Approach." Journal of Marketing Management 23, no. 7-8 (2007): 675-695.

von Mengersen, Belinda. "Etymology and Ethics: Terms for Sustainability in Textiles." Technology Education for the Future: A Play on Sustainability (2013).

Waage, Sissel A. "Re-considering Product Design: a Practical "Road-map" for Integration of Sustainability Issues." Journal of Cleaner Production 15, no. 7 (2007): 638-649.

Wals, Arjen EJ. "Initiative for Transformative Sustainability Education at Wageningen University, The Netherlands." Journal of Education for Sustainable Development 5, no. 2 (2011): 251-255.

- "Sustainability in Higher Education in the Context of the UN DESD: a Review of Learning and Institutionalization Processes." Journal of Cleaner Production 62 (2014): 8-15.

Wals, Arjen EJ. ed. Social Learning towards a Sustainable World: Principles, Perspectives, and Praxis. Wageningen Academic Pub, 2007.

Warburton, Kevin. "Deep Learning and Education for Sustainability." International Journal of Sustainability in Higher Education 4, no. 1 (2003): 44-56.

Watkins, Megan, Greg Noble, and Catherine Driscoll. "The Unsaid of Socio-Cultural Theory." Cultural Pedagogies and Human Conduct (2015): 1. 
Webb, Campbell O. "Engineering Hope." Conservation Biology 19, no. 1 (2005): 275-277.

Wignot, Jamila. American Experience: Triangle Fire (2011) documentary produced and directed by Jamila Wignot, PBS.

Williams, Wendy S. "The Blurring of the Line Between Advertising and Journalism in the On-line Environment." The Electronic Grapevine: Rumor, Reputation, and Reporting in the New On-line Environment, ed. DL Borden and K. Harvey (Mahwah, NJ: Lawrence Erlbaum Associates. (1998): 31-41.

Wilson, Elizabeth. Quoted in: Joy, Annamma, John F. Sherry, Alladi Venkatesh, Jeff Wang, and Ricky Chan. "Fast Fashion, Sustainability, and the Ethical Appeal of Luxury Brands." Fashion Theory: The Journal of Dress, Body \& Culture 16, no. 3 (2012): 292.

Wilson, Elizabeth. Adorned in Dreams: Fashion and Modernity. IB Tauris, 2003.

Winchester School of Art. Accessed on: Jan. 23, 2016.http://www.southampton.ac.uk/wsa/undergraduate/courses/wj24 ba fashion and textile design.page

Wright, Tarah. "The Evolution of Sustainability Declarations in Higher Education." In Higher Education and the Challenge of Sustainability, pp. 7-19. Springer Netherlands, 2004.

Yardley, Jim. "Report on Deadly Factory Collapse in Bangladesh Finds Widespread Blame." New York Times 22 (2013): 1-3. 